\title{
Selected synthetic strategies to cyclophanes
}

\author{
Sambasivarao Kotha ${ }^{\star}$, Mukesh E. Shirbhate ${ }^{\ddagger}$ and Gopalkrushna T. Waghule ${ }^{\ddagger}$
}

\author{
Review \\ Address: \\ Department of Chemistry, Indian Institute of Technology-Bombay, \\ Powai, Mumbai-400 076, India \\ Email: \\ Sambasivarao Kotha* - srk@chem.iitb.ac.in \\ * Corresponding author $\ddagger$ Equal contributors \\ Keywords: \\ addition reactions; coupling reactions; cyclophane; metathesis; \\ muscopyridine; name reactions; natural products
}

Beilstein J. Org. Chem. 2015, 11, 1274-1331.

doi:10.3762/bjoc. 11.142

Received: 06 March 2015

Accepted: 29 June 2015

Published: 29 July 2015

Guest Editor: K. Grela

(c) 2015 Kotha et al; licensee Beilstein-Institut.

License and terms: see end of document.

\begin{abstract}
In this review we cover various approaches to meta- and paracyclophanes involving popular reactions. Generally, we have included a strategy where the reaction was used for assembling the cyclophane skeleton for further functionalization. In several instances, after the cyclophane is made several popular reactions are used and these are not covered here. We included various natural products related to cyclophanes. To keep the length of the review at a manageable level the literature related to orthocyclophanes was not included.
\end{abstract}

\section{Indroduction}

Cyclophanes [1-38] are strained organic molecules which contain aromatic ring(s) as well as aliphatic unit(s). The aromatic rings provide rigidity to their structure, whereas the aliphatic unit(s) form bridge(s) between the aromatic rings and also provide flexibility to the overall structure. Cyclophanes play an important role in "host-guest" chemistry [39-43] and supramolecular assembly [44-47]. "Phane"-containing molecules show interactions with $\pi$-systems, and they can also bind to a large number of cations, anions, and neutral molecules. Cyclophanes are widely used in materials science and molecular recognition processes [48-52]. A general classification of cyclophanes is as follows: $[n]$ orthocyclophane, $[n]$ metacyclophane, and $[n]$ paracyclophane (1-3) (Figure 1). The prefixes represent the position of the attachment to an aromatic system while $[n]$ represents the number of methylene groups present in the aliphatic bridge. The orthocyclophanes are also known as benzocycloalkanes. Several cyclophanes consisting of two or more aromatic systems and aliphatic bridges have been reported in the literature [53]. The representative [2,2] ortho-, meta-, and paracyclophanes (4-6) are shown in Figure 1. In general, cyclophanes with one aromatic ring and two alkyl bridges are called $[n, n]$ metapara or $[n, n]$ paraparacyclophanes $(\mathbf{7}, \mathbf{8})$ based on the position of the attachment of the alkyl chain to the aromatic system. In this review we are not discussing orthocyclophanes but rather focus on meta- and paracyclophanes only.

The aromatic ring present in the cyclophane system can be either heterocyclic or carbocylic in nature. If there is a heteroatom present in the aromatic ring system then the system is called a heterophane (9) [54-56], whereas if the heteroatom is 
<smiles>c1ccc2c(c1)CCCCC2</smiles>

$[n]$ orthocyclophane

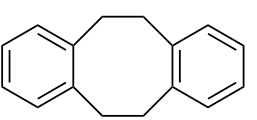

4

$[2,2]$ orthocyclophane

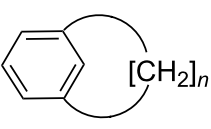

2

$[n] m e t a c y c l o p h a n e$

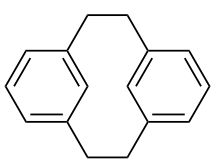

$[2,2]$ metacyclophane

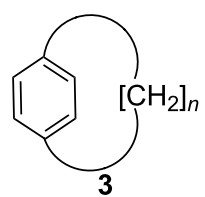

$[n]$ paracyclophane

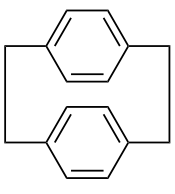

[2,2]paracyclophane

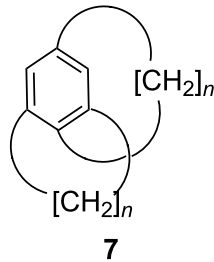

$[n, n]$ metaparacyclophane

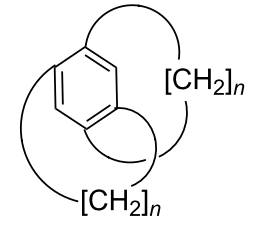

$[n, n]$ paraparacyclophane

Figure 1: General representation of cyclophanes.

present in the alkyl chain of the bridge, then it is called a heteraphane (10) [57-60]. Alternatively, if the heteroatom is present in both the aromatic ring and the alkyl chain, it is called a heteroheteraphane (11, Figure 2).

A number of cyclophane derivatives have been employed as hosts, and their guest-binding properties have been widely investigated. A variety of reviews related to the cyclophane chemistry has been published. Although monomeric cyclophanes show moderate guest-binding abilities, an improved affinity can be achieved by polytopic hosts [61-63] through multivalency effects in macrocycles. Olefin metathesis has played a key role in the development of cyclophane chemistry. Some of the catalysts used for this purpose are listed in Figure 3. The development of new synthetic methods in this area is considered a useful exercise. To this end, name reac- tions or popular reactions, and rearrangement reactions are widely used. In connection with the synthesis of cyclophanes, we describe the employment of these reactions for $\mathrm{C}-\mathrm{C}$ or $\mathrm{C}$-heteroatom-bond formation. The first part of this review focuses on the syntheses of various cyclophanes related to natural products and the subsequent sections describe the use of various popular reactions in cyclophane synthesis.

\section{Natural products containing a cyclophane skeleton}

The cyclophane skeleton is a core structural unit in many biologically active natural products such as macrocidin A (19) and B (20) [64], nostocyclyne A (21) [65], and in the turriane family of natural products 22-24 [66]. Cyclophanes are also applied in research areas such as pharmaceuticals $[67,68]$, catalysis $[69,70]$ and supramolecular chemistry [71].<smiles>C1=CCc2cccc(n2)CC1</smiles>

9

$[n+4]$ heterophane

$[n+4] 2,6-$ pyridinophane<smiles>c1cc2cc(c1)OCCOC2</smiles>

10

$[n+4]$ heteraphane

2-oxa[n+4](1,3)benzenophane<smiles>c1sc2cc1COCCO2</smiles>

11

$[n+4]$ hetero-heteraphane

2-oxa[n+4] $(2,4)$ thiophane

Figure 2: cyclophanes one or more with heteroatom 


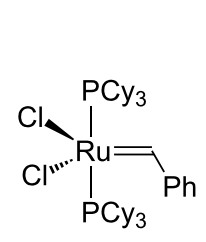

G-I

12

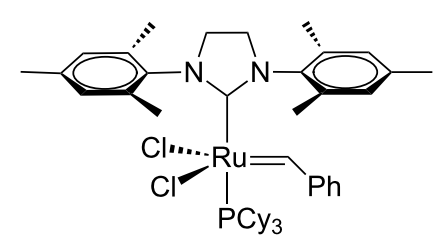

G-II

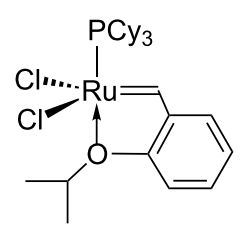

$\mathrm{GH}-\mathrm{I}$

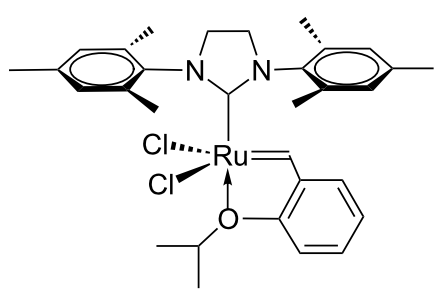

$\mathrm{GH}-\mathrm{II}$

14

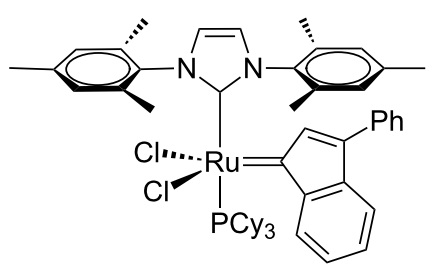

16

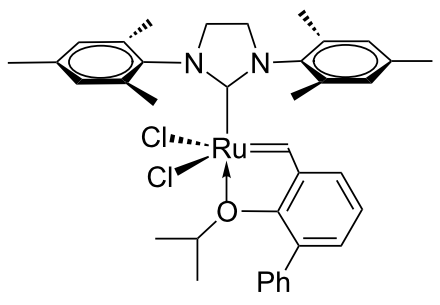

Blechert catalyst 17

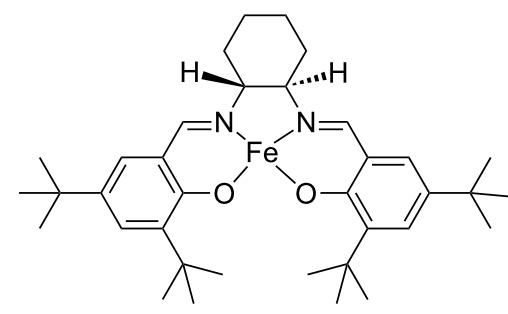

18

Figure 3: Metathesis catalysts $12-17$ and $C-C$ coupling catalyst 18.

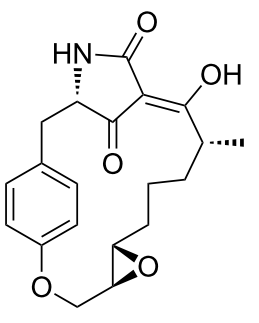

19

macrocidin $\mathrm{A}$<smiles></smiles>

20

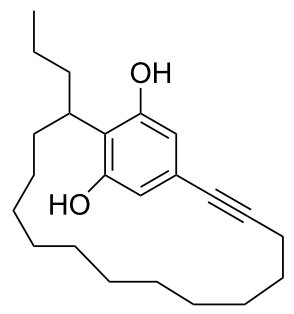

21

Figure 4: Natural products containing the cyclophane skeleton.

Macrocidin A (19) and macrocidin B (20) [64] belong to a family of plant pathogens produced by Phoma macrostoma, a microorganism parasitic to Canadian thistle. Macrocidins contain a tetramic acid group in their skeleton and show selective herbicidal activity on broadleaf weeds but do not affect grasses. Nostocyclyne A (21) is an acetylenic cyclophane derivative isolated from a terrestrial Nostoc species, with antimicrobial activity (Figure 4). The turriane family of natural products 22-24 were isolated from the stem wood of the Australian tree Grevillea striata. Turrianes 22-24 are effective DNA-cleaving agents in the presence of $\mathrm{Cu}(\mathrm{II})$. Fürstner and co-workers [72] have reported the total synthesis of natural products 22-24 by using a metathesis reaction [73-82] as the key step. The ring-closing metathesis (RCM) has been utilized for the synthesis of the turriane with a saturated alkyl chain (22), whereas the unsaturated turrianes 23,24 containing a $(Z)$-alkene moiety have been prepared by alkyne metathesis followed by reduction using Lindlar's catalyst (Figure 5).

\section{Muscopyridine and its analogues}

Musk is a widly used component in Chinese pharmaceuticals and it has also been used in perfume industry. Muscopyridine was first isolated by a Swiss group [83] from the musk deer (Moschus moschiferus). Muscopyridine and its synthetical analogue normuscopyridine are heterophanes, more precisely metapyridinophanes. There are various routes to these compounds and related compounds which are discussed in detail in this review. 


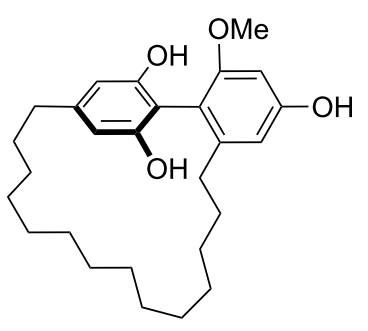

22

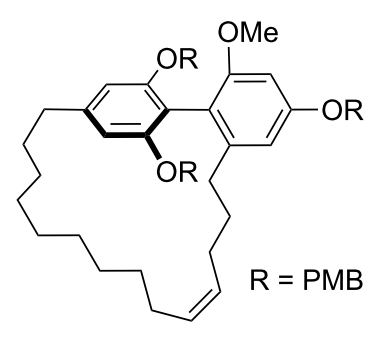

23

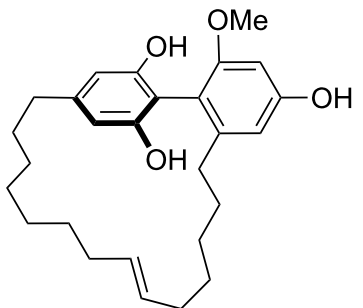

24

Figure 5: Turriane family of natural products.

\section{Review}

\section{Synthetic routes to cyclophanes Addition reactions}

Mannich reaction: In 2001, Erker and co-workers [84] have reported the synthesis of amino-substituted [3]ferrocenophane through an intramolecular Mannich reaction starting with the ferrocene framework. In the first step, the unsaturated aminofunctionalized [3]ferrocenophane $\mathbf{2 8}$ was synthesized from 1,1'diacetylferrocene (25) in the presence of an excess amount of dimethylamine and a stoichiometric amount of a Lewis acid such as $\mathrm{TiCl}_{4}$. These conditions lead to the generation of the bisenamine 26, which was subsequently converted to the cyclophane 28 by a Mannich-type condensation reaction $(40 \%)$ (Scheme 1).

Michael addition: In 1999, Reißig and co-workers [85] have synthesized a functionalized cyclophane by a cascade reaction, which proceeds with desilylation, ring opening, proton transfer, and finally, an intramolecular Michael addition to provide benzannulated large ring compounds 31 and 33. In this regard, substituted methyl 2-alkenyl-2-siloxycyclopropanecarboxylate 29 was converted into the alkylation product and further react with the ester enolate dibromide to yield vinyl cyclopropane derivatives 30 (62\%) and 32 (44\%). Later, Michael addition in the presence of caesium fluoride and benzyltriethylammonium chloride in DMF gave the benzannulated cyclodecanone derivatives $31(11 \%)$ and 33 (10\%) (Scheme 2).

Oxymercuration - Hantzsch pyridine synthesis: Kondo and Miyake [86] have reported the synthesis of [11](2,6)-pyridinophane (37), a normuscopyridine analogue, by an oxymercuration-oxidation strategy. The ketoolefin $\mathbf{3 4}$ was converted to the hydroxyketone 35 by treatment with $\mathrm{Hg}(\mathrm{OAc})_{2}$ and $\mathrm{NaSH}$. Oxidation of the keto alcohol $\mathbf{3 5}$ gave diketone 36, which reacted with hydroxylamine hydrochloride and afforded $[11](2,6)$ pyridinophane (37) (Scheme 3).

\section{Coupling reactions}

Castro-Stephens coupling: Youngs and co-workers [87] have synthesized $p$-methoxy-substituted tribenzocyclotriyne 39 using the Castro-Stephens coupling reaction (Scheme 4). Compound 39 is a planar antiaromatic dehydroannulene that forms complexes with $\mathrm{Ni}(0), \mathrm{Cu}(\mathrm{I}), \mathrm{Co}(0)$ and also with $\mathrm{Ag}^{+}$cations.

Glaser-Eglinton coupling: Whitlock and Cloninger [88] have reported the synthesis of cyclophane $\mathbf{4 3}$ using the Glaser-Eginton coupling reaction. In this regard, compound $\mathbf{4 0}$ was treated with 9,10-bis(chloromethyl)anthracene (41) under basic conditions to generate compound $\mathbf{4 2}$ which was further

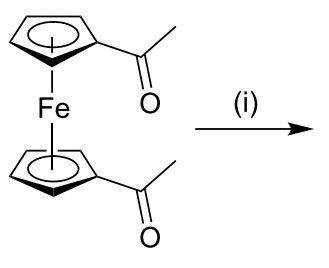

25

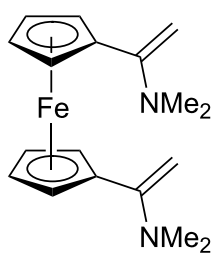

26

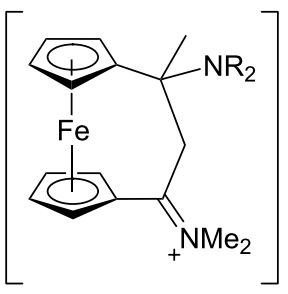

27

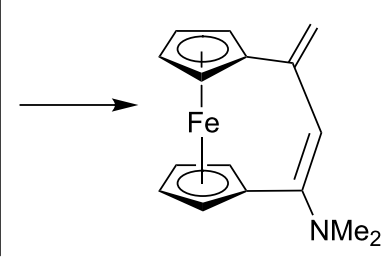

28 


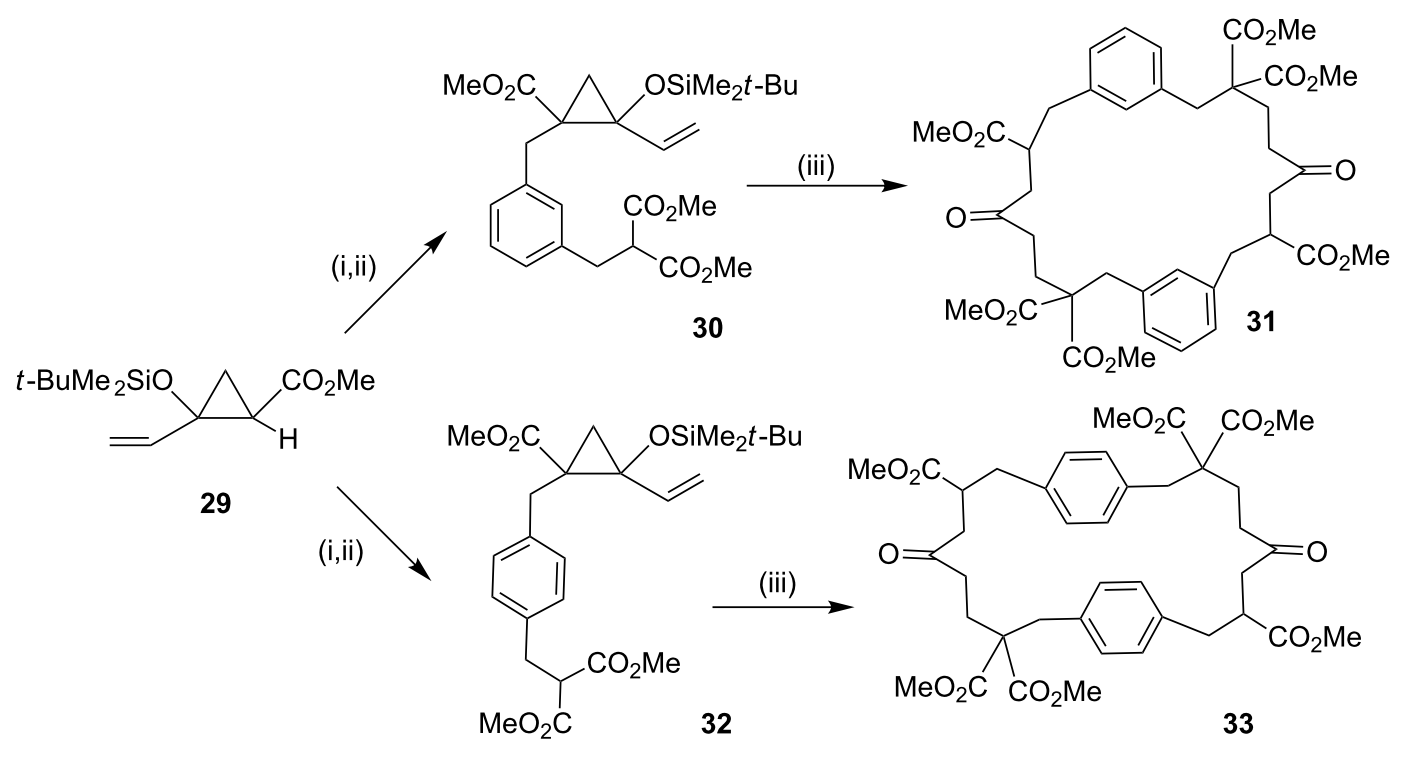

Scheme 2: Synthesis of cyclophanes through Michael addition. Reagents and conditions: (i) xylylene dibromide, LDA, $-70{ }^{\circ} \mathrm{C}, 18 \mathrm{~h}$; (ii) $\mathrm{NaH}$, $\mathrm{CH}_{2}\left(\mathrm{CO}_{2} \mathrm{Me}\right)_{2}$; (iii) $\mathrm{CsF}, \mathrm{BnEt}_{3} \mathrm{~N}^{+} \mathrm{Cl}^{-}$, DMF, $90^{\circ} \mathrm{C}, 3 \mathrm{~h}$.
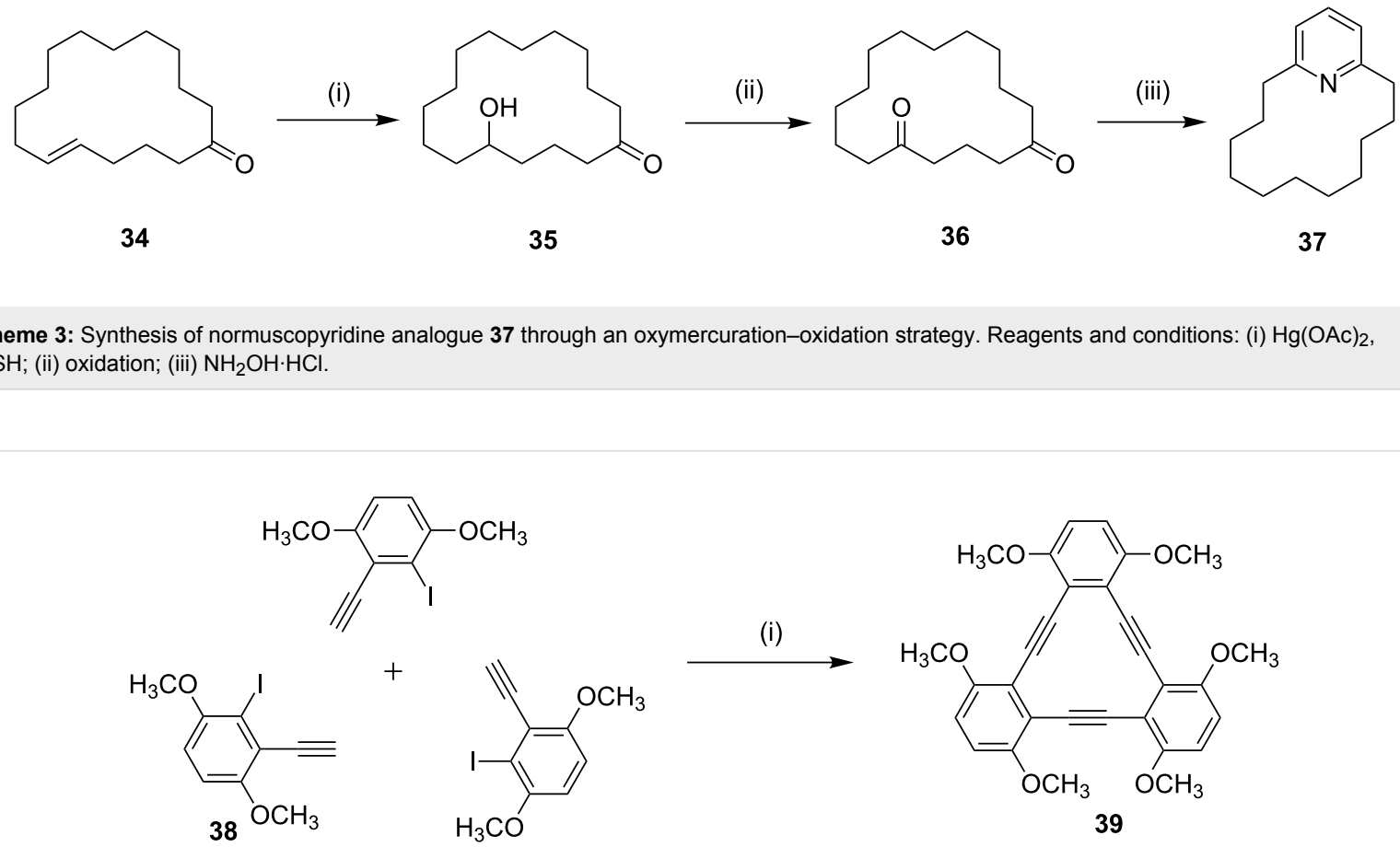

Scheme 4: Synthesis of tribenzocyclotriyne 39 through Castro-Stephens coupling reaction. Reagents and conditions: (i) $\mathrm{CuCl} / \mathrm{NH}{ }_{4} \mathrm{OH} / \mathrm{EtOH}, \mathrm{pyri}-$ dine, reflux, $24 \mathrm{~h}, 80 \%$.

subjected to a Glaser-Eglinton coupling to deliver cyclophane 43 (Scheme 5). A derivative of compound $\mathbf{4 3}$ was used as a host for compounds such as 6-nitro-2-naphthol, stilbene derivatives and serotonin mimics. This paper depicts the edge-face interaction between the face of the anthracene bridge present in the cyclophane molecule and the edge of the host molecule. 


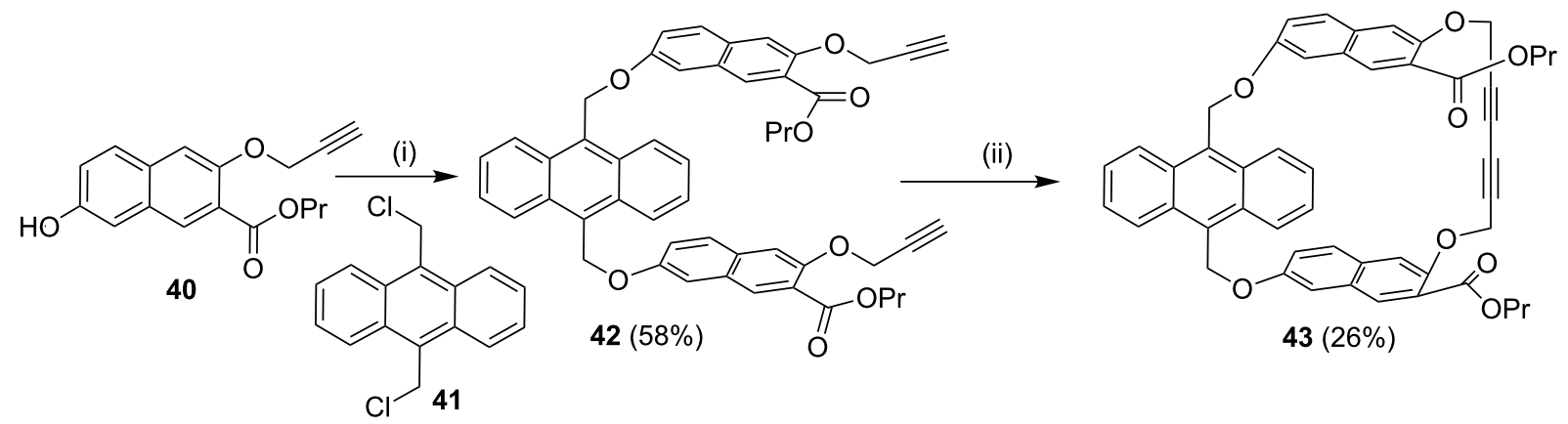

Scheme 5: Synthesis of cyclophane $\mathbf{4 3}$ through Glaser-Eglinton coupling. Reagents and conditions: (i) 9,10-bis(chloromethyl)anthracene (41), $\mathrm{Cs}_{2} \mathrm{CO}_{3}$; (ii) $\mathrm{Cu}(\mathrm{OAc})_{2} \cdot \mathrm{H}_{2} \mathrm{O}, \mathrm{CH}_{3} \mathrm{CN} /$ pyridine.

Bukownik and Wilcox [89] have synthesized macrocyclic C-glycosyl compounds, and obtained the chiral and watersoluble cyclophane 46. They reported on the use of its sulfonamide derivative in preparing glycophane molecule (Scheme 6).
Haley and Langsdorf [90] have reported the synthesis of a cyclophane-containing octacobalt complex 49 using the Glaser-Eglinton coupling reaction [91] as a key step (Scheme 7). In this regard, palladium-catalyzed alkynylation of

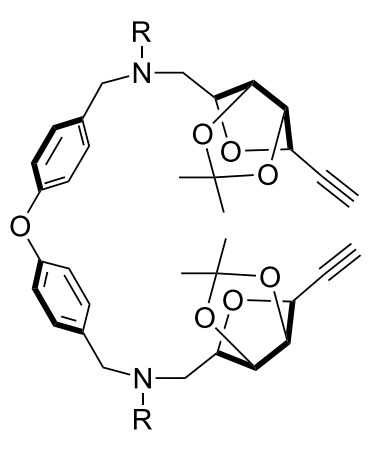

44

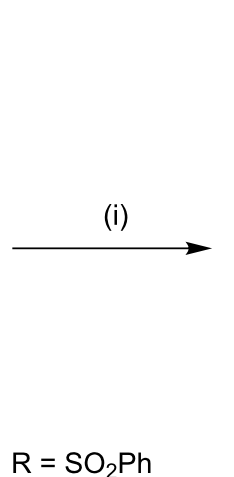

$\mathrm{R}=\mathrm{SO}_{2} \mathrm{Ph}$

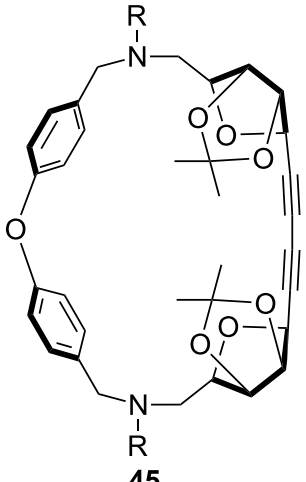

45

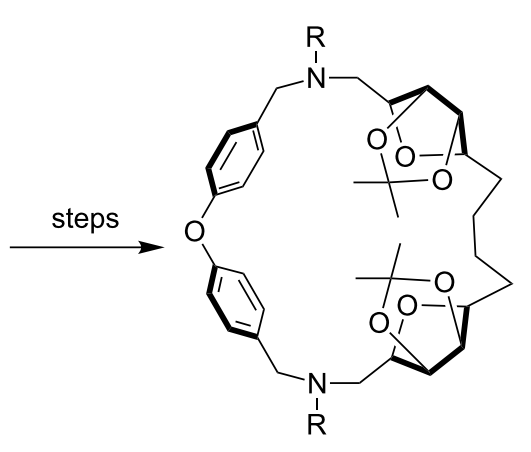

46

Scheme 6: Synthesis of the macrocyclic C-glycosyl cyclophane through Glaser coupling. Reagents and conditions: (i) $\mathrm{Cu}(\mathrm{OAc})_{2}$ (10 equiv), pyridine, reflux, $5 \mathrm{~h}, 54 \%$.

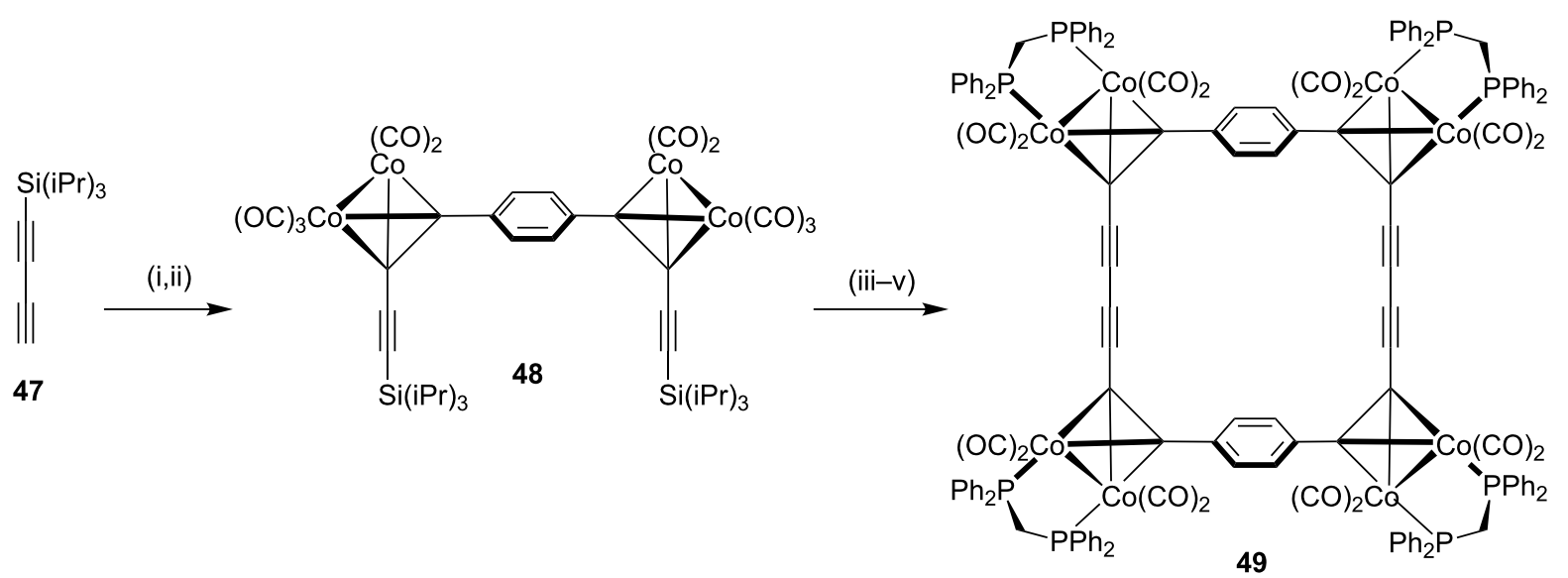

Scheme 7: Synthesis of cyclophane-containing complex 49 through Glaser-Eglinton coupling reaction. Reagents and conditions: (i) 1,4-diiodobenzene, $\mathrm{Pd}\left(\mathrm{PPh}_{3}\right)_{2} \mathrm{Cl}_{2}$, Cul, $\mathrm{Et}_{3} \mathrm{~N}, 25{ }^{\circ} \mathrm{C}, 24 \mathrm{~h}, 73 \%$; (ii) $\mathrm{Co}_{2}(\mathrm{CO})_{8}$, $\mathrm{Et}_{2} \mathrm{O}$, reflux, $6 \mathrm{~h}, 66 \%$; (iii) dppm, $\mathrm{PhMe}, 85 \%$; (iv) $\mathrm{Bu}_{4} \mathrm{NF}, \mathrm{THF},>95 \%$;

(v) $\mathrm{Cu}(\mathrm{OAc})_{2} \cdot \mathrm{H}_{2} \mathrm{O}$, pyridine, reflux, $12 \mathrm{~h}, 47 \%$. 
1,4-diiodobenzene with an excess amount of triisopropylsilylbutadiyne (47) followed by complexation with $\mathrm{Co}_{2}(\mathrm{CO})_{8}$ furnished a pale yellow diyne 48. Exchange of the ligand with bis(diphenylphosphino)methane (dppm) afforded a bridged complex which is stable to fluoride ions. Subsequent desilylation, followed by Glaser-Eglinton coupling of the terminal acetylene groups provided complex 49 in $47 \%$ yield as fine, deep maroon crystals.

In connection with the cyclophane synthesis, Kotha and Waghule [92] demonstrated the use of the Glaser-Eglinton coupling as a key step. The dipropargylated compound $\mathbf{5 1}$ was subjected to a Glaser-Eglinton coupling to generate the macro- cyclic bisacetylene derivative $\mathbf{5 2}$ in 94\% yield. Finally, diyne $\mathbf{5 2}$ was subjected to a hydrogenation sequence with $10 \% \mathrm{Pd} / \mathrm{C}$ under $1 \mathrm{~atm}$ pressure of $\mathrm{H}_{2}$ to generate cyclophane derivative $\mathbf{5 3}$ (92\%). Alternatively, cyclophane $\mathbf{5 3}$ was also obtained by treatment of the bisphenol derivative $\mathbf{5 0}$ with 1,6-dibromohexane in the presence of $\mathrm{K}_{2} \mathrm{CO}_{3}$ in acetonitrile under reflux conditions (56\%, Scheme 8).

Another interesting example of a Glaser-Eglinton coupling reaction reported by Rajakumar and Visalakshi [93] is the synthesis of cyclophane $\mathbf{5 4}$. Whitlock and co-workers have synthesized donut-shaped cyclophanes $\mathbf{5 5}$ and $\mathbf{5 6}$ by using the Glaser-Eglinton coupling as a key step (Figure 6) [94].<smiles>Oc1cccc(OCCOCCOc2cccc(O)c2)c1</smiles>

50

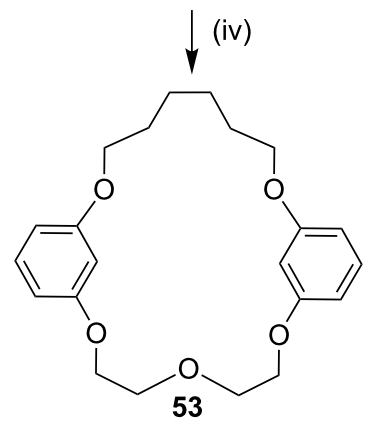

(i)
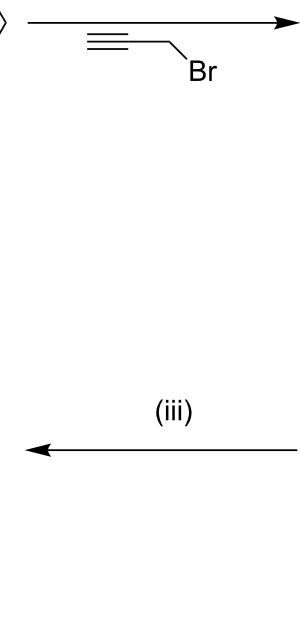<smiles>C#CCOc1cccc(OCCOCCOc2cccc(OCC#C)c2)c1</smiles>

51

(ii)

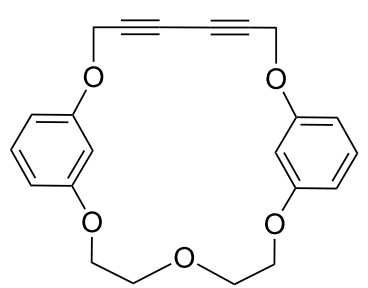

52

Scheme 8: Synthesis of cyclophane 53 through Glaser-Eglinton coupling. Reagents and conditions: (i) $\mathrm{K}_{2} \mathrm{CO}_{3}$, acetone, reflux, $12 \mathrm{~h}, 86 \%$; (ii) $\mathrm{Cu}(\mathrm{OAc})_{2} \cdot \mathrm{H}_{2} \mathrm{O}$, pyridine, $\mathrm{CH}_{3} \mathrm{CN}, 60{ }^{\circ} \mathrm{C}, 2 \mathrm{~h}, 94 \%$; (iii) $\mathrm{H}_{2}, \mathrm{Pd} / \mathrm{C}, \mathrm{EtOAc}, 12 \mathrm{~h}, \mathrm{rt}, 92 \%$; (iv) 1,6 -dibromohexane, $\mathrm{K}_{2} \mathrm{CO}_{3}$, reflux, $\mathrm{CH}_{3} \mathrm{CN}, 56 \%$.

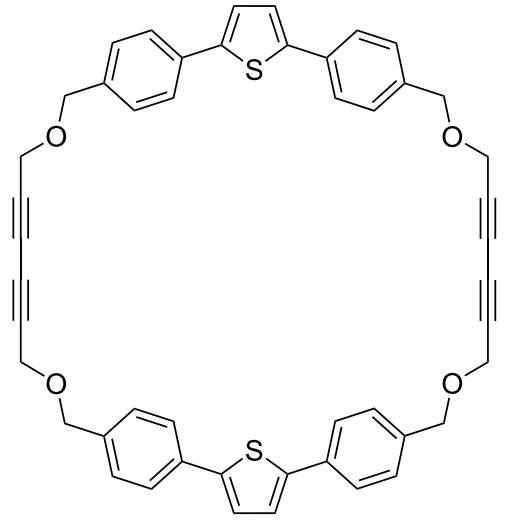

54

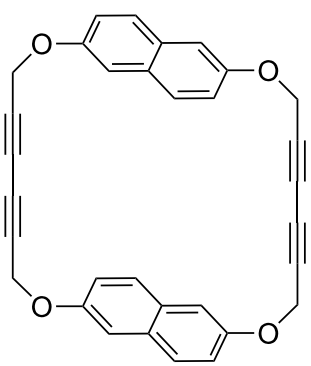

55

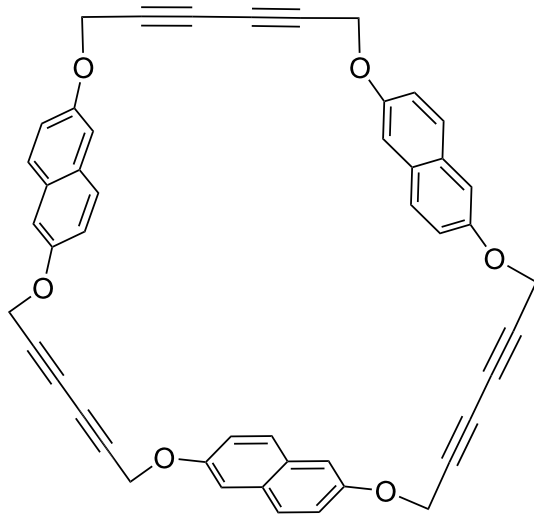

56

Figure 6: Cyclophanes 54-56 that have been synthesized through Glaser-Eglinton coupling. 
Morisaki and co-workers [95] have synthesized 4,7,12,15-tetrasubstituted [2.2]paracyclophane $\mathbf{5 7}$ and further studies were carried out to find out the properties of these macrocycles. These molecules show excellent chiroptical properties such as high fluorescence quantum efficiency and a large circularly polarized luminescence dissymmetry factor. Cyclophanes are carbon-rich materials containing extensive alkyne moieties with a persistent molecular architecture. Orita and co-workers have reported the synthesis of chiral cyclophyne $\mathbf{5 8}$ through the Eglinton coupling reaction [95]. A tandem inter- and intramolecular Eglinton coupling reaction affords the enantiopure threedimensional cyclophyne $\mathbf{5 8}$ with a large cavity size (Figure 7).
Glaser-Hay coupling: In 2010, Collins and co-workers [96] demonstrated a macrocylization, with an inbuilt conformation control element to form rigid cyclophanes through the Glaser-Hay coupling. In this regard, diynes 59a-c were treated with $\mathrm{CuCl}_{2}$ and TMEDA in the presence of oxygen to afford the cyclized products 61a-c (Scheme 9).

Intramolecular Heck coupling: In 2003, Snieckus and co-workers [97] have synthesized the seco-C/D ring analogues of ergot alkaloids through the intramolecular Heck reaction as a key step. The coupling precursors $\mathbf{6 3}$ and $\mathbf{6 8}$ were prepared from 4-bromoindoles by a sequential Vilsmeier-Haack, Henry

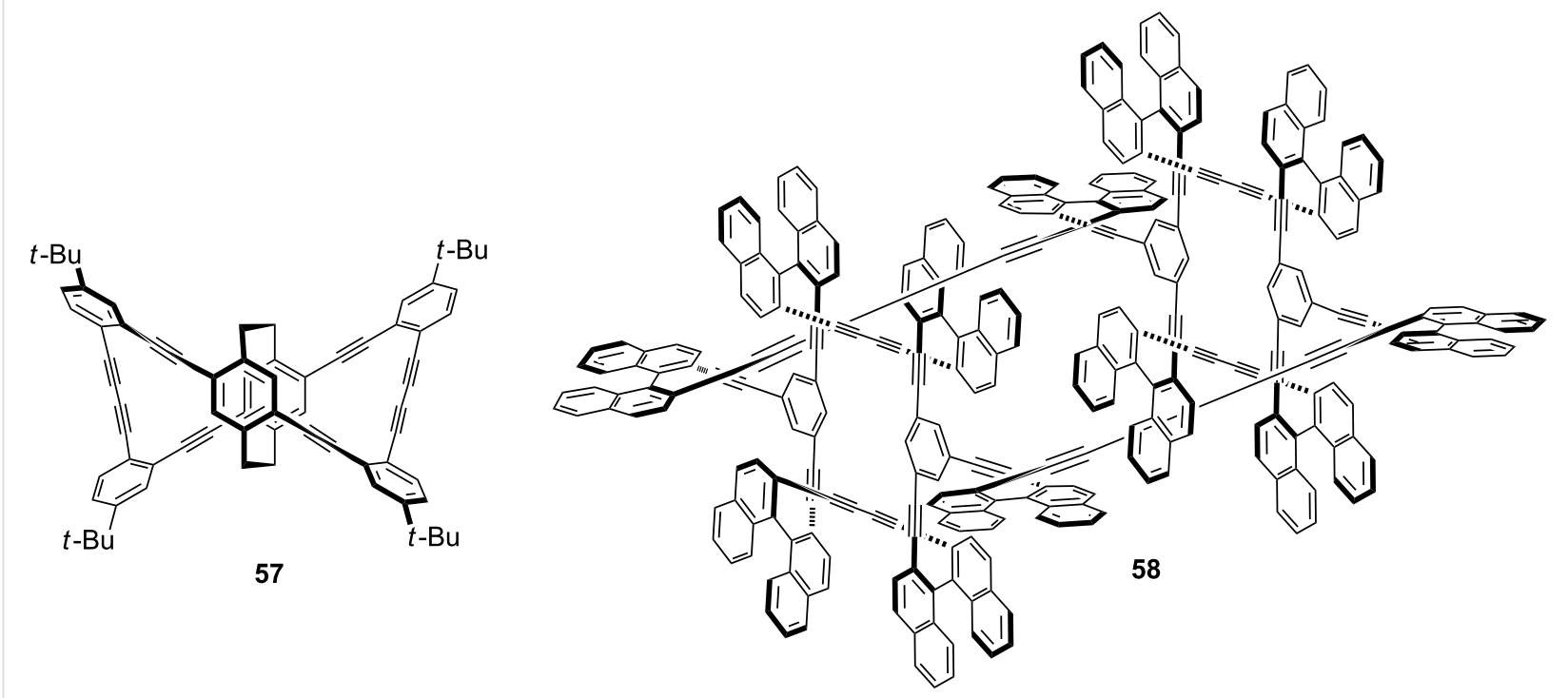

Figure 7: Synthesis of tetrasubstituted [2.2]paracyclophane 57 and chiral cyclophyne $\mathbf{5 8}$ through Eglinton coupling.

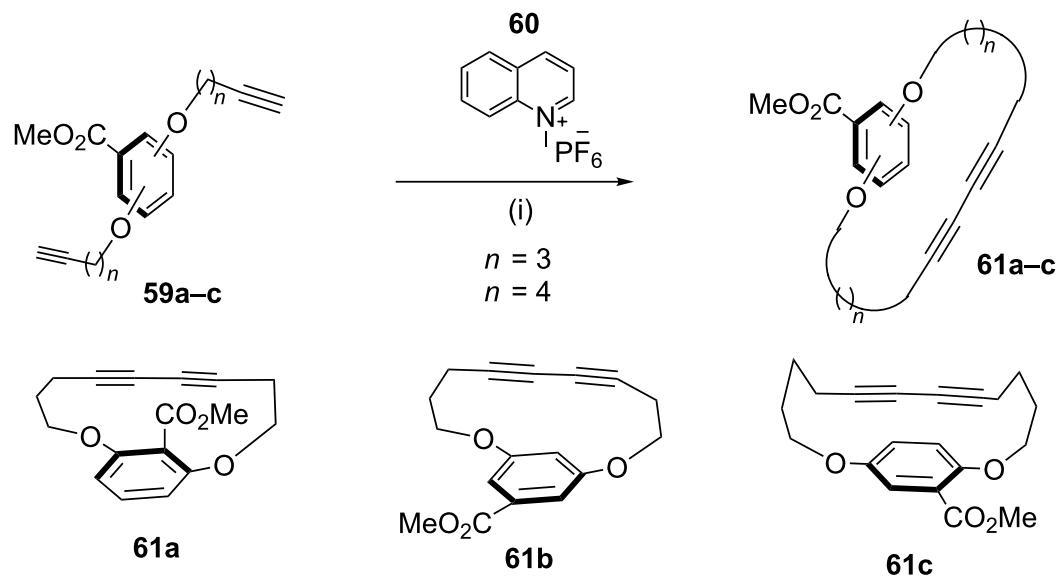

Scheme 9: Synthesis of cyclophane through Glaser-Hay coupling reaction. Reagents and conditions: (i) $\mathrm{CuCl}_{2}\left(12\right.$ equiv), $\mathrm{TMEDA}\left(12\right.$ equiv), $\mathrm{O}_{2}$, $\mathrm{PhMe}, 18 \mathrm{~h}, 80^{\circ} \mathrm{C}$ 
nitroaldol condensation, reduction with $\mathrm{LiAlH}_{4}$, reductive amination and allylation that afforded the indole derivatives $\mathbf{6 3}$ (18\%) and $N$-Boc protected compound 68 (23\%). The reaction of 63 with $\mathrm{Pd}(\mathrm{OAc})_{2}(25 \mathrm{~mol} \%)$ and tri(o-tolyl)phosphine $(55 \mathrm{~mol} \%)$ at reflux gave 9-endo-64a (24\%) and 8-exo-65b $(21 \%)$. However, the compound $\mathbf{6 8}$ under similar reaction conditions gave the cyclized product 8-exo-69 (30\%) as the only isolable compound (Scheme 10).

Kumada coupling: Weber and co-workers [98] have synthesized muscopyridine $\mathbf{7 3}$ starting from 2,6-disubstituted pyridine. The Kumada cross-coupling reaction of 2,6-dichloropyridine (70) with the Grignard reagent $\mathbf{7 1}$ in the presence of a nickel phosphine complex $\mathbf{7 2}$ gave muscopyridine $\mathbf{7 3}$ in a single step (Scheme 11). This strategy has been applied to generate a variety of pyridinophanes by varying the chain length of the Grignard reagent.

McMurry coupling: Kuroda and co-workers [99] have reported the synthesis of polyunsaturated [10]paracyclophane annulated by two azulene rings by using the McMurry reaction $[100,101]$. The bis(trimethylsilyl)enol ether $\mathbf{7 4}$ was reacted with 3-methoxycarbonyl-2H-cyclohepta[b]furan-2-one (75) in refluxing decaline to generate the 1,4-diazulenobenzene derivative 76. Double chain elongation of the bis-azulene derivative 76 with a four-carbon unit has been accomplished by electrophilic substitution with 4,4'-dimethoxybutan-2-one (77) under acidic conditions and subsequent elimination of methanol under basic conditions gave the advanced precursor 78 (28\%). The stereochemistry of the newly generated $\mathrm{C}-\mathrm{C}$ double bonds in $\mathbf{7 8}$ was confirmed as trans with the aid of the NMR vicinal coupling constant. Finally, intramolecular McMurry coupling of 78 using titanium trichloride and lithium aluminum hydride (LAH) heated under reflux in THF provided the cyclophane derivative 79 (20\%, Scheme 12$)$.

In another occasion, Rajakumar and co-workers [102] have synthesized a series of stilbenophanes (e.g., 81) involving $\mathrm{N}$-arylated carbazole moieties possessing small and large cavities. The precursor $\mathbf{8 0}$ required for the McMurry reaction was

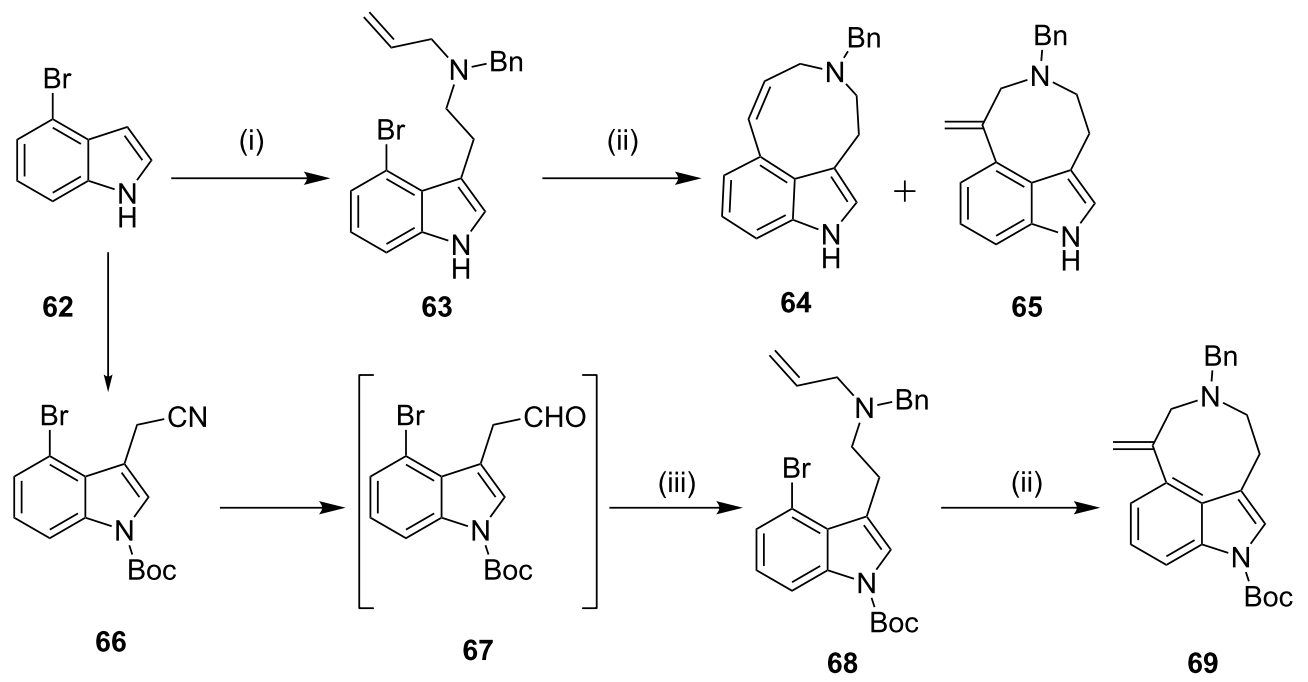

Scheme 10: Synthesis of seco-C/D ring analogs of ergot alkaloids through intramolecular Heck reaction. Reagents and conditions: (i) (a) $\mathrm{POCl}_{3}$, DMF, $0-40{ }^{\circ} \mathrm{C}, 1 \mathrm{~h}, 78 \%$; (b) $\mathrm{MeNO}_{2}$, cat. $\mathrm{NH}_{4} \mathrm{OAc}$, reflux, $3 \mathrm{~h}, 80 \%$; (c) $\mathrm{LiAlH}_{4}$, THF, reflux, $4 \mathrm{~h}, 88 \%$; (d) PhCHO, $\mathrm{NaBH}(\mathrm{OAc})_{3}, \mathrm{CH}_{2} \mathrm{Cl}_{2} / \mathrm{THF}$, rt 46\%; (e) allyl bromide, MeCN, rt, $24 \mathrm{~h}, 69-72 \%$; (ii) $25 \mathrm{~mol} \% \mathrm{Pd}(\mathrm{OAc})_{2}, 55 \mathrm{~mol} \% \mathrm{P}(\mathrm{o}-\mathrm{Tol})_{3}, \mathrm{NEt}_{3}, \mathrm{MeCN}$, reflux, $12 \mathrm{~h}$; (iii) DIBAL-H, $0{ }^{\circ} \mathrm{C}, 15 \mathrm{~min}, \mathrm{rt}$, $2 \mathrm{~h}, \mathrm{CH}_{2} \mathrm{Cl}_{2}$, then allylNHMe, $\mathrm{NaBH}(\mathrm{OAc})_{3}, \mathrm{CH}_{2} \mathrm{Cl}_{2}, \mathrm{rt}, 12 \mathrm{~h}, 38 \%$.<smiles>Clc1cccc(Cl)n1</smiles>

70<smiles>[CH]1CCCCC1</smiles><smiles>CC(Br)CC(C)CCCCBr</smiles>

(i) $\mathrm{NiCl}_{2}\left(\mathrm{Ph}_{2} \mathrm{P}\left(\mathrm{CH}_{2}\right)_{3} \mathrm{PPh}_{2}\right)$ 72

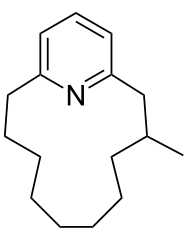

73 

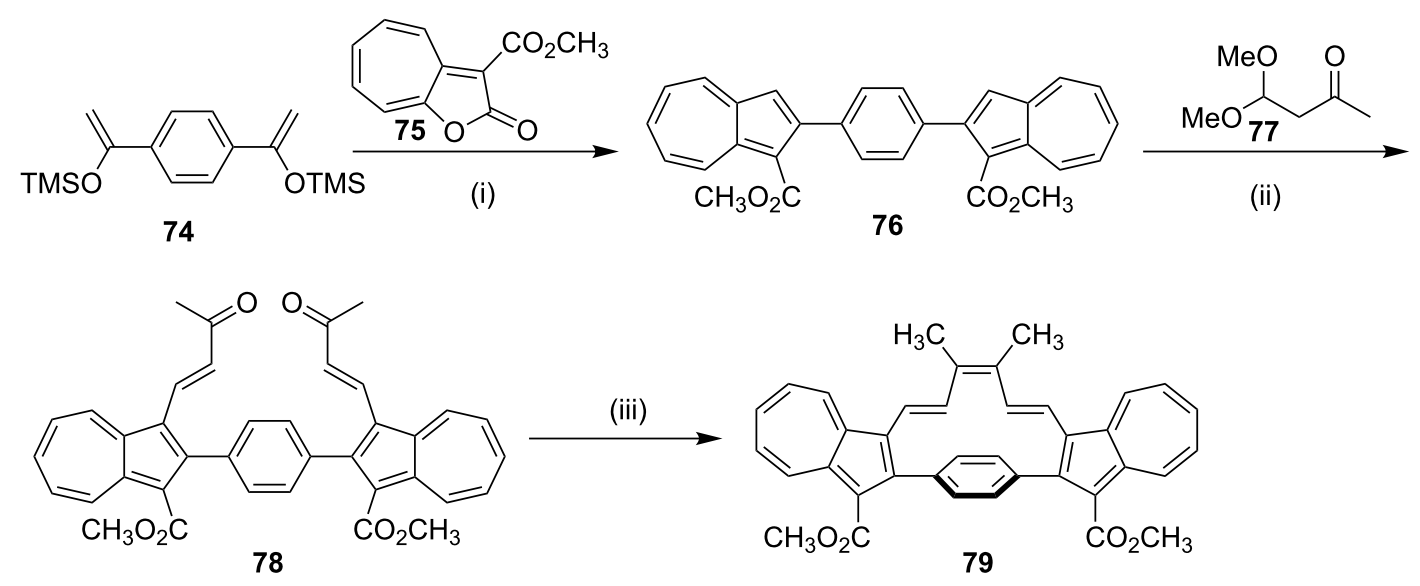

Scheme 12: Synthesis of the cyclophane 79 via McMurry coupling. Reagents and conditions: (i) $\mathbf{7 5}$, decaline, reflux, $4 \mathrm{~h}, 10 \%$; (ii) $\mathbf{7 7}, \mathrm{NaHCO} / \mathrm{HBF}_{4}$, 28\%; (iii) $\mathrm{TiCl}_{3} / \mathrm{LiAlH}_{4}$, THF, reflux, $20 \%$.

synthesized by the N-arylation of carbazole with the corresponding dibromide followed by formylation (Scheme 13).

In 2006, Rajkumar and co-workers [103] have published the synthesis of stilbenophane $\mathbf{8 5}$ via McMurry coupling as a key step (Scheme 14). Terphenyl derivative 82 was subjected to benzylic bromination in the presence of NBS to generate compound 83. Later, dibromide $\mathbf{8 3}$ was converted to bis-aldehyde 84. Finally, McMurry coupling of dialdehyde $\mathbf{8 4}$ provided the cyclophane derivative 85 (28\%).

Yamoto and co-workers have reported the synthesis of mediumsized cyclophanes, [2.n]metacyclophane-1,2-diols 86 and 87 by using the McMurry coupling as a key step (Figure 8) [104-106]. Among the $\pi$-conjugated systems stilbene derivatives found a unique place in materials science due to their optical and charge conducting properties. Tsuge and co-workers [107] reported the synthesis of stilbene $\mathbf{8 8}$ by using the McMurry coupling and studies on the transmission of the electronic effect through transannular interactions. Rajakumar and Selvam [108] also synthesized chiral stilbenophane $\mathbf{8 9}$ with small to large cavity sizes. These chiral stilbenophanes forms a complex with tetracyanoethylene (TCNE) and tetracyanoquinodimethane (TCNQ). The same group also reported on the synthesis of indolophanes 90a-c by using the McMurry coupling [109]. Furthermore, they synthesized dioxastilbenophanes $\mathbf{9 1}$ and carried out charge transfer complexation studies which showed that these molecules form a complex with TCNE and TCNQ [110]. Due to the presence of nitrogen and sulfur atoms benzene rings in phenothiaziophanes exhibit a butterfly conformation and thus have shown an enhanced bending character. When the benzene rings are bent, the reactivity of these cyclophanes is altered. Considering this aspect, Müller and co-workers [111] have devised different routes to these molecules. They have reported the synthesis of ethylene-bridged phenothiazinophane 92 using the McMurry coupling reaction. Also cyclic voltammetry experi-<smiles>CCn1c2ccc(-n3c4ccccc4c4cc(C=O)ccc43)cc2c2cc(-n3c4ccc(C=O)cc4c4ccc(C=O)cc43)ccc21</smiles>

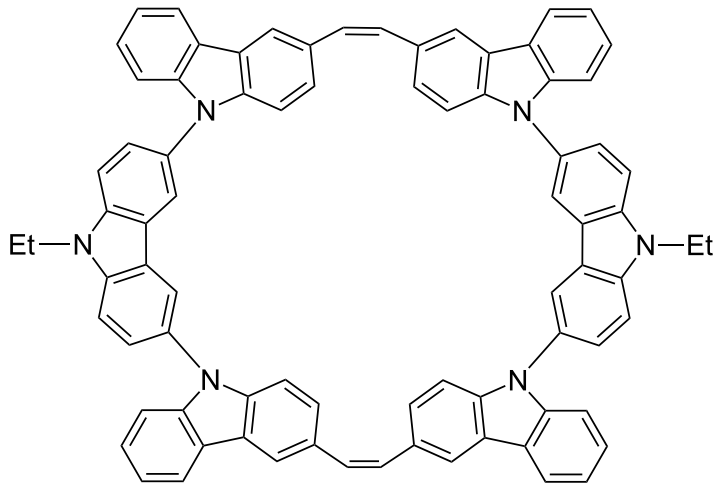




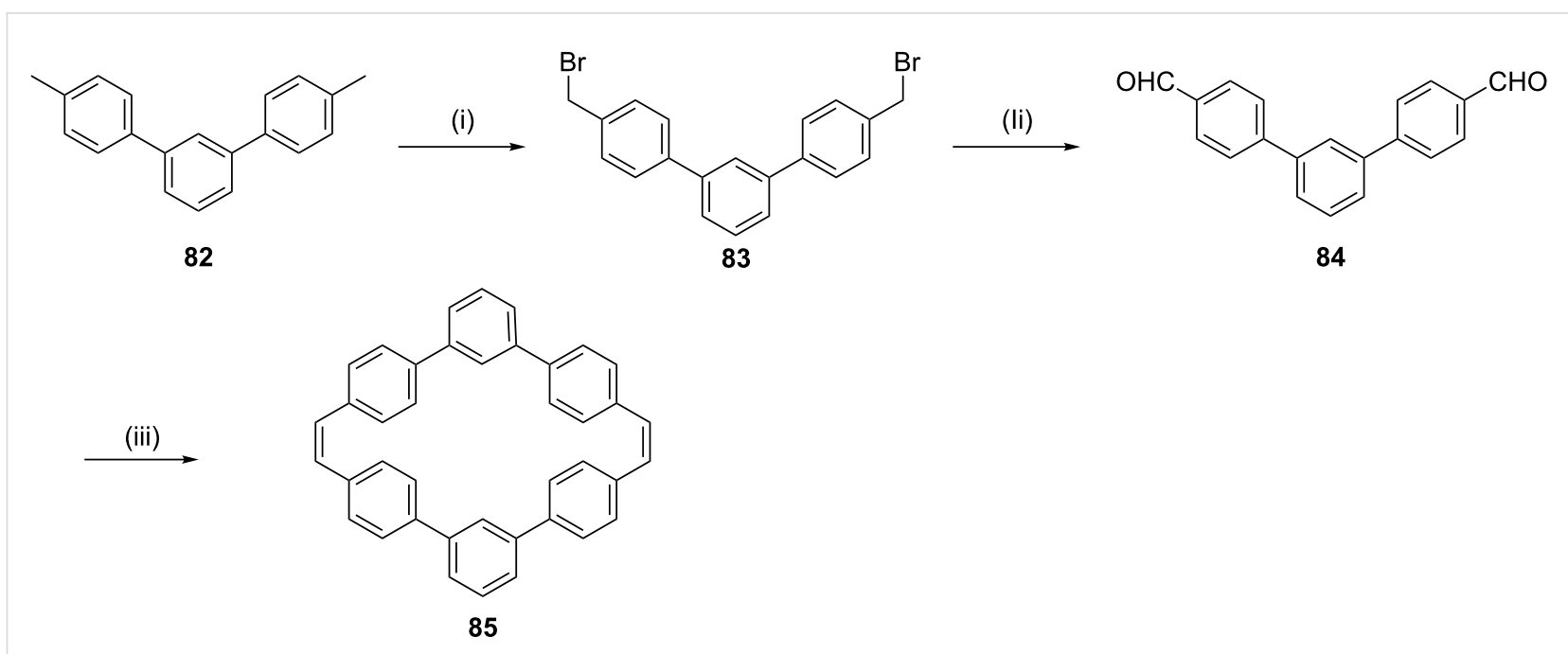

Scheme 14: Synthesis of stilbenophane 85 via McMurry coupling. Reagents and conditions: (i) NBS (2 equiv), benzoyl peroxide, $C \mathrm{Cl}_{4}$, reflux, $40 \mathrm{~h}$, $80 \%$; (ii) tetrabutylammonium dichromate (TBADC), $\mathrm{CHCl}_{3}$, reflux, $6 \mathrm{~h}, 69 \%$; (iii) $\mathrm{TiCl}_{4}$ (20 equiv), $\mathrm{Zn}$ (40 equiv), pyridine, THF, reflux, $6 \mathrm{~h}, 28 \%$.

ments indicated the intramolecular electronic communication between the phenothiazinyl subunits. Calixarene-based macrocycles bind with various metal ions. Lee and Park [112] have synthesized various orthocyclophanes $\mathbf{9 3}$ which were further converted into spirobicyclic polyketals with a $2 n$-crown- $n$ moiety. Lee and co-workers [113] also reported the synthesis of bicyclic bis-cyclophane $\mathbf{9 4}$ by using the McMurry reaction as a key step. Oda and co-workers [114] have reported the first time synthesis of a fully conjugated ionic cyclophane by using the McMurry reaction. The McMurry coupling was carried out with tris(5-formyl-2-thienyl)methane to give an unsubstituted, etheno-bridged trithienylmethanophane 95. Later, it was converted into the novel cage-molecular monocation, dication, and dianion of substantial stability. Riccardin C (96) is a macrocyclic bis-bibenzyl entity with pharmacological properties, including antimycotic and antibacterial effects, and cytotoxicity against P-388 mouse leukaemia and KB cell lines from nasopharyngeal carcinoma. In view of these useful medicinal properties Harrowven and co-workers [115] have reported the synthesis of this molecule by using the McMurry reaction. Kawase and co-workers [116] have reported double-helically twisted macrocycles 97 exhibiting chiral sensor properties. Kasahara and co-workers [117] have reported the synthesis of ferrocenophane derivative $\mathbf{9 8}$ by McMurry reaction as a key step. Oda and co-workers [118] have reported the synthesis of cyclic paraphenylacetylene in which their spectral properties vary mainly with decrease of ring size of the molecule. They have synthesized intermediate $\mathbf{9 9}$ using the McMurry coupling which is required for the synthesis of the paraphenylacetylene compound. Tolanophanes are a new class of cyclophanes possessing a diphenylacetylene moiety which possess interesting structural, electronic, nonlinear optical and luminescent properties. Darabi and co-workers [119] have reported the syntheses of $\mathbf{1 0 0}$ molecules by using the McMurry reaction followed by hydrogenation. Pei and co-workers [120] have synthesized anthracene-based $\pi$-conjugated strained cyclophane $\mathbf{1 0 1}$ by using an intramolecular McMurry reaction. The combination of unsaturated linkages in these molecules might create a twisted conformation that imparts helical chirality. Double helically twisted chiral cyclophanes are important macrocycles due to their potential applications in optics and electronics. Kawase and co-workers [121] have reported the synthesis of 8,14,30,36tetramethoxy[2.0.2.0](1,6)naphthalenophane-1,19-diyne (102) using the McMurry coupling (Figure 8).

Pd(0)-catalyzed cross-coupling reaction: In 1997, Yamamoto and co-workers [122] have synthesized the exomethylene paracyclophane 108 via intramolecular benzannulation of conjugated enynes in the presence of palladium(0). In this regard, dibromoalkane 103 was treated with dilithiated 2-methyl-1butene-3-yne (104) to generate the corresponding bis-enyne 105. Treatment with $\mathrm{Pd}\left(\mathrm{PPh}_{3}\right)_{4}$ in dry toluene under high dilution conditions at $100{ }^{\circ} \mathrm{C}$ afforded the exomethylene paracyclophane 106. The paracyclophane 106 was converted to oxocyclophane $\mathbf{1 0 7}$ by ozonolysis followed by deoxygenation which finally gave the paracyclophane 108 (85\%, Scheme 15).

Pinacol coupling: Kanomata and co-workers [123] have reported the synthesis of the cyclophane $\mathbf{1 1 2}$ by using pinacol coupling [124] mediated by $\mathrm{SmI}_{2}$. A double Sonogashira reaction of 1,4-diiodobenzene (109) with 4-pentyn-1-ol (110) generates the diyne product in quantitative yield. Next, the in situ prepared diyne was subjected to hydrogenation followed by oxi- 
<smiles>CCc1cccc(/C(=C(\C)c2cccc(OC)c2)c2cccc(OC)c2)c1</smiles>
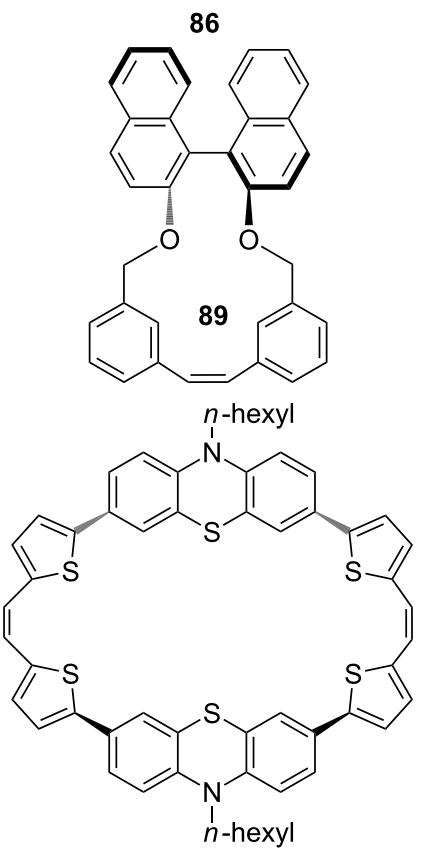

92

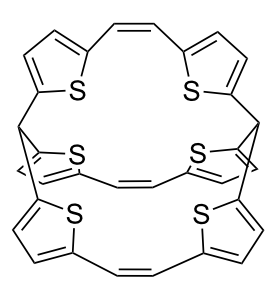

95

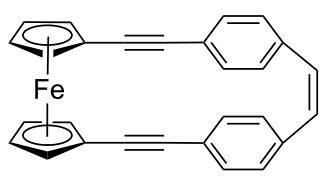

98

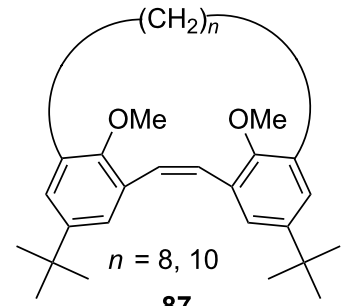

87

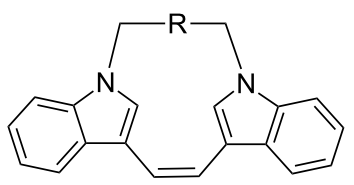

90a R = o-xylyl

90b $\mathrm{R}=m$-xylyl

90c $R=2,6$-dimethylpyridine

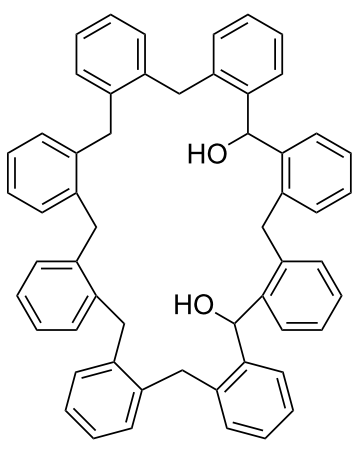

93

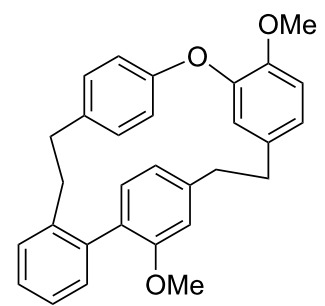

Riccardin C (96)

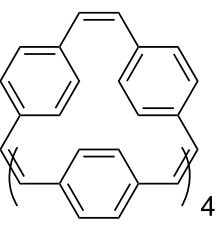

99
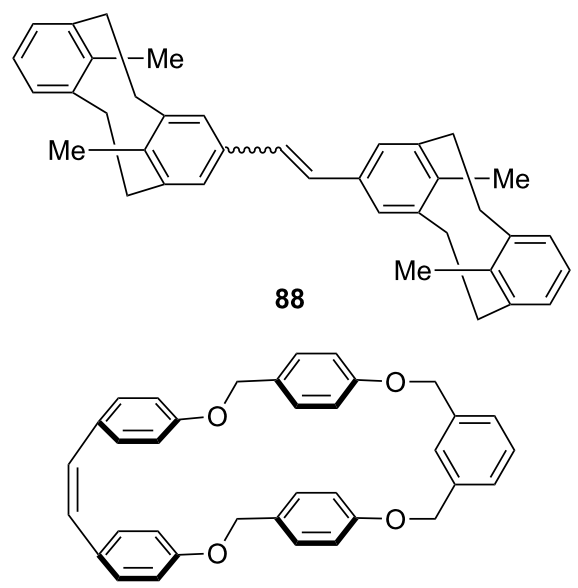

91

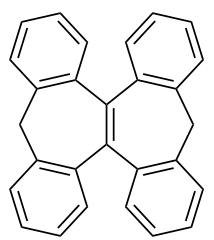

94

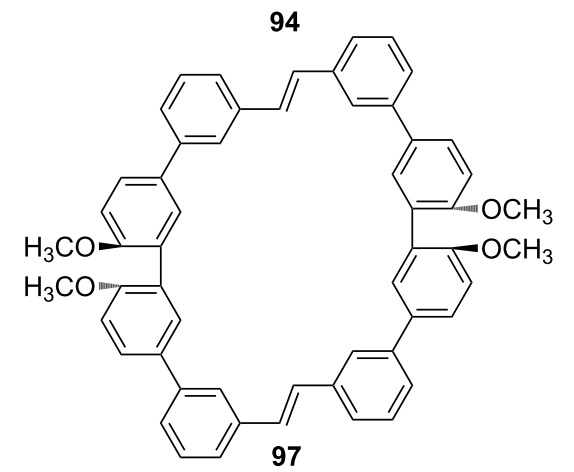

$100 n=2,4$

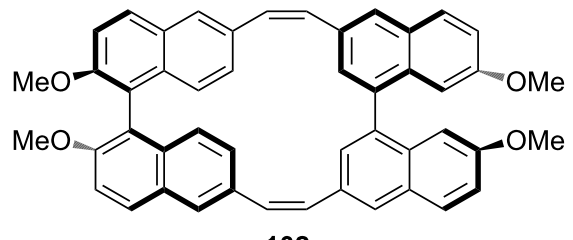

102

Figure 8: List of cyclophanes prepared via McMurry coupling reaction as a key step. 


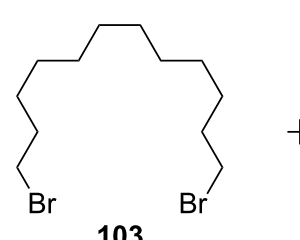

103

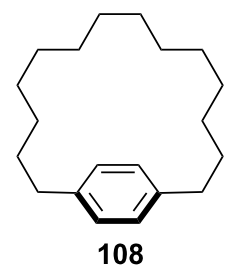

108<smiles>C=C(C#CCl)CCl</smiles>

(i)

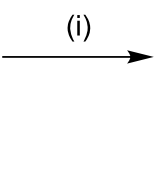

(iv)

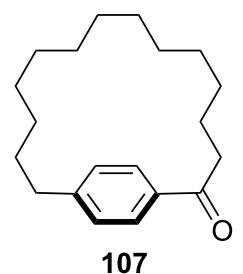

(iii)

(ii)

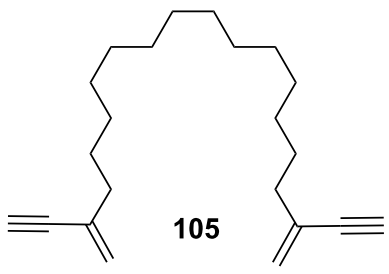

(ii)

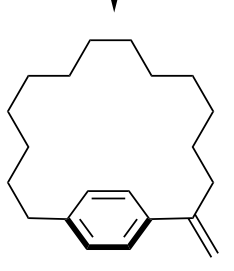

106

Scheme 15: Synthesis of paracyclophane by cross coupling involving Pd(0) catalyst. Reagents and conditions: (i) THF, rt, 72\%; (ii) Pd(PPh $)_{4}, \mathrm{PhMe}$, high dilution, $\Delta, 15 \mathrm{~min}, 32 \%$; (iii) $\mathrm{O}_{3},-78{ }^{\circ} \mathrm{C}, \mathrm{Pd} / \mathrm{C}$ (10 mol \%), $\mathrm{H}_{2}, \mathrm{rt}, 55 \%$; (iv) $\mathrm{Pd} / \mathrm{C}(10 \mathrm{~mol} \%), \mathrm{H}_{2}, 50{ }^{\circ} \mathrm{C}, \mathrm{rt}, 85 \%$.

dation with PCC which gave the dialdehyde 111 (85\%). The pinacol coupling of the dialdehyde $\mathbf{1 1 1}$ in the presence of $\mathrm{Sm}^{2+}$ and HMPA generated the cyclophane $\mathbf{1 1 2}$ in a moderate yield. $\mathrm{RCM}$ of the diene derived from the dialdehyde $\mathbf{1 1 1}$ afforded the macrocyclic cyclophane $\mathbf{1 1 3}$ as a less strained product (Scheme 16).

Sonogashira coupling: Wegner and co-workers [125] have reported the synthesis of cyclophanes 122a-c via Sonogoshira coupling [126] (Scheme 17). To this end, the 1,4-diiodobenzene (109) was reacted with the cyclohexane-1,4-dione (114) in the presence of $\mathrm{CeCl}_{3} / \mathrm{LiCl} / n$ - $\mathrm{BuLi}$ to generate the diol 115 . Then, the hydroxy groups were protected as MOM groups to generate the key synthone 116. The other building blocks 119a-c were obtained by protection of dialkynes $117 \mathbf{a}-\mathbf{c}$ with (3-cyanopropyl)dimethylsilyl chloride (CPDMSCl) (118). This protecting group was chosen to facilitate the separation of the mono- and diprotected products generated in this reaction. The two building blocks 116 and 119a-c were subsequently assembled via the Sonogashira reaction producing differently substituted diynes 120a-c. Deprotection of silyl groups in 120a-c using TBAF furnished the key intermediates $121 \mathbf{a}-\mathbf{c}$ in moderate to good yields. Treatment of 121a-c with $\mathrm{Pd}\left(\mathrm{PPh}_{3}\right)_{4}$ and copper iodide in THF in the presence of diisopropylamine gave the desired macrocycles 122a-c (Scheme 17).

Suzuki-Miyaura coupling: Bodwell and Li [127] have reported the synthesis of the cyclophane $\mathbf{1 3 0}$ involving hydro-

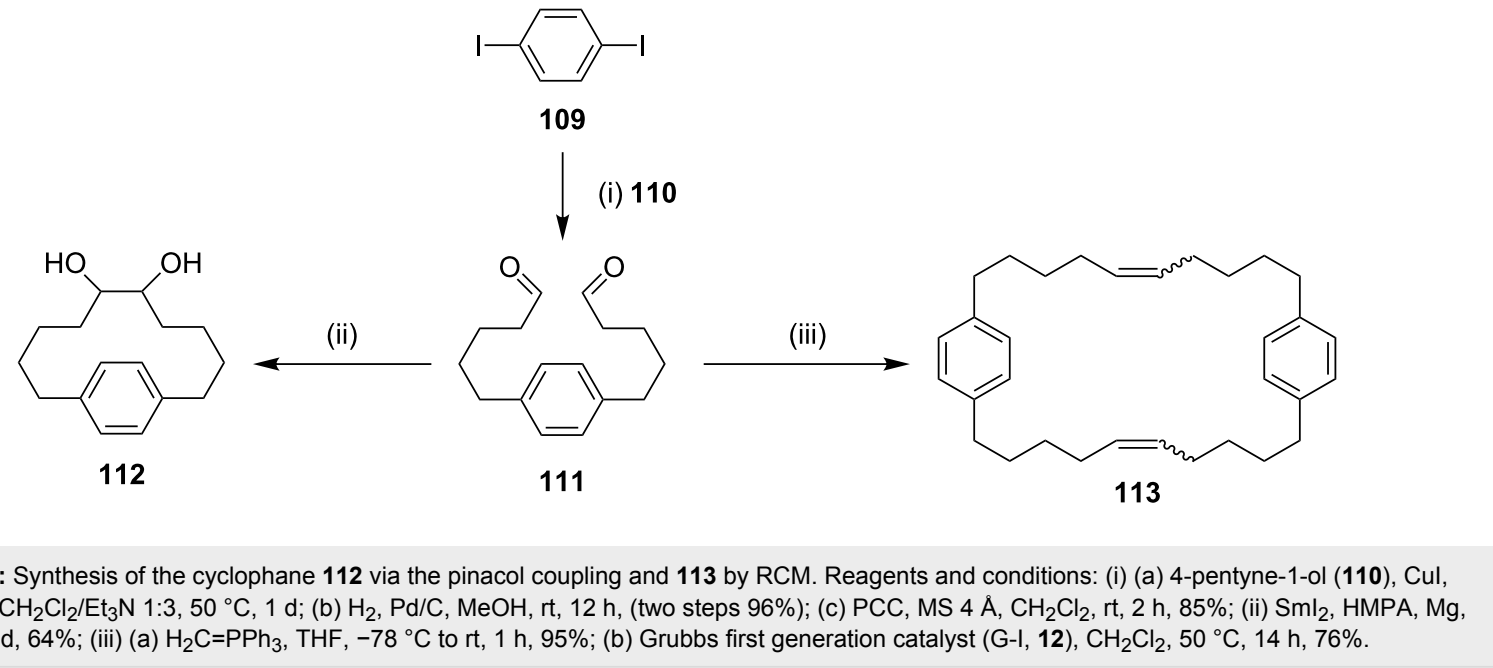




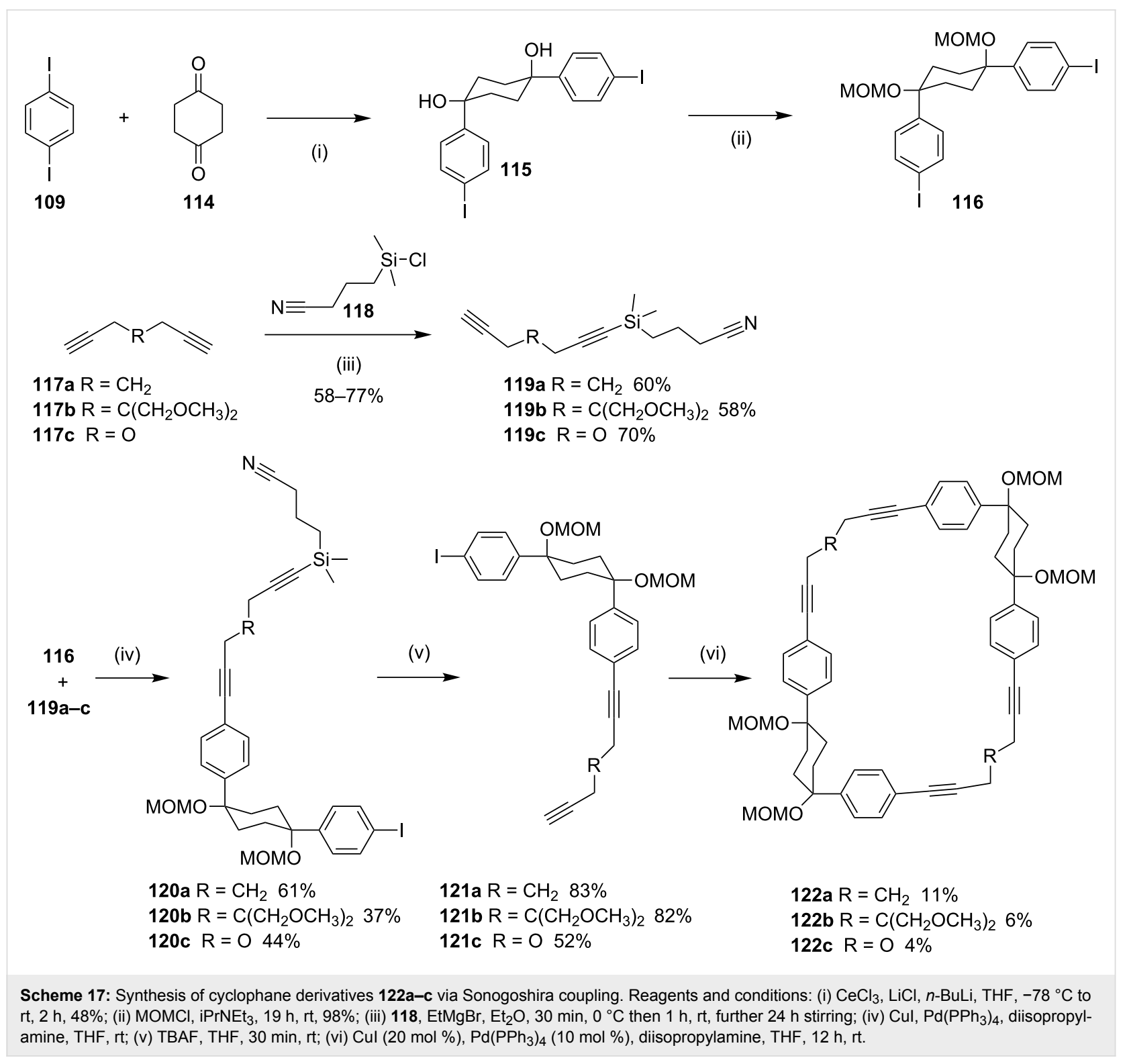

boration and the Suzuki-Miyaura (SM) coupling [128-135] as key steps. 1,3-Diallylindole (127) was first synthesized in two steps from indole (123) by successive allylation at the 3 position to give $126(66 \%)$ and later, $N$-allylation was carried out to afford the diallylindole 127 (69\%, Scheme 18). A three-step $(\mathbf{1 2 3} \rightarrow \mathbf{1 2 4} \rightarrow \mathbf{1 2 5} \rightarrow \mathbf{1 2 7})$ sequence was found to give a higher yield of the 1,3-diallylindole (127). Iodination of $\mathbf{1 2 3}$ gave the 3 -iodoindole (124) quantitatively, which on $N$-allylation afforded 125 (98\%). The treatment of compound 125 with $n$-BuLi followed by alkylation with allyl bromide gave diallylindole 127 (77\%), which on further treatment with 9-BBN (6 equiv) gave the doubly hydroborated species $\mathbf{1 2 8}$. Then, it was directly subjected to the Suzuki-Miyaura coupling reaction with 3,6-diiodopyridazine (129) and the desired cyclophane 130 was obtained (30\%) as an oil (Scheme 18).
In 2012, Hutton and co-workers [136] have synthesized a highly strained bicyclic framework of mycocyclosin (135) by utilizing the intramolecular Suzuki-Miyaura [137] cross-coupling reaction as a key step. The L,L-cyclodi(iodotryrosin) (131) was subjected to a benzylation reaction to give the protected compound $132(76 \%)$. A one-pot Pd-catalyzed borylation and Suzuki-Miyaura coupling was employed to generate the crosscoupling product 134 (42\%). Finally, deprotection of 134 was carried out with trifluoroacetic acid (TFA) in the presence of pentamethylbenzene to generate mycocyclosin $(\mathbf{1 3 5}, 74 \%)$ (Scheme 19).

Wurtz coupling: The Wurtz reaction is one of the oldest methods to form a $\mathrm{C}-\mathrm{C}$ bond in organic synthesis. Baker and co-workers [138] have reported the synthesis of cyclophanes 


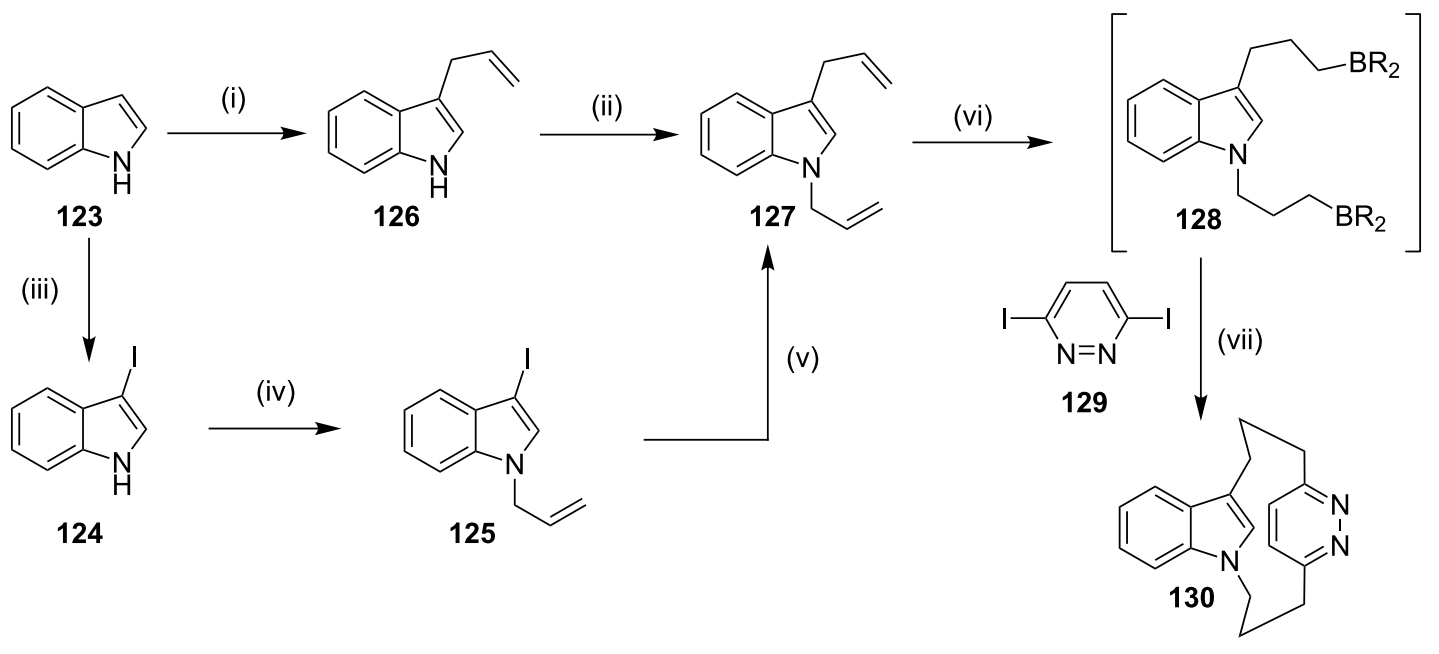

Scheme 18: Synthesis of cyclophane 130 via Suzuki-Miyaura reaction as a key step. Reagents and conditions: (i) MeMgBr, allyl bromide, ether $20{ }^{\circ} \mathrm{C}$, overnight, $66 \%$; (ii) $\mathrm{KOH}$, allyl bromide, TBAB, rt, $6 \mathrm{~h}, 69 \%$; (iii) $\mathrm{KOH}, \mathrm{I}_{2}$, DMF, $20^{\circ} \mathrm{C}, 0.45 \mathrm{~h}, 100 \%$; (iv) $\mathrm{KOH}$, allyl bromide, rt, $6 \mathrm{~h}, 98 \%$; (v) $n$-BuLi, allyl bromide, 77\%; (vi) 9-BBN, THF; (vii) 129, $\mathrm{Pd}\left(\mathrm{PPh}_{3}\right)_{2} \mathrm{Cl}_{2}, \mathrm{PPh}_{3}, \mathrm{Cs}_{2} \mathrm{CO}_{3}$, dioxane, $65{ }^{\circ} \mathrm{C}, 5 \mathrm{~h}, 30 \%$.

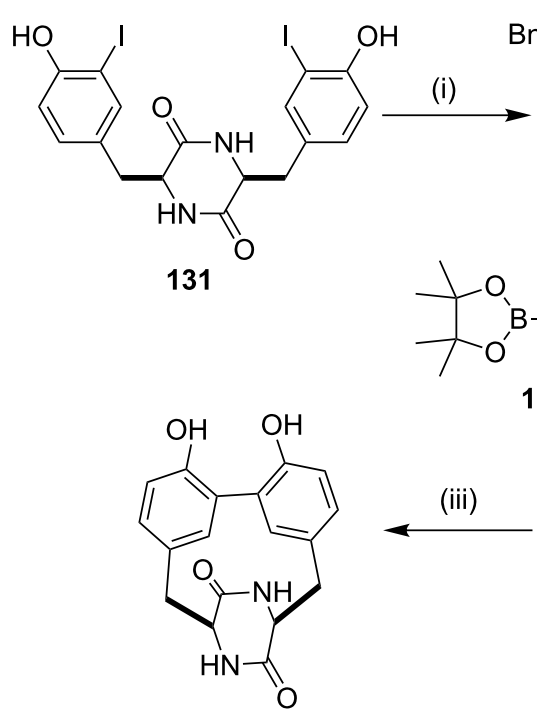

135<smiles>O=C1NC2Cc3cc(ccc3Br)CC(NC2=O)O1</smiles>

Scheme 19: Synthesis of the mycocyclosin via Suzuki-Miyaura cross coupling. Reagents and conditions: (i) benzyl bromide (1.7 mmol), $\mathrm{K}_{2} \mathrm{CO}_{3}$ (1.7 mmol), DMF, $16 \mathrm{~h}, 76 \%$; (ii) Pd(dppf)Cl 2,133 (1 equiv), DMSO, $\mathrm{K}_{2} \mathrm{CO}_{3}, 90^{\circ} \mathrm{C}$ for $16 \mathrm{~h}, 42 \%$; (iii) pentamethylbenzene (1.1 mmol), TFA, $1 \mathrm{~h}, 74 \%$.

137 and 139 by using the Wurtz coupling as a key step (Scheme 20).

\section{Metathesis}

Alkyne metathesis reaction: In 2010, Murphy and Jarikote [139] have developed a useful protocol for assembling nonnatural macrocyclic compounds containing carbohydrates. Compound 140 was prepared in several steps and was further subjected to the RCM with G-I (12) as a catalyst in $\mathrm{CH}_{2} \mathrm{Cl}_{2}$. Later, catalytic hydrogenation followed by deacetylation gave compound 141 (48\%). Similarly, alkyne metathesis of com- pound 142 was carried out in the presence of $\mathrm{Mo}(\mathrm{CO})_{6}$ and 2-fluorophenol in chlorobenzene and heated under reflux to yield the cyclized product. The cleavage of the acetate groups with sodium methoxide in methanol gave the glycophane (a glycophane is a hybrid of carbohydrate and cyclophane) $\mathbf{1 4 3}$ (27\%, Scheme 21).

The synthesis of fullerene-related molecules with high binding affinity and/or high selectivity is an active research area due to the cost and energy demanding purification process and the poor processibility of the fullerenes. To this end, Zhang and 

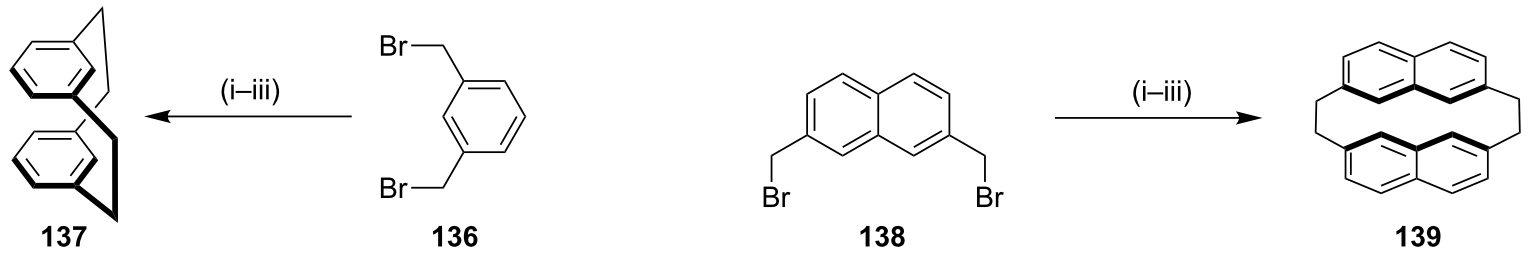

Scheme 20: Synthesis of cyclophanes via Wurtz coupling reaction Reagents and conditions: (i) $\mathrm{PhLi}, \mathrm{Et}_{2} \mathrm{O}, \mathrm{C}_{6} \mathrm{H}_{6}, \mathrm{reflux}, 39 \%$; (ii) $\mathrm{Na}, \mathrm{Nal}$ (cat), $\mathrm{PhBr}$ (cat), $\mathrm{Et}_{2} \mathrm{O}, 12 \%$; (iii) $\mathrm{PhLi}, \mathrm{Et}_{2} \mathrm{O}, \mathrm{C}_{6} \mathrm{H}_{6}, 60^{\circ} \mathrm{C}, 30 \mathrm{~min}, 20 \%$.

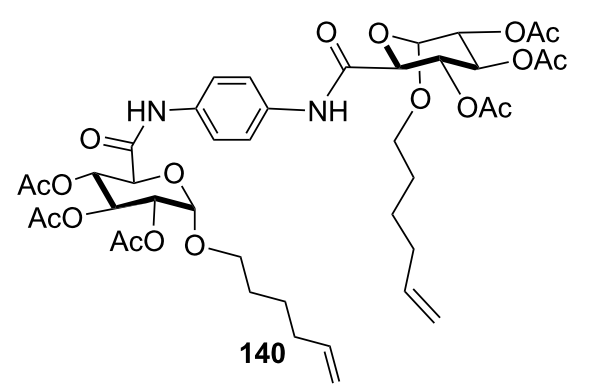

(i,ii)
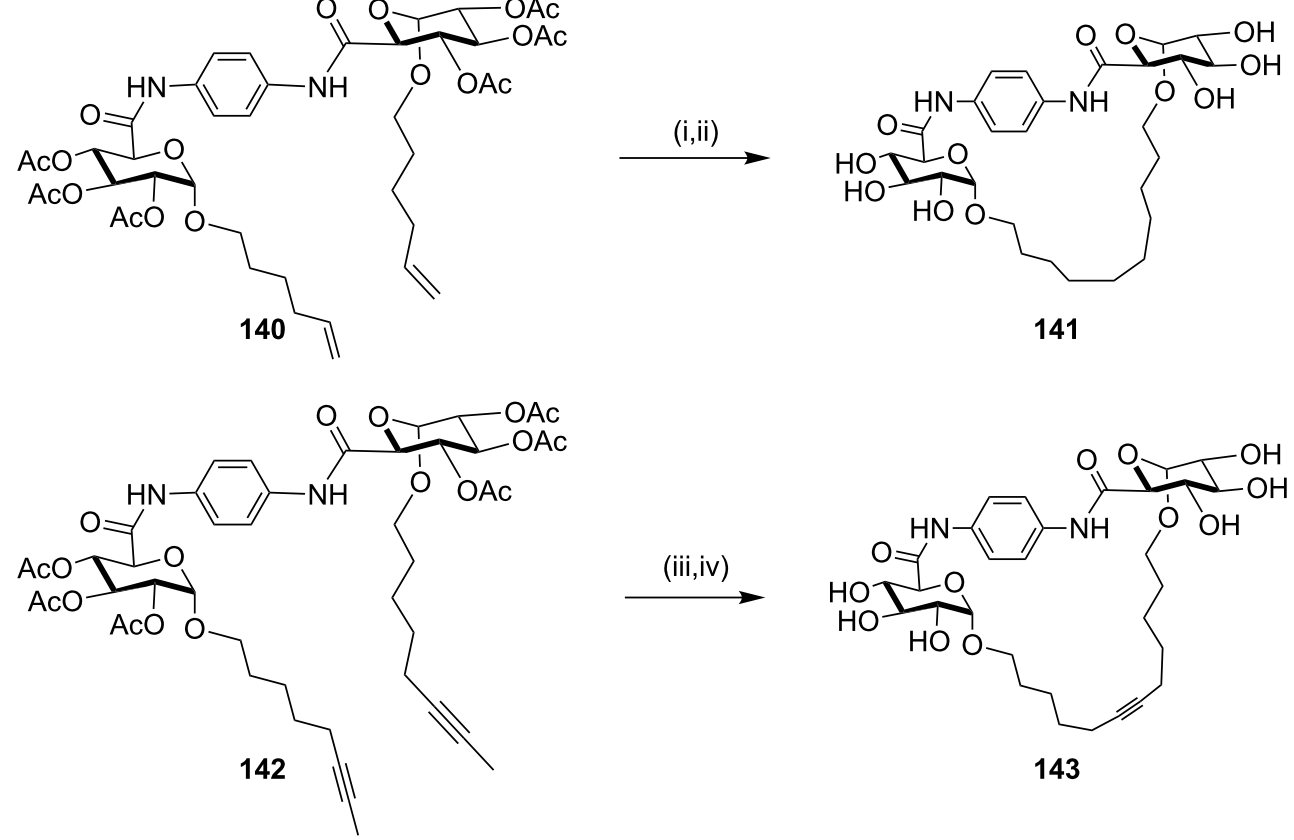

(iii,iv)

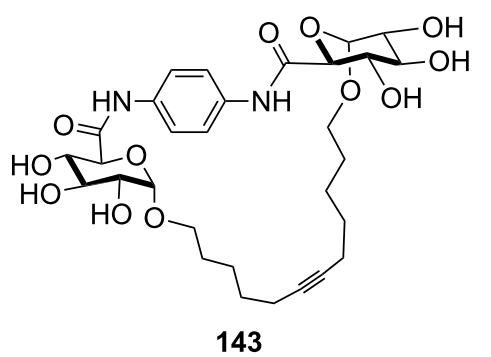

Scheme 21: Synthesis of non-natural glycophanes using alkyne metathesis. Reagents and conditions: (i) G-I (12), $\mathrm{CH}_{2} \mathrm{Cl}_{2}, 8 \mathrm{~h}$; (ii) Pd/C (5 mol \%), $\mathrm{NaOMe} / \mathrm{MeOH}, 48 \%$; (iii) Mo(CO)6, 2-fluorophenol, chlorobenzene, $\Delta$; (iv) $\mathrm{NaOMe} / \mathrm{MeOH}, 27 \%$.

co-workers [140] reported the synthesis of the bisporphyrin macrocycle 144 with an adaptable cavity by using alkyne metathesis with high efficiency. Tamm and co-workers [141] reported the synthesis of meta-cyclophane $\mathbf{1 4 5}$ at room temperature by ring-closing alkyne metathesis of 1,3-bis(3-pentynyloxymethyl)benzenes (Figure 9). This strategy has also been extended to ortho and para-derivatives.

Cross-enyne metathesis: Recently, Kotha and Waghule [142] have synthesized diverse crownophanes by using a cross-enyne metathesis and Diels-Alder (DA) reaction as key steps. Here, the macrocycles 146 and 149 were subjected to a cross-enyne metathesis protocol with ethylene to generate the dienes 147 and 150, respectively. These dienes were subjected to a DA reaction with different dienophiles followed by aromatization which gave the crownophanes (e.g., 148 and 151) (Scheme 22).
Cross metathesis: In 1992, (-)-cylindrocyclophane A (156) and (-)-cylindrocyclophane F (155) were isolated by Moore and co-workers [143] from a blue-green algae belonging to Cylindrospermum licheniforme. These paracyclophane derivatives exhibit potent cytotoxicity against the KB and LoVo tumor cell lines $\left(\mathrm{IC}_{50}=2-10 \mu \mathrm{g} / \mathrm{mL}\right)$. On another occasion, Smith and co-workers have reported the synthesis of (-)-cylindrocyclophane A (156) and (-)-cylindrocyclophane F (155) [144]. The dialkenyl derivative $\mathbf{1 5 2}$ was subjected to dimerization involving cross-metathesis with G-I/G-II/Schrock catalysts which generated the cyclized product $\mathbf{1 5 4}$. Subsequently, hydrogenation of the cyclophane $\mathbf{1 5 4}$ followed by minor functional group modification gave the natural products 155 and 156 (Scheme 23). Furthermore, the same group has reported the syntheses of $(-)$-cylindrocyclophanes A and F $(\mathbf{1 5 6}, \mathbf{1 5 5})$ by a RCM approach using different strategies. 

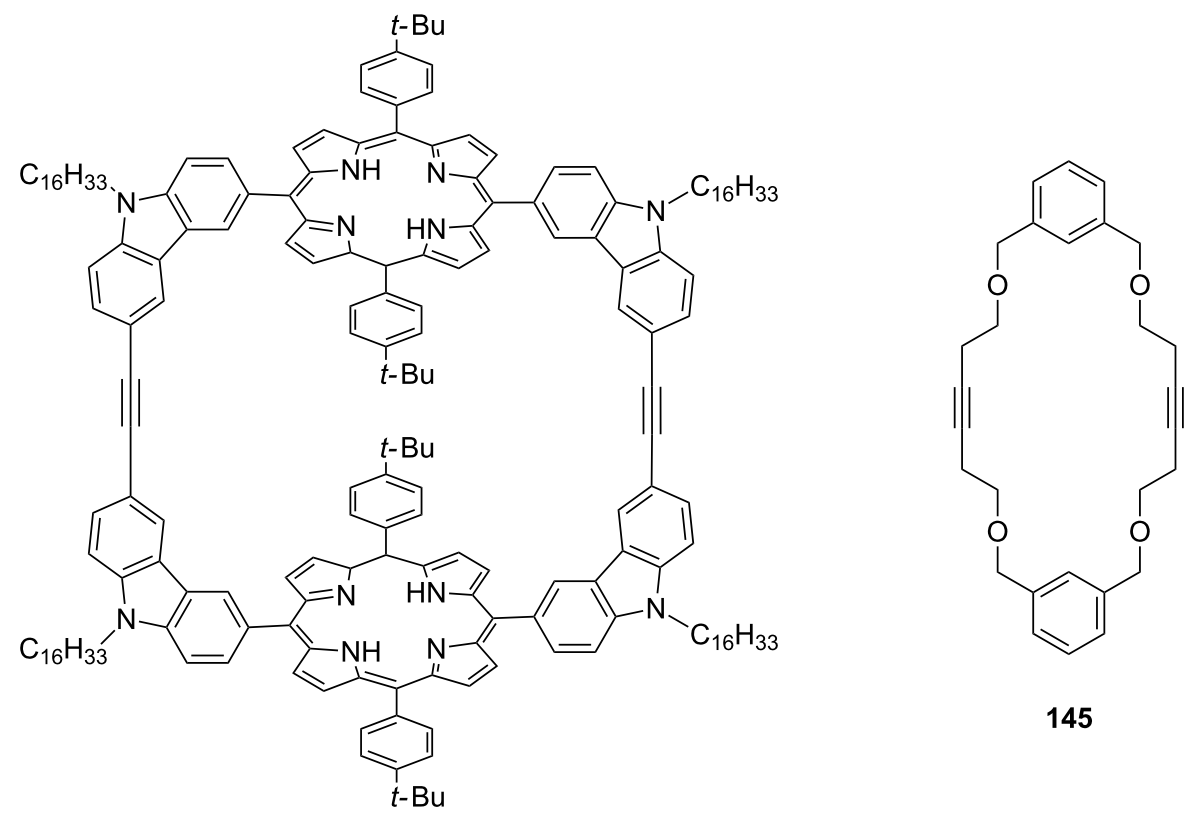

144

Figure 9: Synthesis of cyclophanes via ring-closing alkyne metathesis.

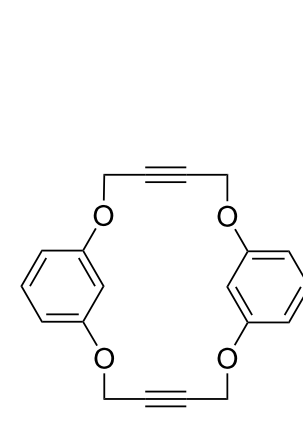

146

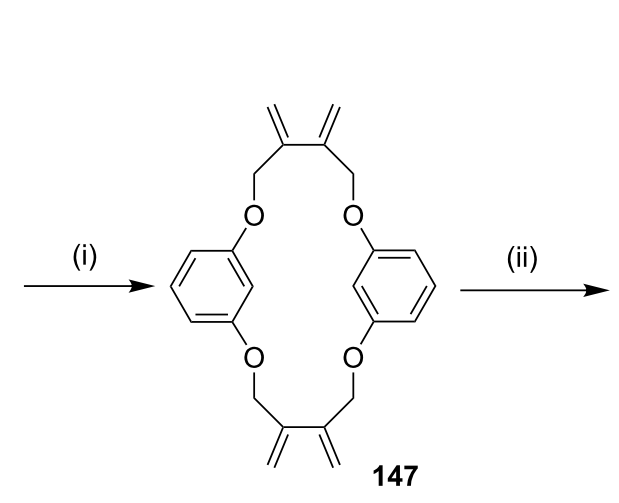<smiles>CC(=O)c1ccc(C(C)=O)cc1</smiles>

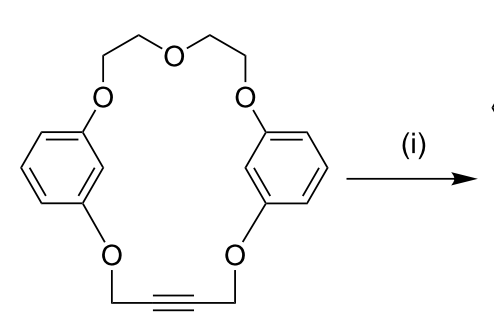

149

(i)

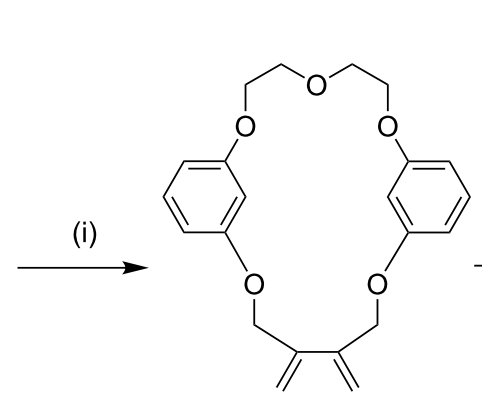

150

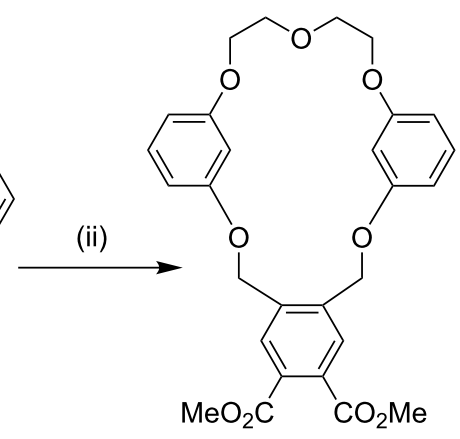

151 
<smiles>[R]C(c1cc(OC)c([C@@H](CC=C)CCCC)c(OC)c1)C(C)CC=C</smiles>

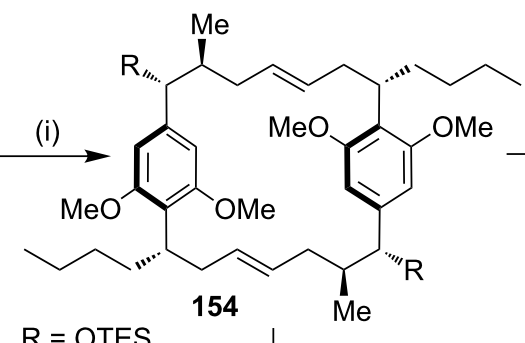

(iii)

$\mathrm{R}=$ OTES

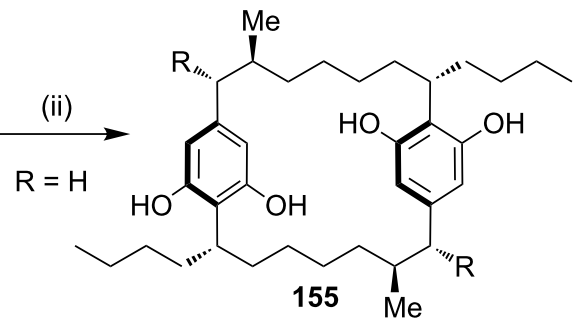

(-)-cyclindrocyclophane F

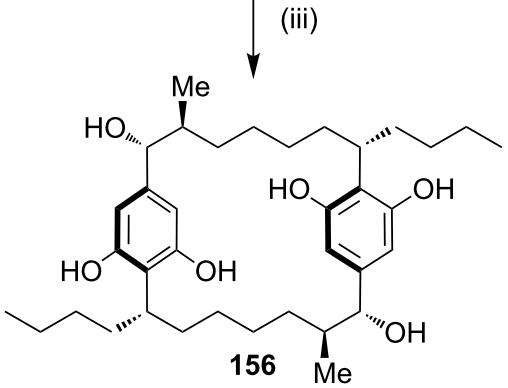

(-)-cyclindrocyclophane A

Scheme 23: Synthesis of (-)-cylindrocyclophanes $A(156)$ and (-)-cylindrocyclophanes $F(155)$. Reagents and conditions: (i) G-I/G-II/Schrock catalyst, 50-80\%; (ii) (a) $\mathrm{H}_{2}, \mathrm{Pd} / \mathrm{C}$; (b) $\mathrm{BBr}_{3}$ (84\% over 2 steps); (iii) (a) TBAF, THF; (b) $\mathrm{H}_{2}, \mathrm{PtO}_{2}$; (c) $\mathrm{PhSH}_{2} \mathrm{~K}_{2} \mathrm{CO}_{3}, \mathrm{NMP}(60 \%$ over 3 steps).

Kotha and co-workers [145] have synthesized cyclophanes by using 1,3-indanedione using freshly prepared KF-Celite followed by SM cross-coupling reaction with an excess amount of allylboronic acid pinacol ester and afforded the required diallyl derivative 157 in good yield. Surprisingly, when the dialkyl compound $\mathbf{1 5 7}$ was subjected to RCM, instead of the monomer, the dimeric cyclophane $\mathbf{1 5 8}$ was obtained which was further subjected to hydrogenation to deliver the saturated cyclophane derivative 159 (Scheme 24).

To prepare $\pi$-conjugated three-dimensional molecules with potential isoelectronic properties and facile processibility, Kurata and co-workers [146] reported sexithiophene 163, a bridged cage shaped compound (Scheme 25). Its synthesis involves a Suzuki-Miyaura coupling reaction followed by cross metathesis. The molecule shows a hypsochromic shift which indicates rigidity in the molecule compared with the other linear molecules.

Enyne metathesis: In 1998, Fürstner and co-workers [147] have employed platinum(II)-catalyzed enyne metathesis as a key step to form cyclophane ring systems which are found in streptorubin B and metacycloprodigiosin [148-150]. In this context, the cyclooctene $\mathbf{1 6 4}$ was reacted with the intermediate formed in situ from chloramine-T and elemental selenium [151] and yielded the allylic amine derivative 165 (75\%). An N-alkylation with propargyl bromide gave the enyne product $\mathbf{1 6 6}$ $(92 \%)$, which on further acylation of terminal alkyne with butanoyl chloride delivered compound 167 (82\%). Then, it was subjected to an enyne metathesis with simple platinum salts such as $\mathrm{PtCl}_{2}$ and $\mathrm{PtCl}_{4}$ to give product 168 (79\%). A subsequent reduction of the $\alpha, \beta$-unsaturated ketone delivered the

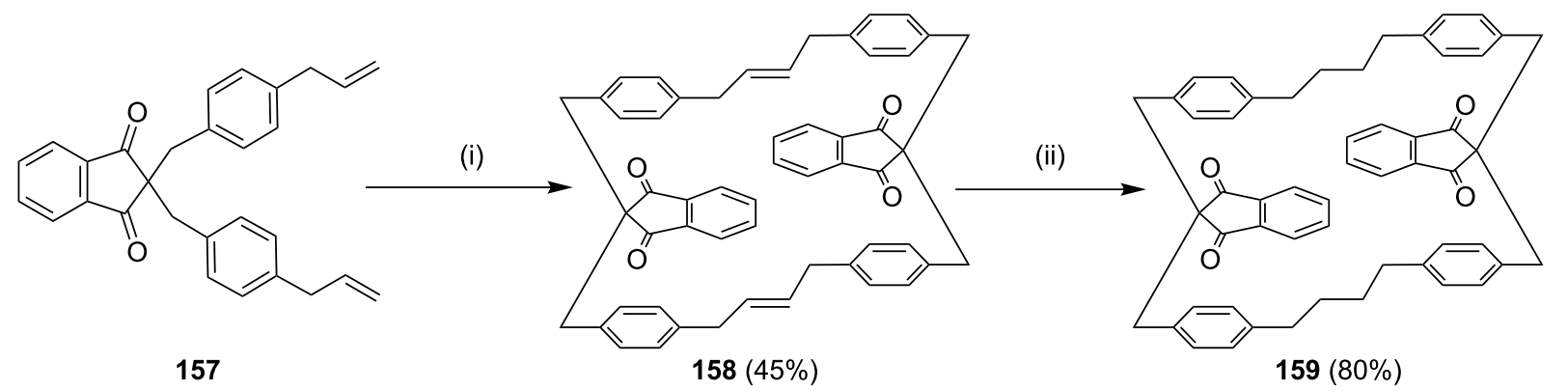

Scheme 24: Synthesis of cyclophane 159 derivatives via SM cross-coupling and $\mathrm{RCM}$. Reagents and conditions: (i) $\mathrm{G}-\mathrm{II}$ (13), $\mathrm{CH}_{2} \mathrm{Cl}_{2}$ (0.002 $\mathrm{M}$ ), $50{ }^{\circ} \mathrm{C}$; (ii) $\mathrm{H}_{2}, 10 \% \mathrm{Pd} / \mathrm{C}, \mathrm{CH}_{2} \mathrm{Cl}_{2} / \mathrm{MeOH}$, rt. 


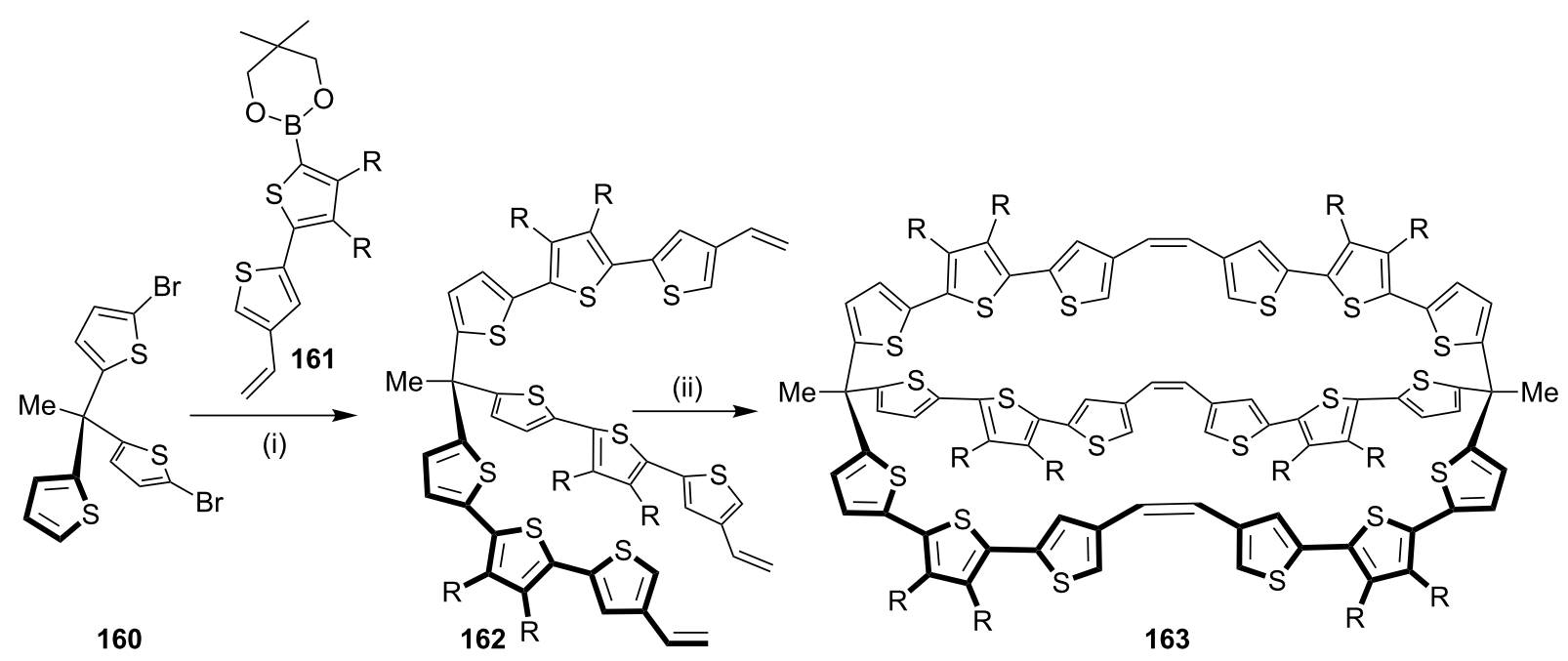

Scheme 25: Sexithiophene synthesis via cross metathesis. Reagents and conditions: (i) $161, \mathrm{Pd}_{\left(\mathrm{PPh}_{3}\right)_{4}, \mathrm{~K}_{2} \mathrm{CO}}, \mathrm{THF} / \mathrm{PhMe} / \mathrm{H}_{2} \mathrm{O}$; (ii) G-II (13), $\mathrm{CH}_{2} \mathrm{Cl}_{2}, 27 \%$.

compound 169 (64\%). Finally, aromatization of compound 169 by using potassium 3-aminopropylamide (KAPA) gave compound 170 (75\%) (Scheme 26).

Ring-closing metathesis (RCM): In 2003, Tae and Yang [152] have reported an efficient macrocyclization of various alkenyl derivatives 171 via RCM/CM using G-I (12) or G-II (13) under high dilution conditions to obtain the $[n],[n, n]$ and $[n, n, n]$ paracyclophanes 172-174. Compounds with a short alkenyl chain gave mainly $[n, n]$ and $[n, n, n]$ paracyclophanes (173 and 174) by a dimerization or trimerization sequence. When the compound has a alkenyl chain of sufficient length the $[n]$ paracyclophane 172 was obtained by an intramolecular cyclization (Scheme 27).

Alcaide and co-workers [153] have reported the synthesis of different bis(dihydrofuryl)cyclophane scaffolds 179 from carbonyl compounds. 1,4-Bis(3-bromoprop-1-ynyl)benzene (175) was reacted with azetidine-2,3-diones $\mathbf{1 7 6}$ under eco-friendly reaction conditions to generate bis(allene) 177. Compound 177 was then converted into bis(dihydrofuran) $\mathbf{1 7 8}$ by using $\mathrm{AuCl}_{3}$.<smiles>C#CCN([As])C1C=CCCCCC1C#CC#CCN([Tl])C1C=CCCCCC1</smiles>

(iv)
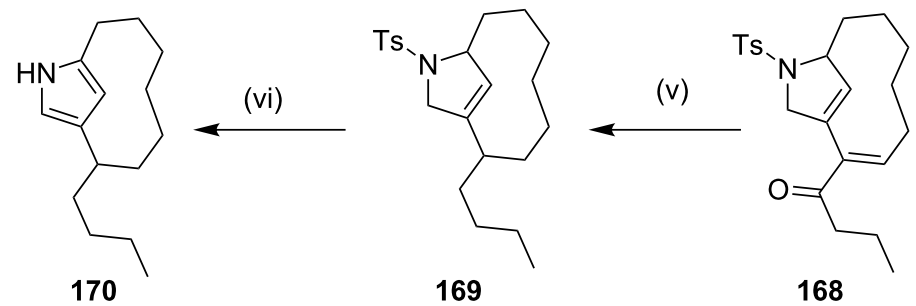

Scheme 26: Synthesis of pyrrole-based cyclophane using enyne metathesis. Reagents and conditions: (i) Se, chloramine-T, 75\%; (ii) NaH, THF, propargyl bromide, $92 \%$; (iii) $n$ - BuLi, $-78{ }^{\circ} \mathrm{C}, \mathrm{ZnCl}_{2},-30{ }^{\circ} \mathrm{C}$, butanoyl chloride, rt, $82 \%$; (iv) $\mathrm{PtCl}_{2}(5 \mathrm{~mol} \%), 66 \mathrm{~h}, 20{ }^{\circ} \mathrm{C}, 79 \%$; (v) (a) $\mathrm{Bu}_{3} \mathrm{SnH}, \mathrm{Pd}(0)$, $\mathrm{HBF}_{4}, 94 \%$; (b) $\mathrm{LiAlH}_{4}, 96 \%$; (c) PhOC(S)Cl, 95\%; (d) Bu $3 \mathrm{SnH}, \mathrm{AlBN}, 64 \%$; (vi) $\left(\mathrm{CH}_{2}\right)_{3}\left(\mathrm{NH}_{2}\right)_{2}, \mathrm{KH}, 3 \mathrm{~h}, \mathrm{KAPA}, 75 \%$. 
<smiles>[Y20]c1ccc([Y4]([H])=CC=C)cc1</smiles>

171

$\mathrm{X}=\mathrm{O}, \mathrm{CH}_{2} \mathrm{O}, \mathrm{C}(\mathrm{O}) \mathrm{O}$ (i)<smiles></smiles>

172

$n=1$

$n=2$

$n=3$<smiles>[Y2]c1ccc([Y])cc1</smiles>

173<smiles>[Y]c1ccc(-c2ccc(-[Y]3ccccc3)cc2)cc1</smiles>

174

Scheme 27: Synthesis of macrocyclic derivatives by RCM. Reagents and conditions: (i) G-I/G-II, $\mathrm{CH}_{2} \mathrm{Cl}_{2}, 0.005 \mathrm{M}, 45^{\circ} \mathrm{C}, 14-22 \mathrm{~h}, 60-76 \%$.

Macrocyclization of $\mathbf{1 7 8}$ was carried out by using a $\mathrm{Ru}(\mathrm{II})$ or $\mathrm{Ru}(\mathrm{III})$ catalyst to generate $\mathbf{1 7 9}$ as a mixture of $E / Z$ isomers (Scheme 28).

In the literature, there are limited reports on the preparation of cyclophane derivatives by a combination of the Suzuki-Miyaura (SM) coupling and an RCM as key steps. Kotha and Mandal [135] reported a new approach to assemble [1.1.6]metaparacyclophane derivative $\mathbf{1 8 3}$ via the SM cross coupling and an RCM as key steps. In this regard, the $\alpha, \alpha^{\prime}-$ dibromo- $m$-xylene (136) was treated with arylboronic acid $\mathbf{1 8 0}$, to give the dialdehyde $\mathbf{1 8 1}$ which on reaction with indiummediated Grignard addition reaction gave diolefin 182. Later RCM of diolefin 182 delivered cyclophane 183. Subsequent oxidation of diol $\mathbf{1 8 3}$ gave [1.1.6]metaparacyclophane derivative 184 (Scheme 29).
Using the same approach, a butenyl Grignard reagent was added to compound 181 to generate diol $\mathbf{1 8 5}$. Surprisingly, after the addition of G-II catalyst 13, the two RCM products 186 and 189 were obtained [135]. The outcome of product 189 was explained on the basis of a tandem isomerization of a terminal double bond followed by the macrocyclization with G-II (13). Finally, the oxidation of diols 186 and 189 generated cyclophanes 187 and 190, respectively (Scheme 30).

Guan and coworkers [154] have reported a novel synthetic approach to cyclophanes by using a template-promoted cyclization involving the RCM as a key step. This approach proceeded via the condensation of compound 191 with acenaphthenequinone in the presence of $p$-TSA to deliver the RCM precursor 192, which facilitate the cyclization protocol with G-II (13) as a catalyst to generate cyclophane derivative 193<smiles>CC1(C)CC[C@@H]([C@H]2C(=O)C(=O)N(C/C=C\CBr)C2=O)O1</smiles><smiles>C=CCCCN1C(C2COC(C)(C)O2)C2(OCC=C2c2ccc(C3=CCOC3)cc2)C(=O)N1CCC=C</smiles>

178

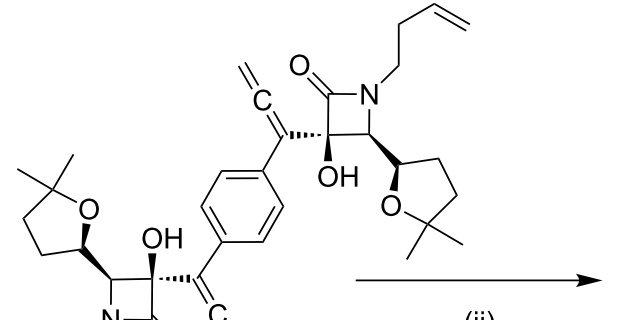

(ii)

(iii) 

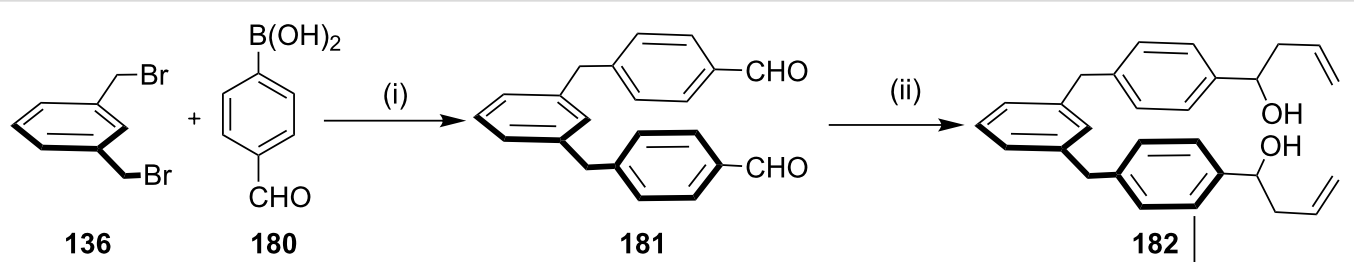

(iii)

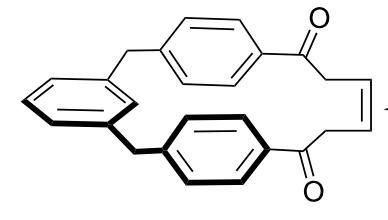

184

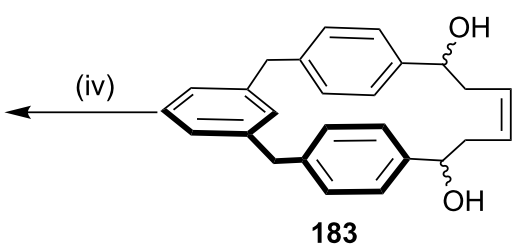

Scheme 29: Synthesis of a [1.1.6]metaparacyclophane derivative 183 via SM cross coupling. Reagents and conditions: (i) $\mathrm{Pd}\left(\mathrm{PPh}_{3}\right)_{4}, \mathrm{Na}_{2} \mathrm{CO}_{3}, \mathrm{THF}$ water, reflux, $12 \mathrm{~h}, 80 \%$; (ii) indium, allyl bromide, DMF; (iii) G-I (12), $\mathrm{CH}_{2} \mathrm{Cl}_{2}$; (iv) $\mathrm{PCC}, \mathrm{CH}_{2} \mathrm{Cl}_{2}$.

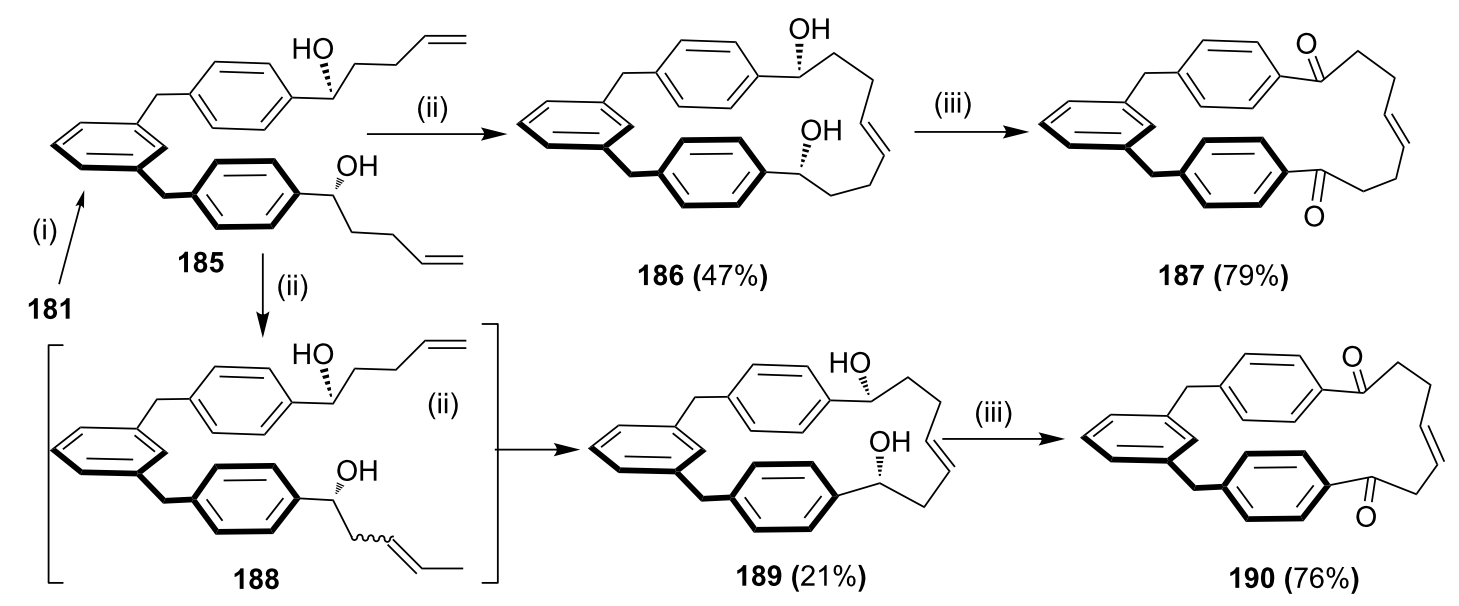

Scheme 30: Synthesis of a [1.1.6]metaparacyclophane derivative 190 via SM cross coupling. Reagents and conditions: (i) Mg, Et $\mathrm{E}_{2} \mathrm{O}$, 4-bromobut-1ene; (ii) G-II (13, $10 \mathrm{~mol} \%$ ), $\mathrm{CH}_{2} \mathrm{Cl}_{2}$; (iii) PCC, $\mathrm{CH}_{2} \mathrm{Cl}_{2}$, rt.

containing an $\alpha$-diimine functionality. Subsequently, the hydrogenation of 193 gave cyclophane 195. The removal of the template under hydrogenolytic conditions gave the macrocyclic compound 194 (Scheme 31).

In continuation of earlier work [145], Kotha and co-workers have demonstrated an interesting strategy to assemble [3.4]cyclophane derivative 197 by using the SM cross coupling and an RCM as key steps. The commercially available active methylene compound diethyl malonate was alkylated with a benzyl bromide derivative followed by the SM cross coupling to give dialkyl 196. Subsequently, an olefin metathesis with G-II (13) as a catalyst delivered dimeric 197 and monomeric 198 cyclophane derivatives. Later, the hydrogenation of 197 and 198 gave the corresponding saturated [3.4]cyclophane derivatives 199 and 200, respectively (Scheme 32).
Müllen and co-workers [155] have synthesized hexa-peri-hexabenzocoronene cyclophane $201 \mathbf{a}-\mathbf{c}$. They studied their properties by carrying out differential scanning calorimetry (DSC), optical microscopy, wide-angle X-ray scattering (WAXD), and scanning tunneling microscopy (STM). Tunneling spectroscopy reveals a diode-like behavior which introduces a high caliber of these molecular complexes. The RCM protocol has been successfully employed to generate a series of dicyanobiphenylcyclophanes $\mathbf{2 0 2}$ which are useful as $n$-type semiconductors [156]. Winkelmann and co-workers [157] have synthesized chiral concave imidazolinium salts $\mathbf{2 0 3}$ as precursors to chiral concave N-heterocyclic carbenes. Molecular encapsulation was achieved by using double RCM to generate insulated oligoynes 204. Here, the masked hexayne plays an important role to lock the flanking chains [158]. The synthesis of planer chiral cyclophanes is a difficult task owing to the flipping of the ansa-chain 

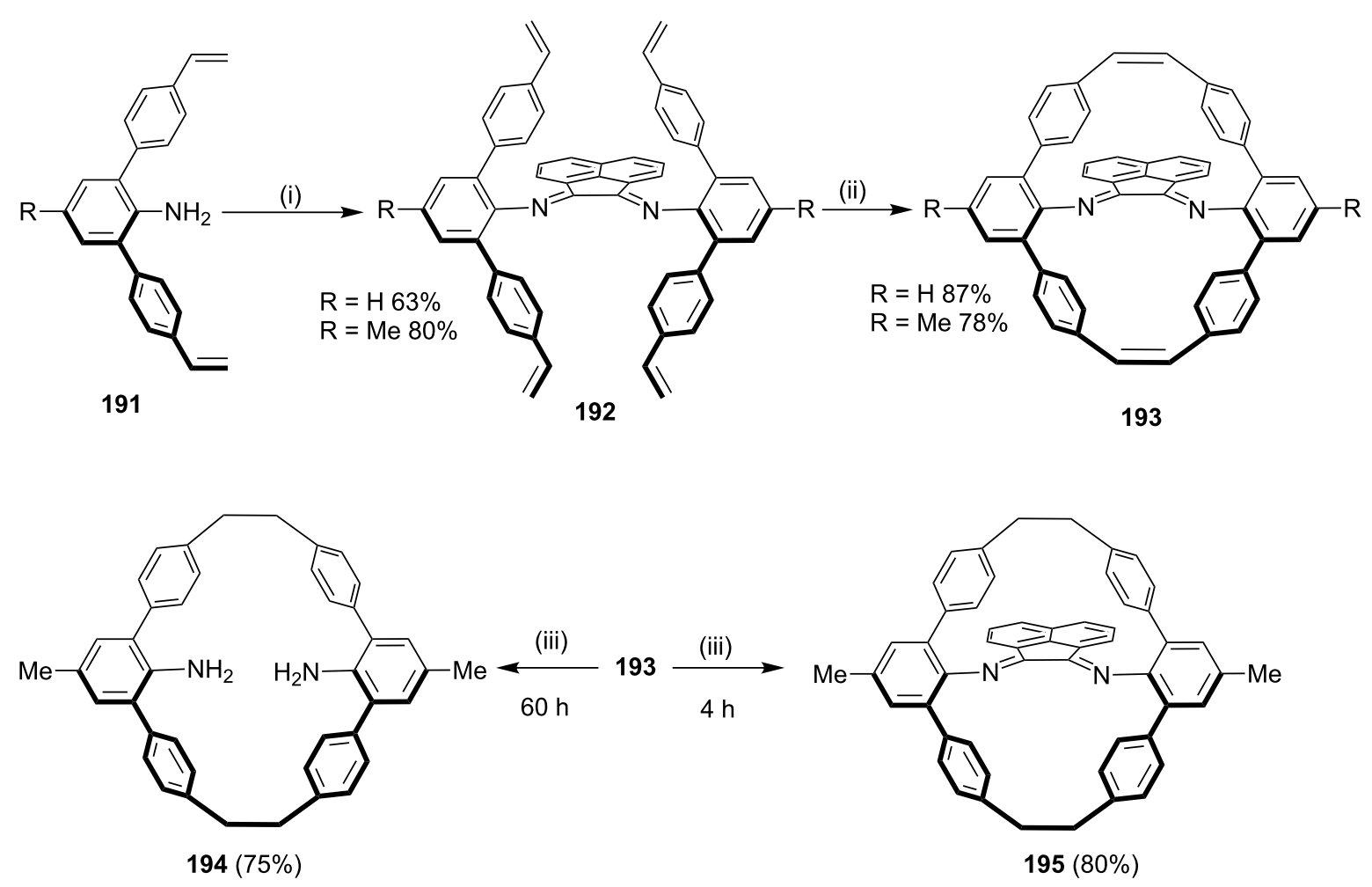

Scheme 31: Template-promoted synthesis of cyclophanes involving RCM. Reagents and conditions: (i) acenaphthenequinone, $p$-TSA, $\mathrm{C}_{6} \mathrm{H}_{6}$; (ii) G-II (13), $\mathrm{CH}_{2} \mathrm{Cl}_{2}(0.002 \mathrm{M}), 50^{\circ} \mathrm{C}$; (iii) $\mathrm{Pd} / \mathrm{C}(10 \mathrm{~mol} \%), \mathrm{H}_{2}, \mathrm{CH}_{2} \mathrm{Cl}_{2} / \mathrm{MeOH}$, rt.
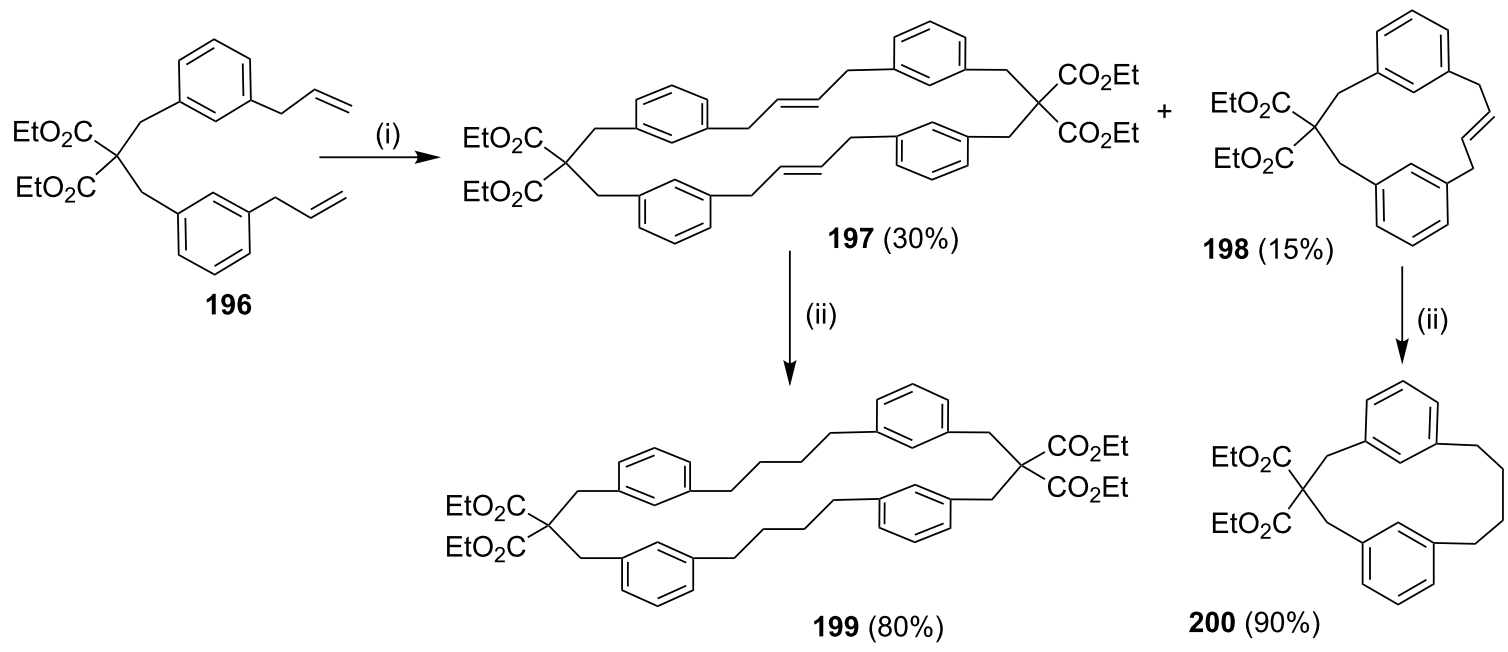

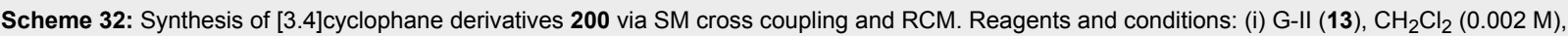
$50^{\circ} \mathrm{C}$; (ii) $\mathrm{H}_{2}, 10 \% \mathrm{Pd} / \mathrm{C}, \mathrm{CH}_{2} \mathrm{Cl}_{2} / \mathrm{MeOH}$, rt.

present in these molecules. Suzuki and co-workers [159] have reported the synthesis of enantiomerically pure planar-chiral [10]- and [12]paracyclophanes $\mathbf{2 0 5}$, which will serve as useful intermediates for the synthesis of various other cyclophane derivatives. Literature reports demonstrate the extensive use of
RCM in the synthesis of different metallophanes involving ferrocenophane (e.g., 206) [160] and other metallophanes [161164]. The synthesis of mechanically interlocked molecules such as catenanes and rotaxanes which are used to assemble molecular machines, sensors and nanomaterials is a challenging task. 
Huang and co-workers [165] have reported a taco complex template method to synthesize a cryptand/paraquat [2]rotaxane and [2]catenane (e.g., 207) by using RCM as a key step. Structural features and interesting bioactivity of the hirsutellones have grabbed the attention of synthetic chemists. Liu and co-workers [166] have constructed the [10]paracyclophane 208 (skeleton of hirsutellones) via RCM. The 2,2'-bipyridine unit is an interesting building block due to its use in chelating ligands, as a binding agent and also a useful template in supramolecular chemistry, Rykowski and co-workers [167] have synthesized azathiamacrocycle 209 using RCM (Figure 10).

Collins and co-workers [168] have reported the application of auxiliaries that engage in quadrupolar interactions in a total synthesis of a macrocyclic portion of longithorone C. To investigate the macrocyclization with the pentafluorobenzyl ester auxiliary, ester $\mathbf{2 1 0}$ was synthesized in a multistep process and then subjected to olefin metathesis to deliver the macrocycle

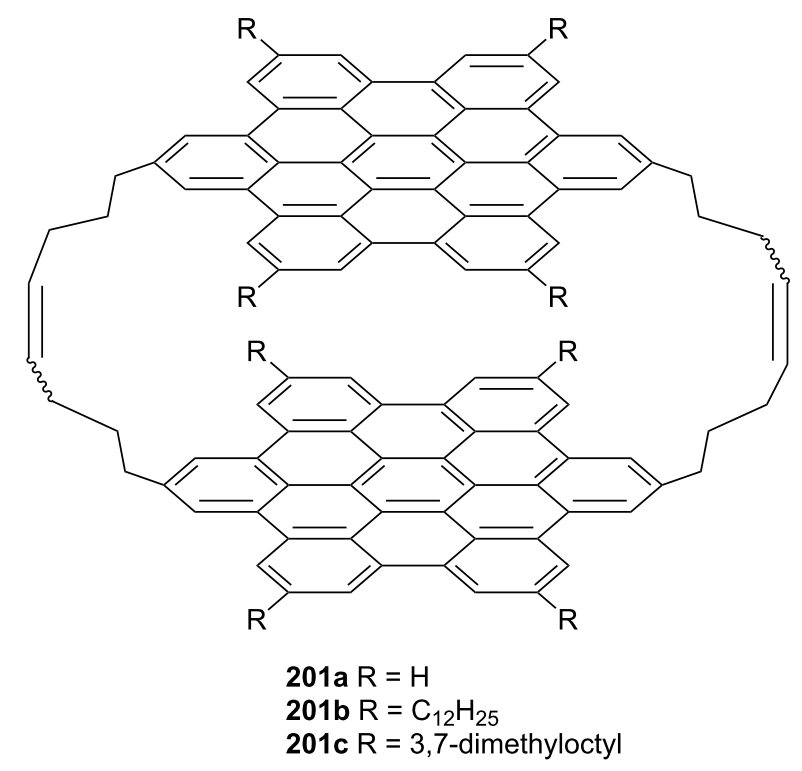

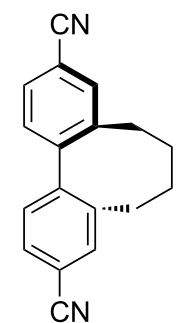

202

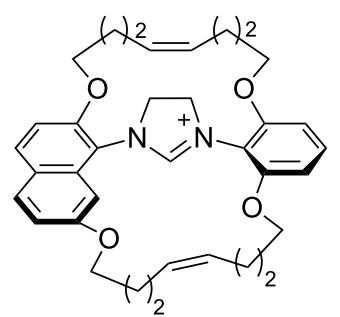

203

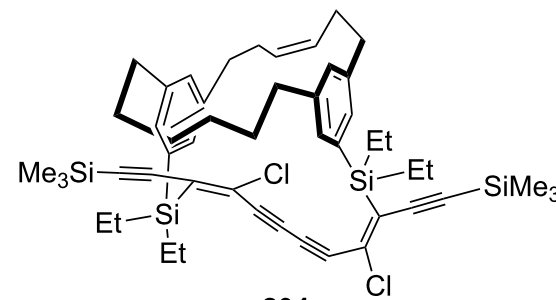

204

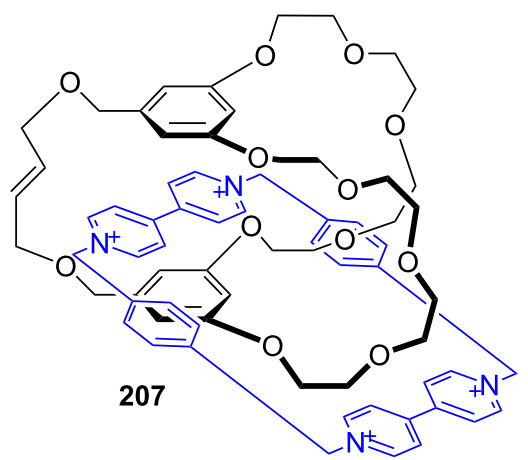

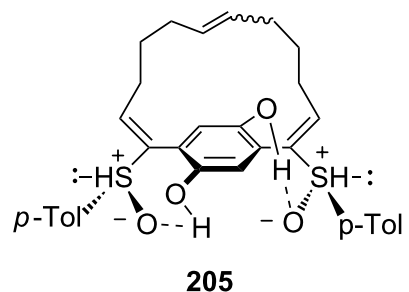

205

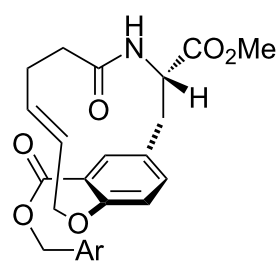

208

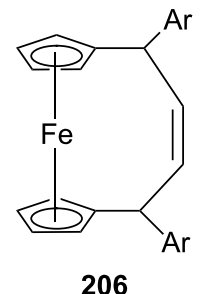<smiles>C1=CC2=NC3=CC=CC(=NC=CCOCCS3)C(=C1)/C=C\COCCS2</smiles>

Figure 10: Examples for cyclophanes synthesized by RCM. 
using the Blechert catalyst 17 . The treatment of the pentafluorophenyl benzyl ester $\mathbf{2 1 0}$ with catalyst $\mathbf{1 7}$ in toluene afforded the rigid macrocycle 211 (39\%, Scheme 33).

Kotha and Shirbhate [169] have reported the longithorone framework by using RCM as a key step. Dibromo compound 212 was reacted with monoalkylated ethyl acetoacetate 213 in the presence of $\mathrm{NaH}$ to deliver bis-alkyated product 214, followed by an oxidation the quinone derivative $\mathbf{2 1 5}$ (67\%) was obtained. Next, the quinone 215 was subjected to $\mathrm{RCM}$ to generate the cyclized product $\mathbf{2 1 6}$ (71\%, Scheme 34).

Nicolaou and $\mathrm{Xu}$ [170] assembled the floresolide B 219 via $\mathrm{RCM}$ as a key step. Compound $\mathbf{2 1 7}$ underwent cyclization in the presence of G-II (13) in DCM heated under reflux to generate the two isomers of 218 (89\%). Subsequently, the cleavage of the nitrobenzoate group with $\mathrm{K}_{2} \mathrm{CO}_{3}$ in $\mathrm{MeOH}$ gave the floresolide B 219 (Scheme 35).

Fürstner and Leitner [171] have reported the synthesis of the normuscopyridine (223) by a cross-coupling reaction and an RCM as key steps. The treatment of the pyridine derivative $\mathbf{2 2 0}$ with an excess amount of the 5-hexenylmagnesium bromide in the presence of a catalytic amount of iron complex $\mathbf{1 8}$ as the precatalyst provides the dialkylation product 221 (75\%). The treatment of the hydrochloride solution of $\mathbf{2 2 1}$ with $\mathrm{Ru}$ catalyst 17 in a dilute $\mathrm{CH}_{2} \mathrm{Cl}_{2}$ solution gave the cycloalkene 222 which on subsequent hydrogenation yielded the targeted normuscopyridine (223, 68\%, Scheme 36).

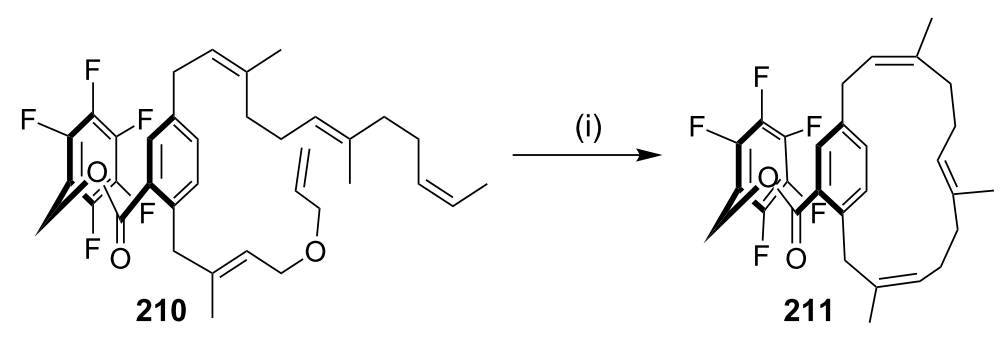

Scheme 33: Synthesis of the longithorone $\mathrm{C}$ framework assisted by fluorinated auxiliaries. Reagents and conditions: (i) Blechert catalyst (17, $10 \mathrm{~mol} \%)$, $\mathrm{Ti}(\mathrm{iOPr})_{4}, \mathrm{CH}_{2} \mathrm{Cl}_{2}, 4 \mathrm{~h}, 39 \%$.<smiles>C=CCCCC(Cc1cc(OC)c(CC(CCCC=C)C(=O)OCC)cc1OC)C(=O)OCC</smiles><smiles>C#CC1=CC(=O)C(CC(CCCC=C)C(=O)OCC)=CC1=O</smiles>

(iii)

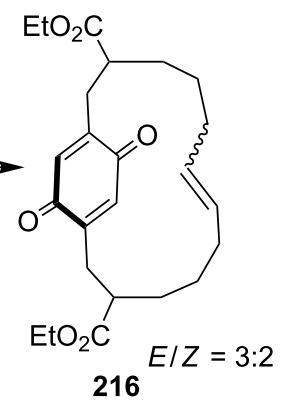

Scheme 34: Synthesis of the longithorone framework via RCM. Reagents and conditions: (i) 213, $\mathrm{NaH}, \mathrm{THF}, \mathrm{rt}, 10-15 \mathrm{~h}$; (ii) $\mathrm{CAN} \mathrm{SiO}{ }_{2}, \mathrm{H}_{2} \mathrm{O}, \mathrm{CH}_{2} \mathrm{Cl}_{2}$ $5 \mathrm{~min}, \mathrm{rt}, 67 \%$; (iii) 13, (5 mol \%), PhMe, reflux, $10 \mathrm{~h}, 71 \%$.<smiles>C=CCCC1=CCc2cc(OC(=O)c3c(C)cccc3[N+](=O)[O-])ccc2C(CCC(=C)C)c2cc(C(C)C)ccc21</smiles>

Scheme 35: Synthesis of floresolide $B$ via RCM as a key step. Reagents and conditions: (i) $\mathrm{G}-\mathrm{II}(13,0.1 \mathrm{equiv}), 0.5 \mathrm{mM}^{\mathrm{in}} \mathrm{CH}_{2} \mathrm{Cl}_{2}, 40{ }^{\circ} \mathrm{C}, 15 \mathrm{~min}$; (ii) $\mathrm{K}_{2} \mathrm{CO}_{3}$ (10.0 equiv), $\mathrm{MeOH} / \mathrm{H}_{2} \mathrm{O} 1: 1,25^{\circ} \mathrm{C}, 2 \mathrm{~h}, 90 \%$. 


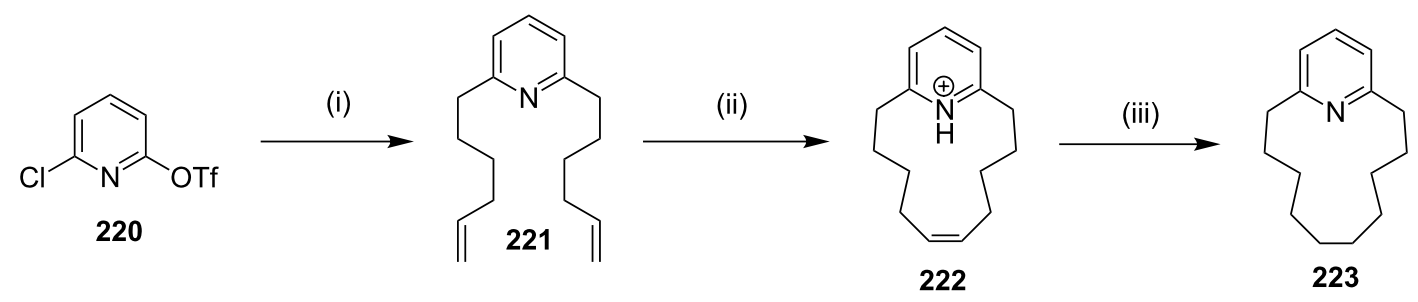

Scheme 36: Synthesis of normuscopyridine (223) by the RCM strategy. Reagents and condition: (i) Mg, THF, hexenylmagnesium bromide, Fe complex 18 (10 mol \%), THF/NMP, $0{ }^{\circ} \mathrm{C}, 75 \%$; (ii) (a) $\mathrm{HCl}, \mathrm{Et}_{2} \mathrm{O}$; (b) Ru catalyst 17 (10 mol \%), $\mathrm{CH}_{2} \mathrm{Cl}_{2}$, reflux, $14 \mathrm{~h}$; (iii) (a) $\mathrm{H}_{2}$ (50 atm.), $70{ }^{\circ} \mathrm{C}$; (b) aq sat. $\mathrm{NaHCO}_{3}, 68 \%$.

Donohoe and coworkers [172] have reported the synthesis of muscopyridine (73) by RCM as a key step. The Wadsworth-Emmons olefination of the commercially available undecenal $\mathbf{2 2 4}$ provided acrylate $\mathbf{2 2 6}$, which was subjected to enantioselective copper-catalyzed conjugate addition with a methyl Grignard reagent involving $(R)$-tol-BINAP ligand to generate ester 227 in good yield and high enantiopurity. This intermediate was then converted to the key metathesis precursor involving a three step sequence of a Weinreb amide formation 228, epoxidation, and double addition of the vinyl Grignard 229 to generate the advanced intermediate 230. Finally, RCM of diolefin 230 under high dilution conditions afforded muscopyridine (73) (Scheme 37).

Hagiwara and co-workers [173] have synthesized muscopyridine starting with methyl acetoacetate (231). They treated $\mathbf{2 3 1}$ with 5-bromo-1-pentene to generate keto ester 232 (60\%). The coupling of keto ester $\mathbf{2 3 2}$ with vinyl ketone $\mathbf{2 3 3}$ under phasetransfer catalysis conditions generated the new keto ester $\mathbf{2 3 4}$ $(93 \%)$, which on treatment with lithium chloride at $120{ }^{\circ} \mathrm{C}$ in dimethyl propylene urea (DMPU) gave dione 235 (72\%). An RCM sequence of compound 235 in the presence of G-I (12) catalyst gave the RCM product 236. A subsequent catalytic hydrogenation generated the saturated dione 237. Finally, the pyridine ring has been introduced by reacting dione 237 with hydroxylamine hydrochloride in a sealed tube to furnish muscopyridine (73, 61\%, Scheme 38$)$.

Normuscopyridine has been also obtained by an RCM approach. To this end, commercially available 2,6-lutidine dibromide $\mathbf{2 3 8}$ was reacted with sodium benzenesulfinate to deliver 2,6-bis(benzenesulfonylmethyl)pyridine (239) in quantitative yield. Next, bis-sulfone 239 was reacted with 5-bromo-1pentene (240) in the presence of $\mathrm{NaH}$ to give an inseparable mixture of cis and trans-sulfones $241 \mathrm{a}$ and $\mathbf{2 4 1 b}$, respectively. An RCM sequence of these sulfones in the presence of the G-I (12) catalyst gave cyclophane 243 (51\%) and dimeric cyclophane 242 (20\%, Scheme 39) [174]. The reduction of the sulfonyl group with $\mathrm{Mg}$ /ethanol in the presence of 1,2-dibromoethane aided by TMSCl afforded cyclophane derivative 244

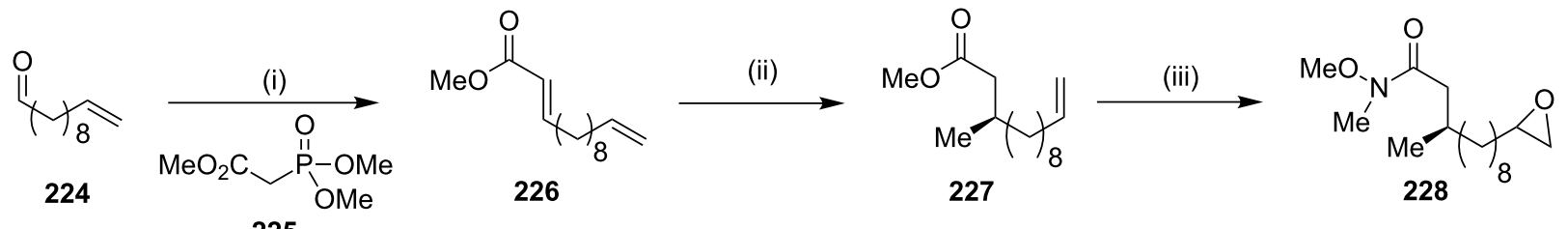

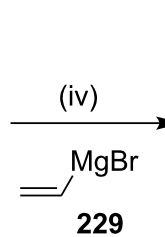

229<smiles>C=CCC(=O)CC(C)C(C)C</smiles>

230

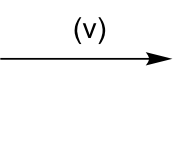<smiles>C[C@@H]1CCCCCCCCc2cccc(n2)C1</smiles>

73

$17 \%$ overall yield

Scheme 37: Synthesis of muscopyridine (73) via RCM. Reagents and conditions: (i) 225, NaH, THF, $0{ }^{\circ} \mathrm{C}$ to rt, $1.5 \mathrm{~h}, 95 \%$; (ii) $\mathrm{Cul}(5 \mathrm{~mol} \%)(R)$-tolBINAP (7.5 mol \%), $t$ - $\mathrm{Bu}_{2} \mathrm{O}, \mathrm{MeMgBr},-20^{\circ} \mathrm{C}, 1 \mathrm{~h}, \mathrm{rt}, 15 \mathrm{~h}, 77 \%$; (iii) (a) iPrMgCl, THF, $-10^{\circ} \mathrm{C}$ to rt, $20 \mathrm{~min}, 89 \%$; (b) $\mathrm{NHMeOMe}^{\circ} \mathrm{CH}_{2} \mathrm{Cl}_{2}, \mathrm{~m}^{\circ} \mathrm{CPBA}$, rt, 19 h, 96\%; (iv) 229, cat. Cul, DMP, $-10{ }^{\circ} \mathrm{C}, 1 \mathrm{~h}, 68 \%$; (v) (a) G-H-II (10 mol \%), $\mathrm{CH}_{2} \mathrm{Cl}_{2}, 55{ }^{\circ} \mathrm{C}$, (b) $\mathrm{NH}_{4} \mathrm{OAc}, \mathrm{AcOH}, \mathrm{EtOH}, 96 \mathrm{~h}, 42 \%$. 


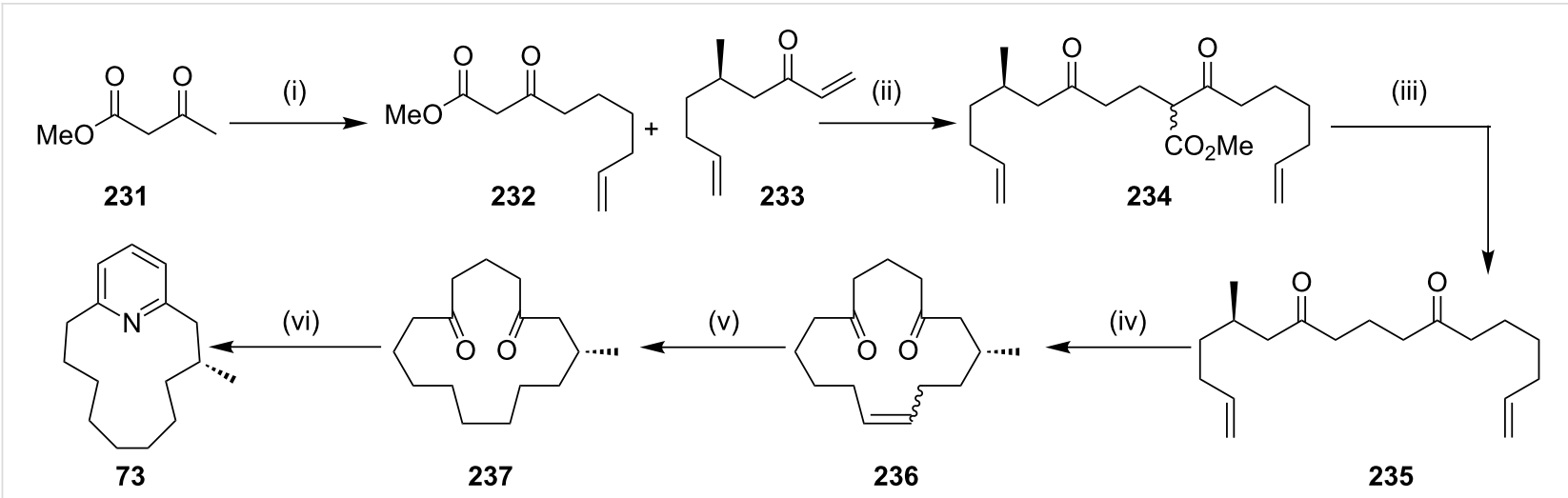

Scheme 38: Synthesis of muscopyridine (73) via RCM strategy. Reagents and conditions: (i) NaH, $n$-BuLi, 5-bromo-1-pentene, rt, 2.5 h, $60 \%$; (ii) 233, $\mathrm{K}_{2} \mathrm{CO}_{3},(n-\mathrm{Bu})_{4} \mathrm{NI}, \mathrm{rt}, 1 \mathrm{~h}, 93 \%$; (iii) LiCl, DMPU, $120^{\circ} \mathrm{C}, 7 \mathrm{~h}, 72 \%$; (iv) G-I (12), $\mathrm{CH}_{2} \mathrm{Cl}_{2}, 40{ }^{\circ} \mathrm{C}, 16.5 \mathrm{~h}, 90 \%$; (v) Pd/C, $\mathrm{H}_{2}, \mathrm{EtOH}, \mathrm{rt}, 5 \mathrm{~h}, 98 \%$; (vi) $\mathrm{NH}_{2} \mathrm{OH} \cdot \mathrm{HCl}, 150-160{ }^{\circ} \mathrm{C}, 16 \mathrm{~h}, 61 \%$.

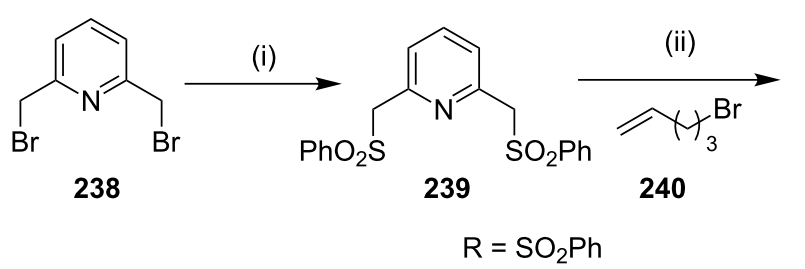<smiles>[Z14]CCCC[C@@H]([R])c1cccc([C@H]([R])CCCC=C)n1</smiles>

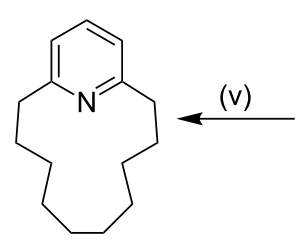

223<smiles>C1=CCc2cccc(n2)CCCCC1</smiles>

244 (iv)<smiles></smiles>

243<smiles>[R]C(C)c1cccc(C([R])C(C)C)n1</smiles>

242 (vi,vii)<smiles>C1=CCCc2cccc(n2)CCCCCCCc2cccc(n2)CCCC1</smiles>

245

Scheme 39: Synthesis of pyridinophane derivatives 223 and 245. Reagents and conditions: (i) $\mathrm{PhSO}_{2} \mathrm{Na}, \mathrm{TBAB} \mathrm{CH}_{3} \mathrm{CN}, \mathrm{reflux}, 12 \mathrm{~h}, 87 \%$; (ii) $\mathbf{2 4 0}$, $\mathrm{NaH}, \mathrm{THF}, \mathrm{rt}, 24 \mathrm{~h}, 65 \%$; (iii) G-I (12) (5 mol \%), $\mathrm{CH}_{2} \mathrm{Cl}_{2}$, rt, 48 h, 243 (51\%), 242 (20\%); (iv) Mg/TMSCl, 1,2-dibromoethane, EtOH, 12 h, 80\%; (v) H EtOAc, Pd/C, rt, 12 h, 84\%; (vi) Mg/TMSCl, 1,2-dibromoethane, EtOH, 12 h; (vii) H2, EtOAc, Pd/C, rt, 12 h, (two steps 64\%).

(80\%). Subsequently, the hydrogenation of the double bond with $\mathrm{Pd} / \mathrm{C}$ under a $\mathrm{H}_{2}$ atmosphere gave normuscopyridine (223, $84 \%$ ). Similar reaction conditions were employed with the dimeric product $\mathbf{2 4 2}$, to generate the macrocyclic pyridinophane 245 (64\%).

It is interesting to note that when the same strategy was applied with a benzene analogue, dipentenylation of bis-sulfone $\mathbf{2 4 6}$ gave compounds 247 and $\mathbf{2 4 8}$, which were easily separable by column chromatography [174]. Moreover, it was observed that cis-sulfone generates the monomeric cyclophane $\mathbf{2 4 9}$ during the metathesis as confirmed by single crystal X-ray diffraction data while the trans-sulfone gave the dimer $\mathbf{2 5 2}$. Finally, the desulfonylation followed by the hydrogenation sequence of 249 and
252 generate the cyclophanes 251 and 253, respectively (Scheme 40).

With regard to the synthesis of cyclophane, Kotha and co-workers [174] have demonstrated another synthetic route to normuscopyridine (223) involving a short synthetic sequence. This route involves the reaction of dicyanopyridine 254 with alkenylmagnesium bromide to generate $\mathbf{2 5 5}$ and 256. Further, these compounds were cyclized with the aid of the G-II catalyst $\mathbf{1 3}$ to generate the corresponding RCM products $\mathbf{2 5 7}$ and $\mathbf{2 5 8}$, respectively. The removal of the two carbonyl groups and the hydrogenation of the double bond was accomplished in a onepot reaction under Wolff-Kishner reaction conditions to generate $\mathbf{2 2 3}$ and 259, respectively (Scheme 41). 


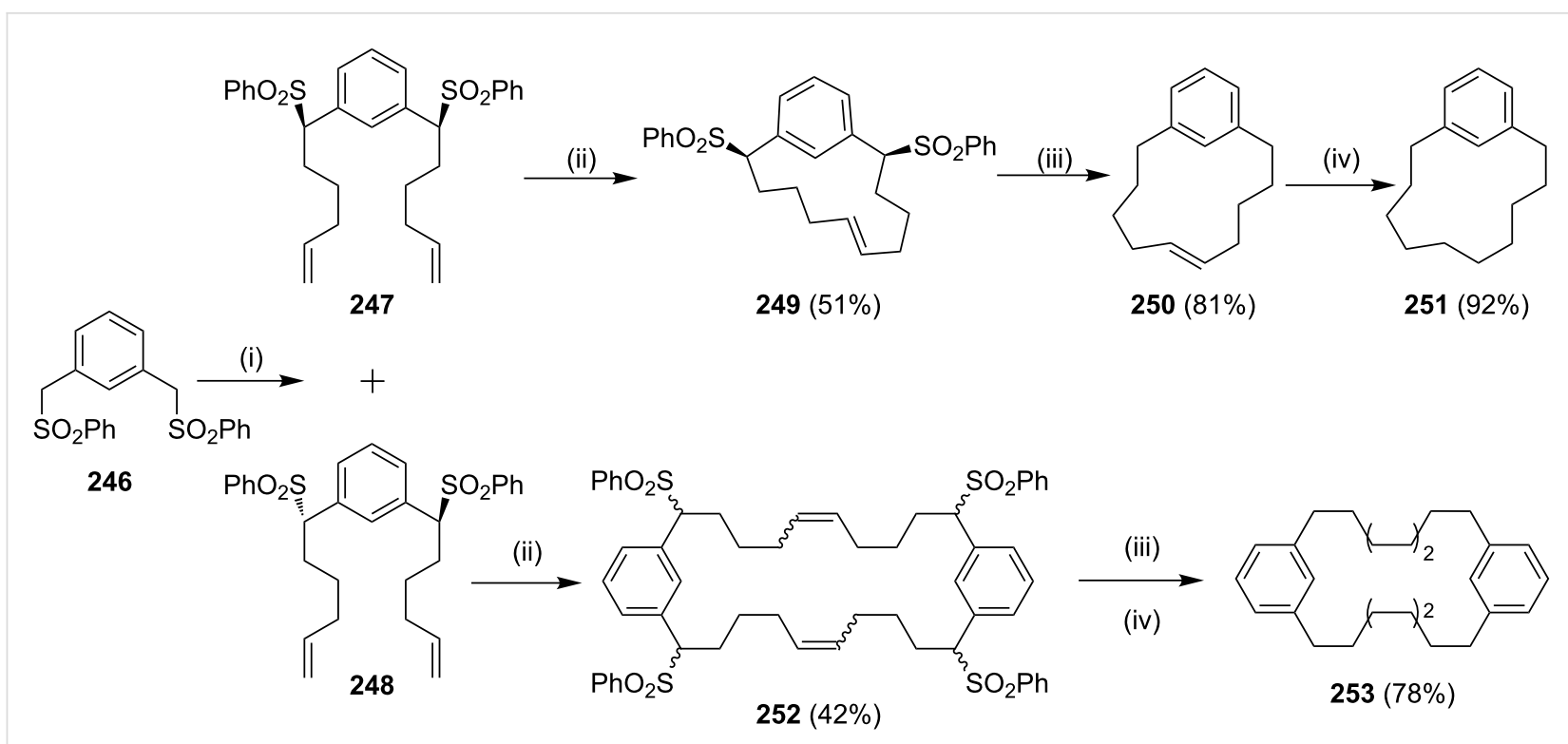

Scheme 40: Synthesis of metacyclophane derivatives 251 and 253. Reagents and conditions: (i) 240, NaH, THF, rt, 24 h; (ii) G-I (12, 5 mol \%), $\mathrm{CH}_{2} \mathrm{Cl}_{2}$, rt, 48 h, 247 (29\%), 248 (30\%); (iii) Mg/TMSCl, 1,2-dibromoethane, EtOH, 12 h; (iv) H $\mathrm{H}_{2}$ EtOAc, Pd/C, rt, 12 h.

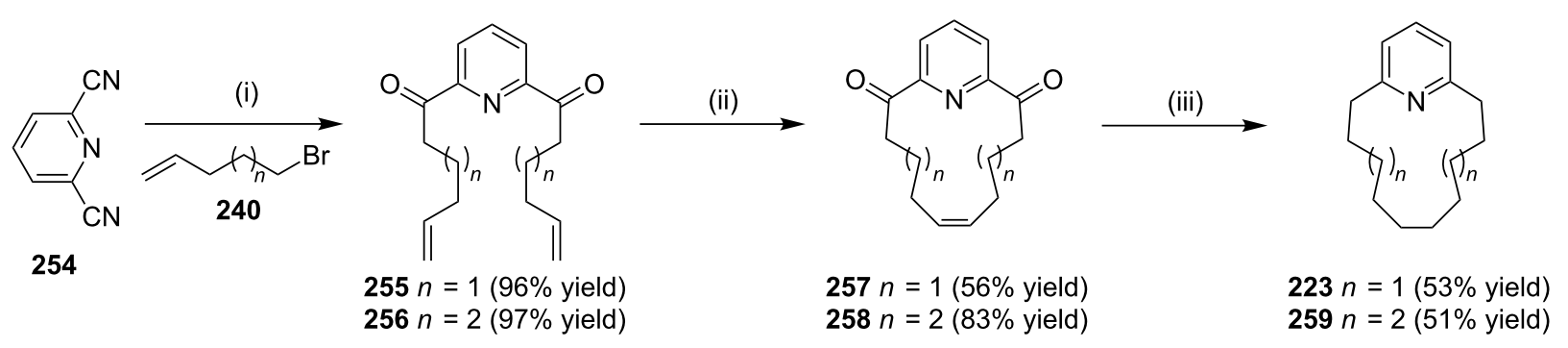

Scheme 41: Synthesis of normuscopyridine and its higher analogues. Reagents and conditions: (i) alkenyl bromide, $\mathrm{Mg}$, ether, $\mathrm{H}_{2} \mathrm{O} / \mathrm{H}^{+}$; (ii) $\mathrm{G}-\mathrm{Il}(\mathbf{1 3}$, $5 \mathrm{~mol} \%$ ), PhMe, reflux; (iii) $\mathrm{N}_{2} \mathrm{H}_{4}, \mathrm{~K}_{2} \mathrm{CO}_{3}$, ethylene glycol, $180^{\circ} \mathrm{C}$.

\section{Cycloaddition reactions}

[2 + 2] Cycloaddition: Roemer and Lentz [175] have reported the synthesis of fluorinated ferrocenophanes from 1,10bis(trifluorovinyl)ferrocene and 1,4-(1,10-ferrocenediyl)1,1,2,2,3,3,4-heptafluorobutane. The authors have reported a $[2+2]$ cycloaddition reaction under thermal conditions. 1,10Bis(trifluorovinyl)ferrocene (261) was synthesized starting with diiodoferrocene 260 by Negishi-type coupling. Compound 261 was subjected to a $[2+2]$ cycloaddition sequence to generate cyclobutane derivative 262. Finally, the ring opening occurs with catalytic amounts of potassium hexacyanoferrate(III) in the presence of KF to deliver the fluorinated ferrocenophane $\mathbf{2 6 3}$ (Scheme 42).

Okada and Nishimura [6] have reported the synthesis of syn[2.n]metacyclophane $\mathbf{2 7 0}$ as a key building block for the synthesis of calix[4]arene. Here, $\alpha, \omega$-bis( $p$-methoxyphenyl)alkanes 264 were used as starting materials. Compound 264 was treated with acetic anhydride and $\mathrm{AlCl}_{3}$ in nitrobenzene and 1,1,2,2tetrachloroethane to generate diketone 265 in 58-93\% yield. Diketone 265 was then treated with LAH to generate diol 266 (72-92\%). The dehydration of diol 266 with pyridinium $p$-toluenesulfonate in benzene gave diolefin 267. [2 + 2] Photocycloaddition of diolefin 267 was carried out by irradiation with a $400 \mathrm{~W}$ high-pressure $\mathrm{Hg}$ lamp (Pyrex filter) in benzene for 26-92 h. After evaporation, 268 and [2.n]metacyclophane 269 were isolated (61-87\%). Finally, demethylation of compound 269 with $\mathrm{BBr}_{3}$ in $\mathrm{CH}_{2} \mathrm{Cl}_{2}$ gave cyclophane $\mathbf{2 7 0}$ (Scheme 43).

$[\mathbf{2}+\mathbf{2}+\mathbf{2}]$ Co-trimerization: In 2003, Tanaka and Shirasaka [176] have reported a one-step synthesis of [6]metacyclophane 273 by a $[2+2+2]$ co-trimerization of two different alkynes with a high chemo- and regioselectivity. The $\mathrm{Rh}(\mathrm{I}) / \mathrm{H} 8$-BINAP complex catalyzed the partially intermolecular cyclotrimerization of 1,9-decadiyne (271) and diethyl acetylenedicarboxylate 


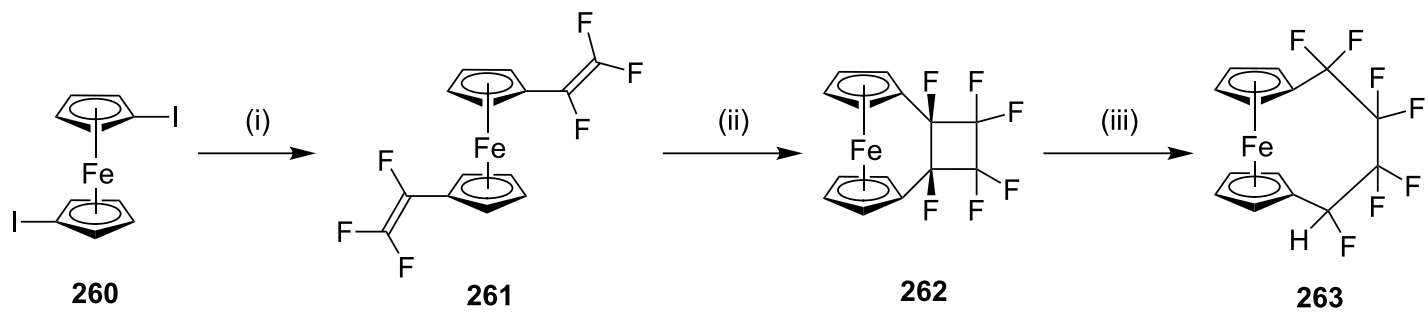

Scheme 42: Synthesis of fluorinated ferrocenophane 263 via a [2 + 2] cycloaddition. Reagents and conditions: (i) $\mathrm{Pd}(\mathrm{OAc})_{2}, \mathrm{PPh}_{3}, \mathrm{CF}_{2} \mathrm{CFZnCl}, \mathrm{THF}$ 5 h, reflux, 95\%; (ii) PhMe, $110{ }^{\circ} \mathrm{C}, 2 \mathrm{~h}, 5 \%$; (iii) $\mathrm{K}_{3} \mathrm{Fe}(\mathrm{CN})_{6}, \mathrm{KF}, \mathrm{H}_{2} \mathrm{O}, t-\mathrm{BuOH}$, rt, $1 \mathrm{~h}, 67 \%$.

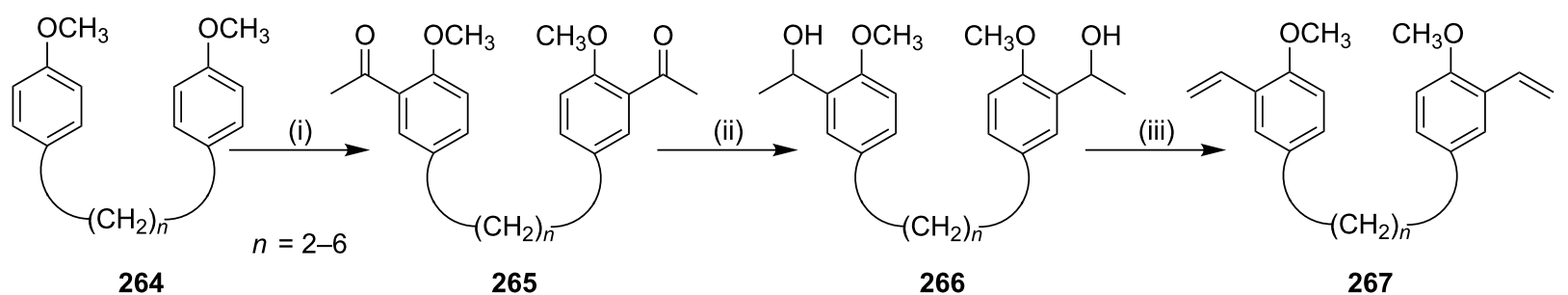

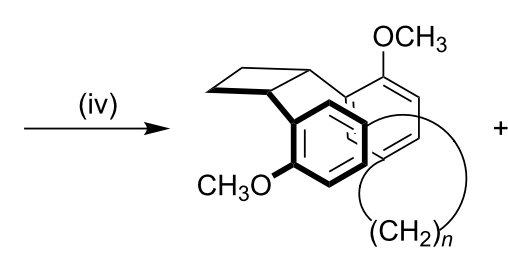

268<smiles>CCCc1cc(OC)c(OC)c2c1CCCCCCCCCCCCC2</smiles>

269

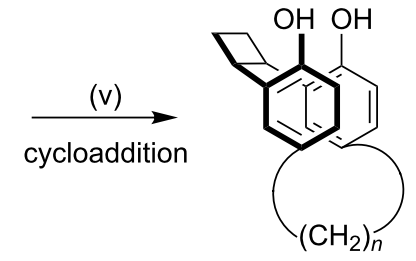

270

Scheme 43: Synthesis of [2.n]metacyclophanes 270 via a [2 + 2] cycloaddition. Reagents and conditions: (i) $\mathrm{Ac}_{2} \mathrm{O}, \mathrm{AlCl}_{3}, \mathrm{PhNO}_{2}, \mathrm{Cl}_{2} \mathrm{CHCHCl}_{2}, \mathrm{rt}$, 12 h, 58-93\%; (ii) $\mathrm{LiAlH}_{4}$, THF, rt, $1 \mathrm{~h}, \sim 100 \%$; (iii) PyHOTs, $\mathrm{C}_{6} \mathrm{H}_{6}$, reflux, 5 d, 72-92\%; (iv) hv, $\mathrm{C}_{6} \mathrm{H}_{6}, \mathrm{rt}, 26-92 \mathrm{~h}, 61-87 \%$; (v) $\mathrm{BBr}_{3}, \mathrm{CH}_{2} \mathrm{Cl}_{2}$, rt, $12 \mathrm{~h}$, $70-80 \%$.

(272) to give [6]metacyclophane derivative $\mathbf{2 7 3}$ (Scheme 44) [177]. This approach is also applicable to synthesize various polyether-based cyclophanes. In this report, they have synthesized various polyether containing cyclophanes by a crosscyclotrimerization catalyzed by a cationic rhodium(I)/H8BINAP complex as a key step. The ether linked $\alpha, \omega$-diynes and dimethyl acetylenedicarboxylate were treated with the Ru catalyst to deliver the metacyclophane in a regioselective manner. The ratio of para, meta, and orthocyclophane formation depends on the chain length of the diynes employed (Scheme 44).

Tanaka and co-workers [178] demonstrated a useful approach to strained dioxa[7]paracyclophane $\mathbf{2 7 6}$ by the application of a $[2+2+2]$ cycloaddition sequence (Scheme 45). To this end, $[2+2+2]$ cycloaddition of 1,10-diyne $\mathbf{2 7 4}$ was carried out with methyl propiolate (275) in the presence of a cationic rhodium(I)-(S)-BINAP complex (10 mol \%) as a catalyst. The desired $[2+2+2]$ cycloaddition was carried out at room temperature to generate dioxa[7]paracyclophane 276 with a

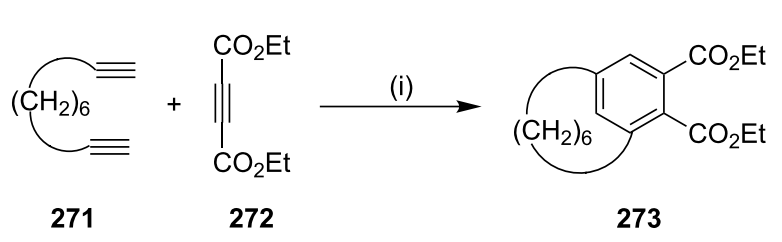

Scheme 44: Synthesis of metacyclophane 273 by a [ $2+2+2]$ co-trimerization. Reagents and conditions: (i) $\left[\mathrm{Rh}(\operatorname{cod})_{2}\right] \mathrm{BF}_{4} / \mathrm{H} 8$ BINAP, $\mathrm{CH}_{2} \mathrm{Cl}_{2}, 1 \mathrm{~h}$, rt, $50 \%$.

moderate ee value. The effect of biaryl bis(phosphine) ligands was examined, and it revealed the use of $(S)$-H8-BINAP afforded the cyclophane $\mathbf{2 7 6}$ with a good yield and optimum ee value.

Similarly, they also reported the synthesis of the planar-chiral carba-paracyclophane $\mathbf{2 7 8}$ by using the cationic rhodium $(\mathrm{I}) /(S, S)$-bdpp-catalyzed $[2+2+2]$ cycloaddition of 


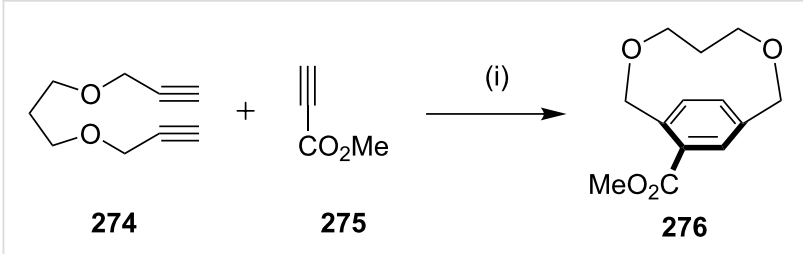

Scheme 45: Synthesis of paracyclophane 276 via a $[2+2+2]$ cycloaddition reaction. Reagents and conditions: (i) $\left[\mathrm{Rh}(\operatorname{cod})_{2}\right] \mathrm{BF}_{4} / \mathrm{H} 8-$ BINAP, (5-10 mol \%), $\mathrm{CH}_{2} \mathrm{Cl}_{2}$, rt, $1 \mathrm{~h}$, (18\% yield, $75 \%$ ee).

cyclic diyne 277 with terminal methyl propiolate (275) under high substrate concentration conditions (Scheme 46) [179].

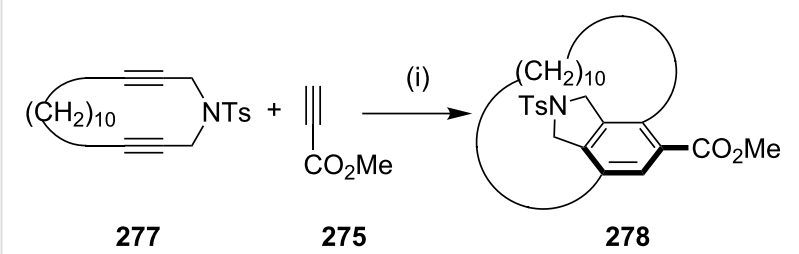

Scheme 46: Synthesis of cyclophane 278 via a [2+2+2] cycloaddition reaction. Reagents and conditions: (i) $5-20 \mathrm{~mol} \%$ $\left[\mathrm{Rh}(\mathrm{cod})_{2}\right] \mathrm{BF}_{4} /(\mathrm{S}, \mathrm{S})-\mathrm{bdpp}, \mathrm{CH}_{2} \mathrm{Cl}_{2}, \mathrm{rt}, 16 \mathrm{~h},(91 \%$ ee $)$.

Shibata and co-workers [180] have synthesized chiral tripodal cage compounds (e.g., 280) by using a $[2+2+2]$ cycloaddition reaction of branched triynes (Scheme 47). The best results for a cycloaddition were observed when triyne $\mathbf{2 7 9}$ was added dropwise over a period of $10 \mathrm{~min}$ to a solution of a chiral catalyst at elevated temperature $\left(120^{\circ} \mathrm{C}\right)$. Also, highly enantioselective intramolecular reactions of different nitrogen-branched triynes were carried out to obtain diverse cyclophanes (Scheme 47).

Malacria and co-workers [181] have demonstrated an efficient use of a $[2+2+2]$ cycloaddition reaction to generate the tetracyclic structure $\mathbf{2 8 2}$ related to taxane skeleton (Scheme 48).

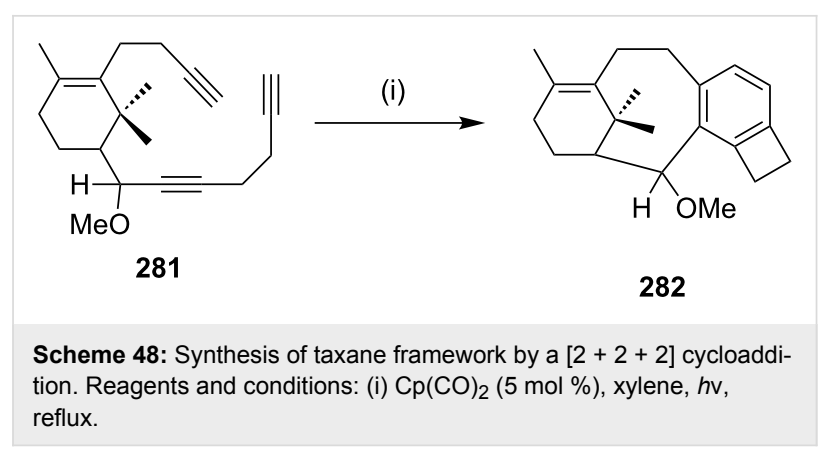

Ohsima and co-workers [182] have reported a rhodiumcatalyzed $[2+2+2]$ cyclotrimerization of triynes $\mathbf{2 8 3}$ in a water-organic biphasic system. The biphasic system provides dilute reaction conditions suitable for macrocyclization. Selective cross-annulation between hydrophobic diynes and hydrophilic alkynes was achieved to generate ortho- and metacyclophane 284 and 285 (Scheme 49).

Maryanoff and co-workers [183] have synthesized the bis(indolyl)maleimido pyridinophanes via a $[2+2+2]$ cycloaddition reaction as a key step. In this regard, indole-3-acetamide (286) was treated with 5-chloro-1-pentyne and $\mathrm{NaH}$ in DMF to deliver compound $\mathbf{2 8 7}$. Then, indole-3-glyoxylate $\mathbf{2 8 8}$ was<smiles>[R]C#CCN(CC#C[R])c1ccccc1OCCCC#CCOC</smiles>

279
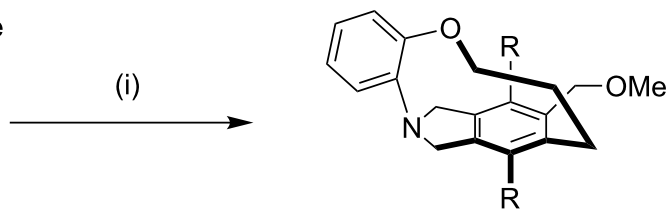

280

Scheme 47: Synthesis of cyclophane 280 via a [2 + 2 + 2] cycloaddition. Reagents and conditions: (i) [(Rh(cod)(S,S)-Me-duphos)]OTf (10 mol \%), DCE, $120^{\circ} \mathrm{C},(77 \%$ yield, 98 ee $)$.

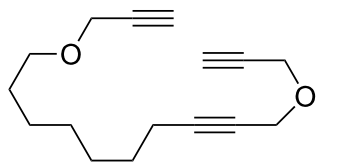

283

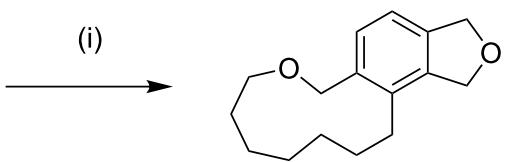

284<smiles>COCC1=C2CCCCCCCOCC=C1COCC2</smiles>

285

Scheme 49: Synthesis of cyclophane 284 and 285 via a [2+2+2] cycloaddition reaction. Reagents and conditions: (i) RhCl(cod) ${ }_{2}$ tppts (2.5 mol \%), $\mathrm{H}_{2} \mathrm{O} / \mathrm{Et}_{2} \mathrm{O}, 2 \mathrm{~h}$. 
converted to $\mathrm{N}$-alkylated derivative $\mathbf{2 8 9}$ by the treatment with 5-chloro-1-pentyne in the presence of cesium carbonate. The maleimide condensation of $\mathbf{2 8 7}$ and $\mathbf{2 8 9}$ was carried out in the presence of $\mathrm{KO} t$-Bu at $0-23{ }^{\circ} \mathrm{C}$ to give the $\alpha, \alpha^{\prime}$-diyne substrate 290 (63\%, Scheme 50). Next, the diyne 290 was reacted with $N, N^{\prime}$-dimethylcyanamide (291) or 292 and $\mathrm{CpCo}(\mathrm{CO})_{2}$ under argon to afford 17-membered $m$-pyridinophanes 293a,b and 18-membered parapyridinophanes 294a,b in $10-15 \%$ isolated yield (Scheme 50).

Maryanoff and co-workers [184] have reported the synthesis of various pyridinophanes by a $[2+2+2]$ cycloaddition reaction mediated by a cobalt catalyst (Scheme 51). To this end, different bisalkynes 271 were reacted with $p$-toluenenitrile (295, 1 mol equiv) in 1:1 ratio to obtain [2,4]pyridinophane 296 and [2,5]pyridinophane 297 (Scheme 51).
[3 + 2] Cycloaddition (1,3-dipolar cycloaddition/click reaction): In 2010, Raghunathan and co-workers [185] have synthesized a $C_{2}$-symmetric triazolophane by a copper(I)-catalyzed azide-alkyne cycloaddition, involving a click reaction. The dipropargyl fluorenyl derivative $\mathbf{2 9 9}$ was prepared from $9 H$-fluorene (298) and propargyl bromide, which on further treatment with 1,4-diazidobutane (300) and xylyl azides 302a-c in the presence of $\mathrm{CuSO}_{4} \cdot 5 \mathrm{H}_{2} \mathrm{O}$ and sodium ascorbate in THF/ water (1:1) gave the corresponding macrocycles $(\mathbf{3 0 1}, 42 \%)$ and (303a-c, 60-70\% yield, Scheme 52).

Murphy and Leyden [186] have reported the synthesis of a glycotriazolophane 309 (carbohydrate-triazole-cyclophane hybrid) from a sugar amino acid via a copper-catalyzed azidealkyne cycloaddition sequence. An aminosugar acid was identified as a useful building block to generate cyclophanes. Thus,<smiles>C#CCCCn1cc(CC(N)=O)c2ccccc21</smiles><smiles>COC(=O)C(=O)c1c[nH]c2ccccc12</smiles>

288

(iv)

287 (iii)<smiles>C#CCCCn1cc(C2=C(c3cn(CCCC#C)c4ccccc34)C(=O)NC2=O)c2ccccc21</smiles>

$291 \mathrm{R}=\mathrm{R}^{\prime}=\mathrm{Me}$ $292 \mathrm{R}=\mathrm{R}^{\prime}=\left(\mathrm{CH}_{2}\right)_{4}$<smiles>[R17]c1cc(CCCn2cc(C3=C(c4cn(CCCCc5cc([R17])[R1]([H])n5)c5ccccc45)C(=O)NC3=O)c3ccccc32)[nH]n1</smiles>

293a $R=R^{\prime}=$ Me $9 \%$ 293b $\mathrm{R}=\mathrm{R}^{\prime}=\left(\mathrm{CH}_{2}\right)_{4} 12 \%$ (ii)<smiles>C#CCCCn1cc(C(=O)C(=O)OC)c2ccccc21</smiles>

OR<smiles></smiles>

294a $\mathrm{R}=\mathrm{R}^{\prime}=\mathrm{Me} 10 \%$ 294b $R=R^{\prime}=\left(\mathrm{CH}_{2}\right)_{4} 15 \%$

Scheme 50: Synthesis of pyridinophanes 293a,b and 294a,b via a [2+2+2] cycloaddition. Reagents and conditions: (i) 5-chloro-1-pentyne, NaH, DMF, 0-55 ${ }^{\circ} \mathrm{C}, 12 \mathrm{~h}, 90 \%$; (ii) 5-chloro-1-pentyne, $\mathrm{Cs}_{2} \mathrm{CO}_{3}$, DMF, $10 \mathrm{~h}, 59 \%$; (iii) KOt-Bu, THF, 0-23 ${ }^{\circ} \mathrm{C}, 6 \mathrm{~h}, 63 \%$; (iv) $\mathrm{CpCo}(\mathrm{CO}) 2$, $1,4-$ dioxane, $105-110^{\circ} \mathrm{C}, 24 \mathrm{~h}$.

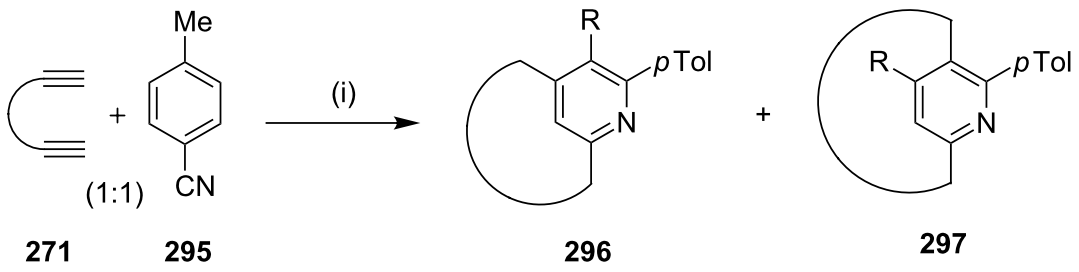

Scheme 51: Synthesis of pyridinophanes 296 and 297 via a [2 + 2+ 2] cycloaddition. Reagents and conditions: (i) 15 mol \% CpCo(CO) 2 , o-xylene (0.001 M), $140{ }^{\circ} \mathrm{C}, 100 \mathrm{~h}, 50-61 \%$. 


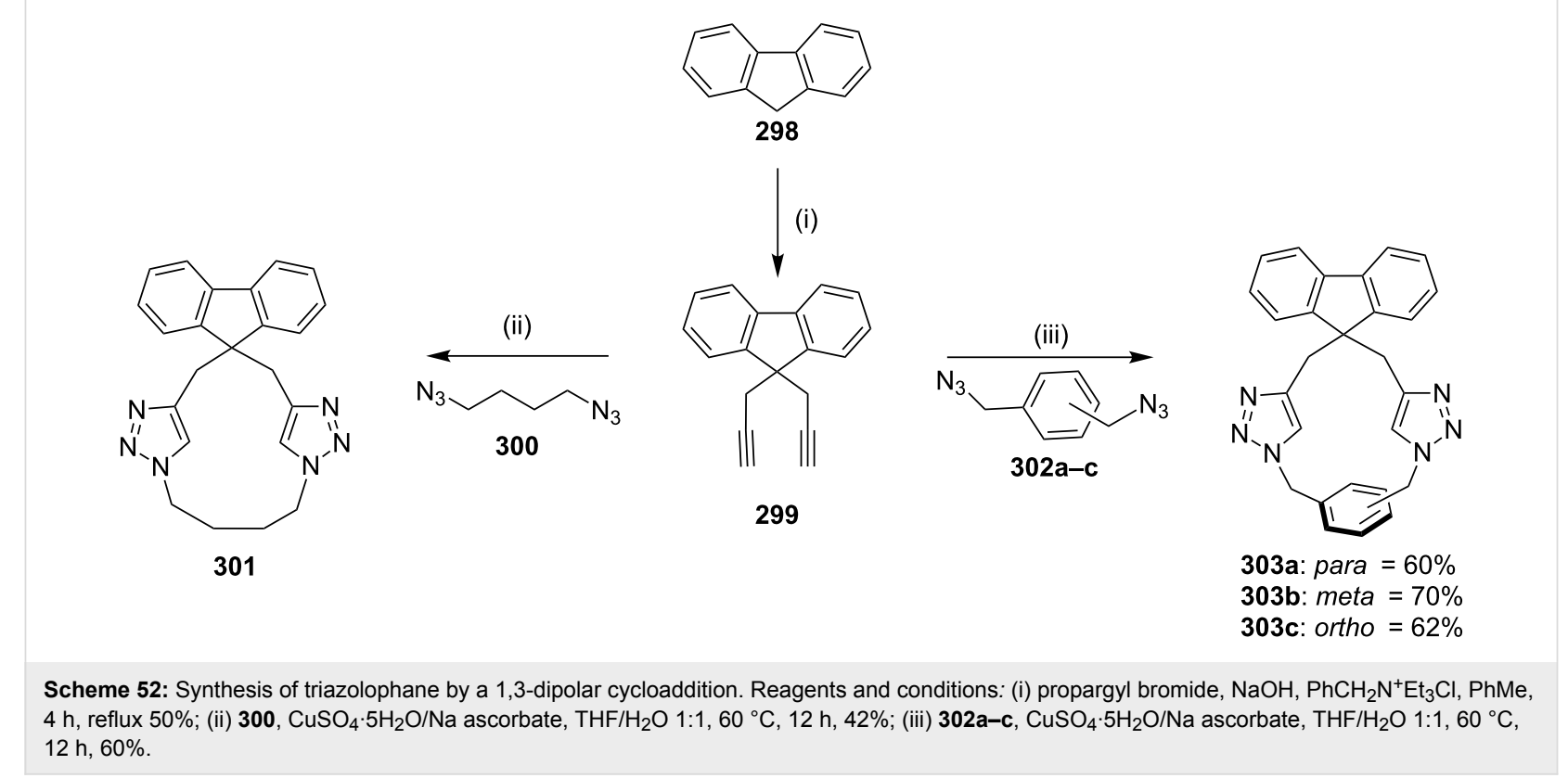

the treatment of $\mathbf{3 0 4}$ with oxalyl chloride in the presence of DMF generated the acid chloride, which on further reaction with $p$-xylylenediamine (306) in the presence of $N, N$ '-diisopropylethylamine (DIPEA) in dichloromethane followed by de- $O$-acetylation gave the bisazide 307 (37\%). The latter compound was reacted with the dialkyne $\mathbf{3 0 8}$ in the presence of
$\mathrm{CuSO}_{4}$ and sodium ascorbate in acetonitrile/water to deliver the desired cyclophane derivative 309 (56\%, Scheme 53).

Similarly, a novel BINOL-based cyclophane $\mathbf{3 1 0}$ has been synthesized via click chemistry by incorporating two triazole moieties in the macrocycle [187]. Li and co-workers [188] have<smiles>CC(=O)OC(C(=O)O)C(OC(N)C(=O)O)C(=O)O</smiles>

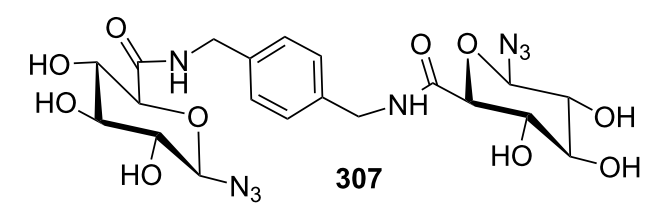

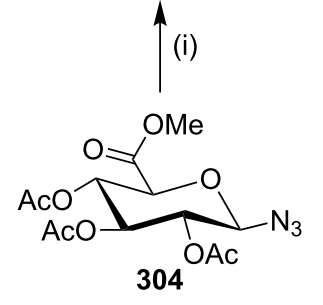

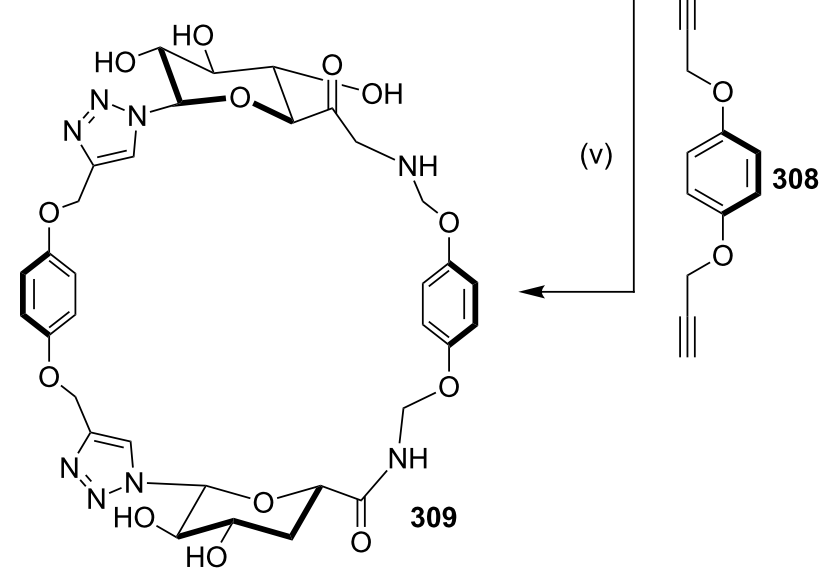

Scheme 53: Synthesis of glycotriazolophane 309 by a click reaction. Reagents and conditions: (i) LiOH, $\mathrm{H}_{2} \mathrm{O}, \mathrm{MeOH}, \mathrm{THF}, 16 \mathrm{~h}$, rt, $93 \%$; (ii) ClCO$\mathrm{COCl}$, DMF (cat), $\mathrm{CH}_{2} \mathrm{Cl}_{2}$, rt, $0.5 \mathrm{~h}$; (iii) 306, DIPEA, $4 \AA \mathrm{MS}, \mathrm{CH}_{2} \mathrm{Cl}_{2}, 0{ }^{\circ} \mathrm{C}, 2 \mathrm{~h}$; (iv) $\mathrm{NaOMe}, \mathrm{MeOH} / \mathrm{CH}_{2} \mathrm{Cl}_{2}$, rt, $3 \mathrm{~h}$, (three steps $37 \%$ ); (v) 308, $\mathrm{CuSO}_{4}$, sodium ascorbate, $\mathrm{MeCN} / \mathrm{H}_{2} \mathrm{O}$, rt, $13 \mathrm{~h}, 56 \%$. 
reported the synthesis of the naphthalene-diimide-based cyclophane $\mathbf{3 1 1}$ for understanding supramolecular interactions by metal ions (Figure 11).

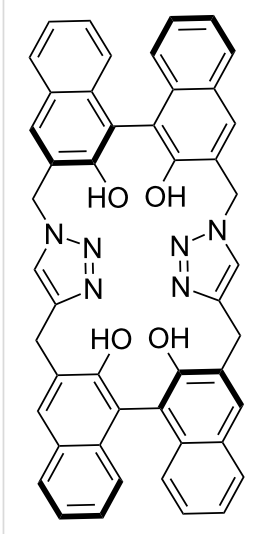

310

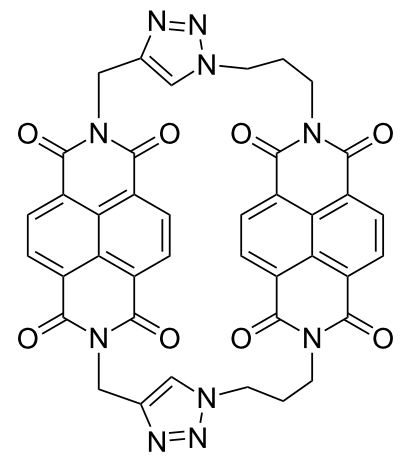

311

Figure 11: Cyclophanes 310 and 311 prepared via click chemistry.

$[3+2+1]$ Cycloaddition (Dötz benzannulation): In 2003, Wulff and co-workers [189] synthesized cyclophane derivatives using the Dötz benzannulation as a key step. They found that the Fischer carbene complex 314 in a coordinating solvent such as THF lead to the products 312 (15\%) and 313 (42\%) whereas a non-coordinating solvent like benzene delivered products 315 (40\%) and 316 (21\%, Scheme 54).

Wulff and Wang [190] have synthesized [6,6]metacyclophane via an intermolecular benzannulation reaction of Fischer carbene complexes with a residual alkyne to generate the 18-membered ring. Two molecules of the Fischer carbene complex 317 reacted by an intermolecular fashion to generate the [6,6]metacyclophane 318 (39\%). Alternatively, a double benzannulation of a biscarbene complex 319 with 1,9decadiyne (271) delivered [6,6]metacyclophane 318 (31\%) (Scheme 55).

Dötz and Gerhardt [191] have synthesized the [2,2]metacyclophane via chromium-mediated intermolecular benzannulation. In this connection, methoxy(alkynyl)carbene complex undergo<smiles>COc1cc2c(O)c(c1)CCCCCCCCCC2</smiles>

312

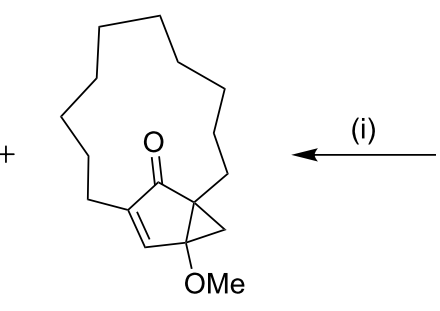

313<smiles>C#C[14C](=O)C(=C)C(OC)=C(C(=O)[O-])C(=O)O[O-]</smiles>

314<smiles>C#CCCCCCCCCCc1cc(O)c(CCCCC)cc1OC</smiles>

315<smiles>COc1cc2cc(O)c1CCCCCCCCC2</smiles>

316

Scheme 54: Synthesis of cyclophane via the Dötz benzannulation. Reagents and conditions: (i) THF, $100{ }^{\circ} \mathrm{C}, 12 \mathrm{~h},(\mathbf{3 1 2}, 15 \%),(313,42 \%)$; (ii) benzene, $12 \mathrm{~h}, 100^{\circ} \mathrm{C},(315,40 \%),(316,21 \%)$.<smiles>C#CC/C=C/C(C(=O)OC)=C(OC)C(=O)OC</smiles> 
an intramolecular benzannulation reaction in the presence of a polar solvent such as THF to deliver [6,6]metacyclophane (321a, 25\%, 321b, 20\% and 321c, 38\%). Similarly metabenzoquinonophane $\mathbf{3 2 2}$ has been synthesized starting with $\mathbf{3 2 0}$ by an in situ oxidation of the benzannulated product by using cerium(IV) ammonium nitrate (40\%, Scheme 56).

Intramolecular Diels-Alder (DA) reaction: Suwa and co-workers [192] have synthesized the muscopyridine by a $[4+2]$ cycloaddition of the bisketene 325 . The condensation of acid dichloride derived from $\mathbf{3 2 3}$ with two molecules of Meldrum's acid gave $\mathbf{3 2 4}$ which on thermal activation in chlorobenzene yielded bisketenes 325a and 325b. These two ketene derivatives underwent an intramolecular cycloaddition to afford a 1:1 mixture of $\mathbf{3 2 6}$ and $\mathbf{3 2 7}$ (96\%, Scheme 57). On heating with concentrated $\mathrm{HCl}, \mathbf{3 2 6}$ and $\mathbf{3 2 7}$ were transformed to pyrone derivative 328 (89\%). A solution of the compound 328 in ethanol saturated with ammonia was heated in a stain- less sealed tube for 3 days to deliver the pyridinone derivative 329 (87\%). Further, chlorination of the pyridinone $\mathbf{3 2 9}$ afforded the chloropyridine 330 (93\%). Subsequently, hydrogenolysis of the pyridine derivative $\mathbf{3 3 0}$ gave the target muscopyridine (73, $89 \%)$.

[4 + 2] Cycloaddition (Diels-Alder reaction): In 2003, Tochtermann and co-workers [193] have synthesized a bis[10]paracyclophane with two chiral planes and one chiral axis via the DA reaction as a key step. The bifuran derivative 331 was subjected to a DA sequence with dimethyl acetylenedicarboxylate (DMAD) to deliver compounds 332a,b (77\%). These DA adducts were irradiated in diethyl ether/ dichloromethane $(5: 1)$ to offer the corresponding bioxaquadricyclane 333, subsequent thermolysis gave the bioxepine $\mathbf{3 3 4}$ (81\%). Finally, aromatization of bioxepine 334 with trifluoroacetic acid (TFA) delivered ketophenol 335 (37\%), which on further treatment with potassium tert-butoxide/methyltriflate<smiles></smiles><smiles>CC#CC</smiles><smiles>[CaH]</smiles>

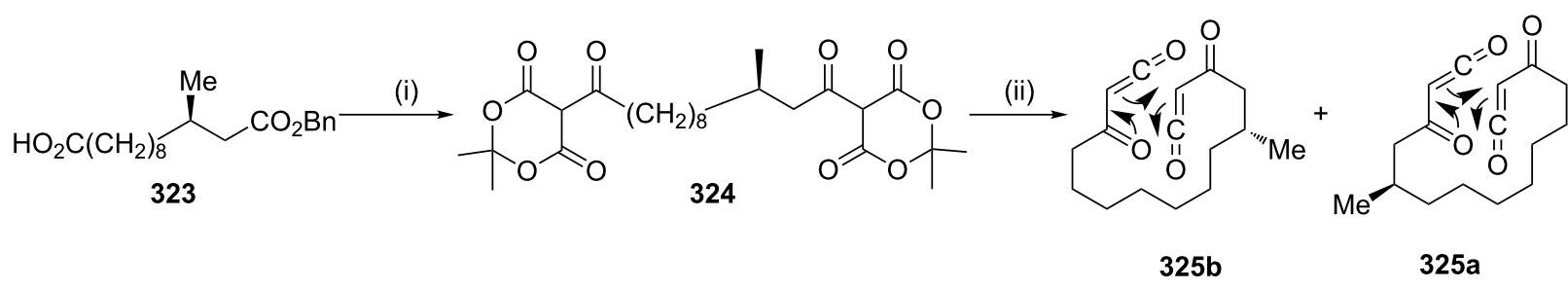

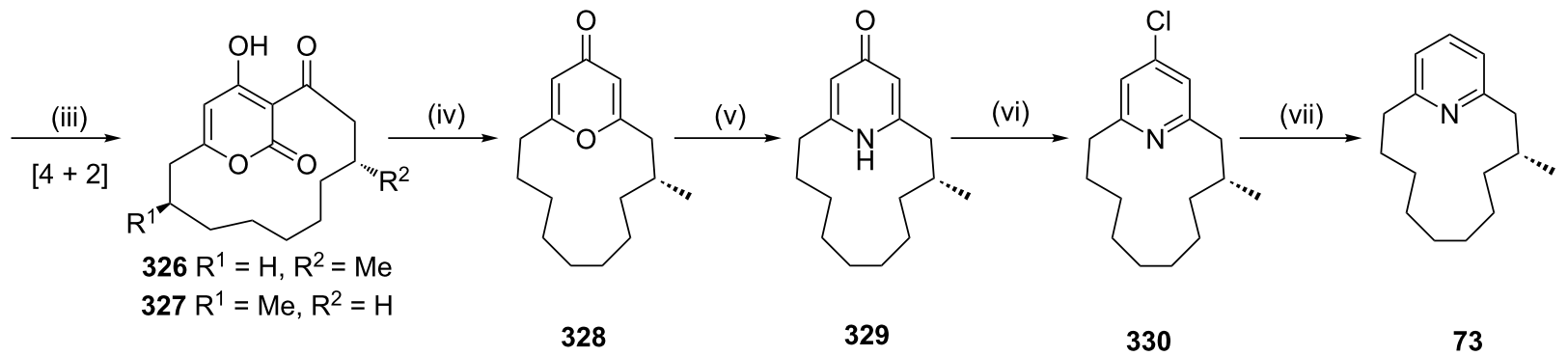

Scheme 57: Synthesis of muscopyridine (73) via an intramolecular DA reaction of ketene. Reagents and conditions: (i) (a) SOCl 2 , reflux, 30 min; (b) Meldrum's acid, DMAP, $\mathrm{CH}_{2} \mathrm{Cl}_{2}, 0{ }^{\circ} \mathrm{C}, 2 \mathrm{~h}$, then rt, $1 \mathrm{~h}$; (ii) $\mathrm{Ph}-\mathrm{Cl}$, reflux, $20 \mathrm{~h}, 84 \%$; (iii) heating; (iv) conc. $\mathrm{HCl}$, reflux, $12 \mathrm{~h}, 89 \%$; (v) $\mathrm{NH}$, $\mathrm{EtOH}$, sealed tube, $140{ }^{\circ} \mathrm{C}, 72 \mathrm{~h}, 87 \%$; (vi) $\mathrm{POCl}_{3}$, reflux, $1 \mathrm{~h}, 93 \%$; (vii) $\mathrm{H}_{2}, \mathrm{Pd} / \mathrm{C}, \mathrm{AcONa}, \mathrm{rt}, 12 \mathrm{~h}, 89 \%$. 
mixture, gave the dimethyl ether bis[10]paracyclophane 336 (63\%, Scheme 58).

In 1980, Gassman and co-workers [194] have synthesized [8]paracyclophane via the DA reaction as a key step. In this connection, 1,3-cyclododecadiene (337) was reacted with maleic anhydride to give the DA product $338(21 \%)$. Later, the DA adduct 338 was heated under reflux in $10 \%$ aq tetrahydrofuran to afford the diacid, which on decarboxylation in the presence of lead tetraacetate in a toluene/pyridine mixture delivered compound 339 (22\%). Treatment of $\mathbf{3 3 9}$ with 1 equiv of $m$-chloroperbenzoic acid gave the epoxide $\mathbf{3 4 0}(80 \%)$, followed by $\mathrm{HCl}$ treatment gave [8]paracyclophane 341 (93\%) (Scheme 59).

Synthesis of the macrocyclic portion of longithorone C (DA reaction): In 1994 longithorone A was first described by Schmitz and co-workers [195]. This unusual heptacyclic marine natural product is a cytotoxic agent. Its synthesis is considered difficult due to the stereocenters present in the ring system of longithorone A and E. Moreover, hindered rotation around the quinone moiety adds even more complexity to its synthesis.

Recently, Shair and co-workers [196] have reported the enantioselective synthesis of (-)-longithorone A by using a conventional synthesis to realize the proposed biosynthesis, which was put forward by Schmitz involving an intermolecular and an intramolecular DA reaction of two [12]paracyclophanequinone [197]. Based on this proposal Shair and co-workers attempted the synthesis of the natural product (-)-longithorone A. Diene $\mathbf{3 4 3}$ and the dienophile $\mathbf{3 4 2}$ were synthesized by several steps and subsequently subjected to the DA sequence to afford the rigid (-)-longithorone A (346, 90\%, Scheme 60).

Nicolaou and co-workers [198] have reported the synthesis of sporolide B (349). The synthesis involves a DA reaction

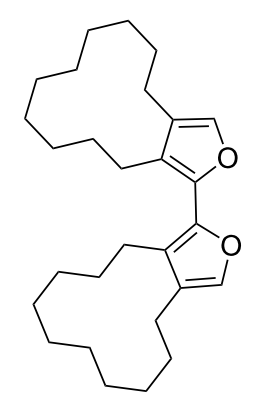

331

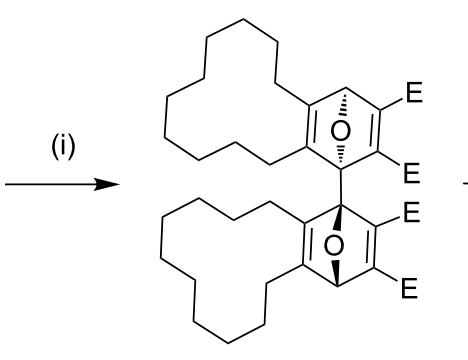

$332 a$

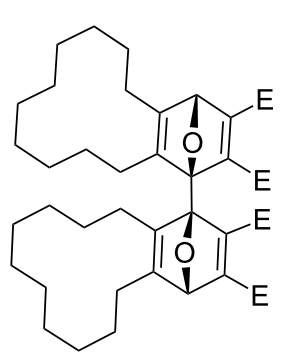

332b

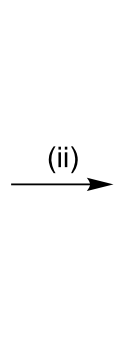

(iv)

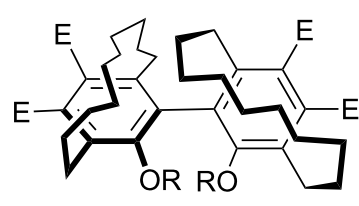

336

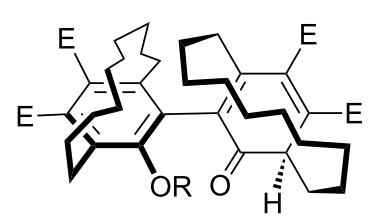

335

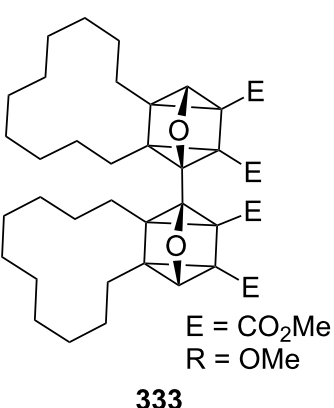

(iii)

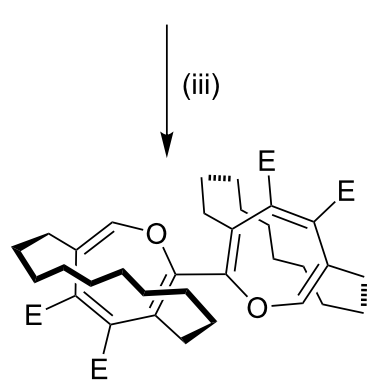

334

Scheme 58: Synthesis of bis[10]paracyclophane 336 via Diels-Alder reaction. Reagents and conditions: (i) DMAD, PhMe, reflux, $4 \mathrm{~h}, 77 \%$; (ii) Et ${ }_{2} \mathrm{O}$, hv, 2 h, 78\%; (iii) THF, reflux, 2 h, 81\%; (iv) $\mathrm{CF}_{3} \mathrm{OAc}, \mathrm{CH}_{2} \mathrm{Cl}_{2}$, rt, $24 \mathrm{~h}, 37 \%$; (v) $\mathrm{CH}_{2} \mathrm{Cl}_{2}, t$-BuOK, methyl triflate, rt, $2 \mathrm{~h}, 63 \%$.

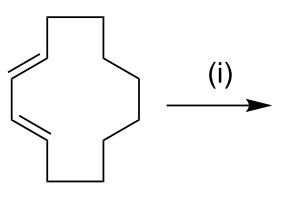

337<smiles>O=C1OC(=O)C2CC3C=C1C2CCCCCCCC3</smiles>

338

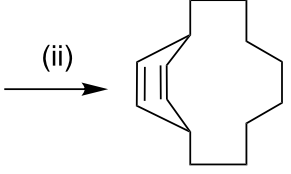

339
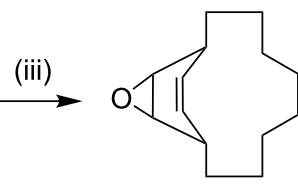

340

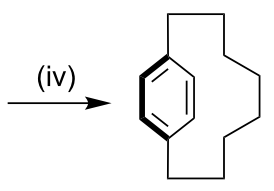

341

Scheme 59: Synthesis of [8]paracyclophane via DA reaction. Reagents and conditions: (i) maleic anhydride, $3-5 \mathrm{~h}, 21 \%$; (i) $\mathrm{Pb}(\mathrm{OAc}) 4$, $\mathrm{PhMe} / \mathrm{pyri}-$ dine, $2 \mathrm{~h}, 21 \%$; (iii) $m \mathrm{CPBA}, 80 \%$; (iv) $\mathrm{HCl}, 93 \%$. 
<smiles>C=C(/C=C/CC(=CC=O)CCc1cc(OCC)cc(OCC)c1)CC/C=C\C</smiles>

342

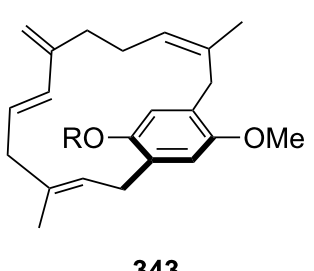

343

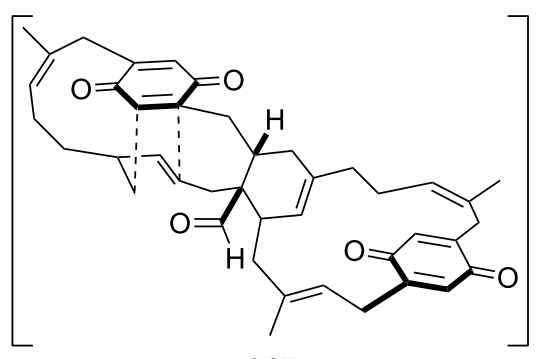

345

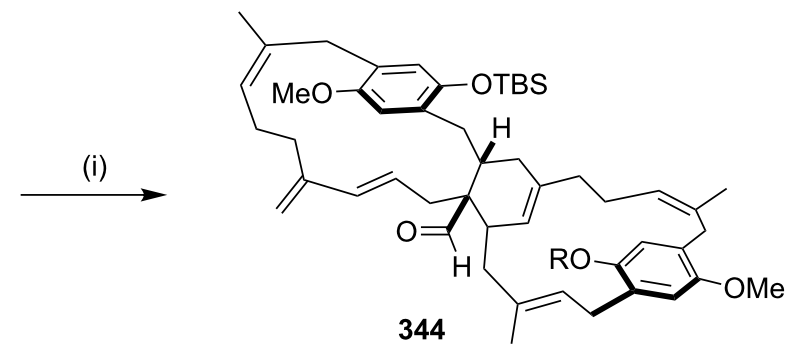

longithorone A (346)

Scheme 60: Biomimetic synthesis of (-)-longithorone A. Reagents and conditions: (i) $\mathrm{Me}_{2} \mathrm{AICl}, \mathrm{CH}_{2} \mathrm{Cl}_{2},-20{ }^{\circ} \mathrm{C}, 70 \%, 1: 1.4$ diastereomers; (ii) $\mathrm{TBAF}$, THF, $0{ }^{\circ} \mathrm{C}$; (iii) $\mathrm{Phl}(\mathrm{O}), \mathrm{MeCN} / \mathrm{H}_{2} \mathrm{O}, 0-25^{\circ} \mathrm{C}, 90 \%$ two steps.

between $o$-quinone as the diene component and indene derivatives as dienophiles. This total synthesis also involves a Ru-catalyzed [ $4+2]$ cycloaddition reaction to generate a highly substituted indene system containing a chlorine substituent on the aromatic ring (Scheme 61).

Cavicularin, a natural product containing a cyclophane system was isolated from the liverwort Cavicularia densa. Among several approaches to prepare this natural product, Beaudry and Zhao [199] have reported the synthesis of the basic architecture of $(+)$-cavicularin (352) by using the DA reaction of pyrone and vinyl sulfone (Scheme 62). They have reported the first intramolecular enantioselective DA reaction of the $\alpha$-pyrone, also regioselective one-pot three-component Suzuki reaction of a dibromoarene to form a highly substituted terphenyl system (Scheme 62).<smiles>COC(C(=O)OCC(OC(C)=O)c1cc(Cl)c2c(c1)C1=C(C(O)CC1CCc1ccccc1)C2OC(C)=O)C1=CC(=O)C(=O)C(C)=C1O</smiles>

347

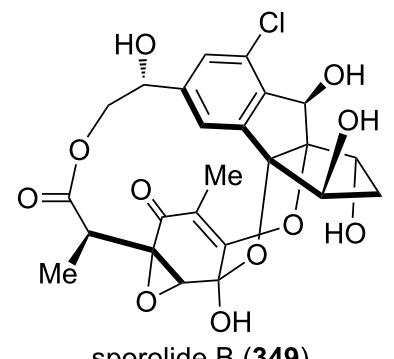




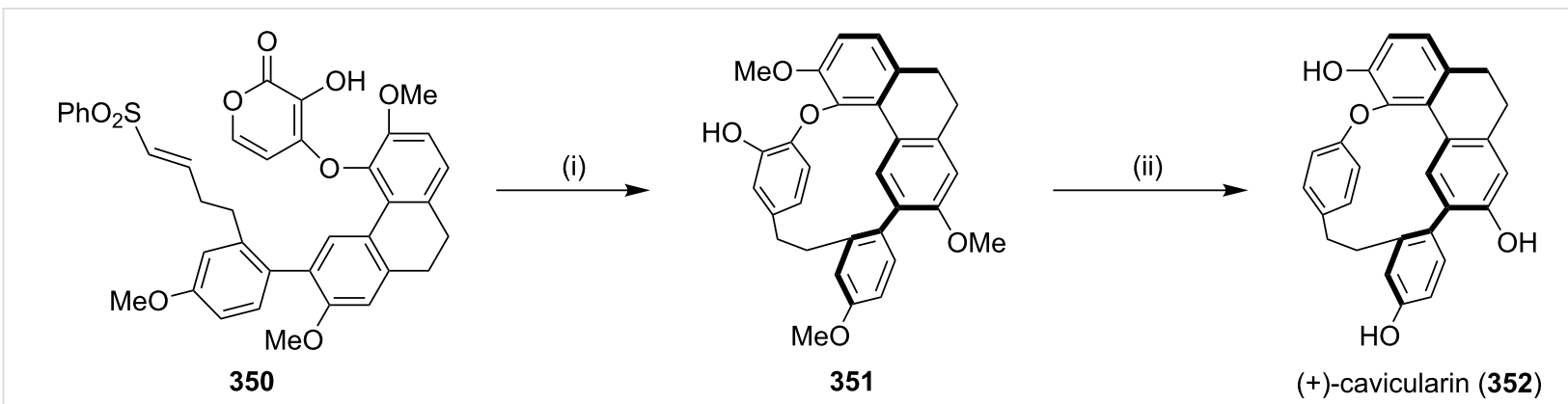

Scheme 62: Synthesis of the framework of (+)-cavicularin (352) via a [4 + 2] cycloaddition. Reagents and conditions: (i) cinchona alkaloid derivative, EtOAc, $3 \AA \mathrm{MS}, 45^{\circ} \mathrm{C}$; (ii) (a) $\mathrm{Tf}_{2} \mathrm{O}, \mathrm{CH}_{2} \mathrm{Cl}_{2}, 0{ }^{\circ} \mathrm{C}, 45 \%$ (2 steps); (b) $\mathrm{NH}_{4} \mathrm{CO}_{2} \mathrm{H}, \mathrm{Pd} / \mathrm{C}, \mathrm{MeOH}, 70{ }^{\circ} \mathrm{C}$, quant.; (c) $\mathrm{BBr}_{3}, \mathrm{CH}_{2} \mathrm{Cl}_{2}, 80 \%$.

\section{Rearrangement reactions}

Beckmann rearrangement: Uemura and coworkers [200] have synthesized the cyclophane-containing oxazole moiety via a Beckmann rearrangement as a key step. $\alpha$-Formylketoxime dimethyl acetal $\mathbf{3 5 3}$ was synthesized in several steps and subjected to a Beckmann rearrangement by using polyphosphoric acid in toluene heated under reflux conditions to give oxazole-based cyclophane 354 in 46\% (Scheme 63).

Benzidine rearrangement: Benniston and co-workers [201] have reported the synthesis of cyclophanes $\mathbf{3 6 0 a}-\mathbf{c}$ involving a benzidine rearrangement [202-208]. The $m$-nitrophenol (355) was reacted with ditosylate 356 to generate $m$-nitrophenol ether derivative 357, which on a reduction with $\mathrm{Zn}$ in $\mathrm{MeOH}$ gave azo-derivative 358. It was further converted into the hydrazo compound 359 which underwent a benzidine rearrangement under acidic conditions to deliver cyclophanes $360 \mathbf{a}-\mathbf{c}$. The cyclophanes obtained here involve the migration of nitrogen on the aromatic ring (Scheme 64).

Cho and co-workers [209] have reported the synthesis of 4,4diaminobiphenyls (benzidine) connected with a polyether unit at the 2,2'-positions using the benzidine rearrangement. The cyclophane synthesis of $\mathbf{3 6 5}$ starts with the preparation of 361a-c starting with $m$-bromophenol and polyether ditosylates. The $\mathrm{Cu}(\mathrm{I})$-catalyzed coupling reactions of the bis $(m-$ bromophenyl) ethers 361a-c provided the monohydrazides 362a-c (53-57\%). Cyclization reactions were carried out by using a Pd catalyst delivering diarylhydrazides 363a-c (46-50\%). Later, the hydrazides 363a-c were heated in EtOH with a catalytic amount of aq $\mathrm{HCl}$ to generate the corresponding benzidines $364 \mathrm{a}-\mathbf{c}$, as indicated by their crude ${ }^{1} \mathrm{H}$ NMR spectra. These products were subjected to an acetylation sequence to generate the cyclophane-based acetamides 365a-c (Scheme 65).

Ciamician-Dennstedt rearrangement: Reese and Dhanak [210] have synthesized a strained cyclophane such as $[6](2,4)$ pyridinophane derivatives 367 by using a ring expansion strategy. Here, pyrrole derivative 366 was treated with dihalocarbene giving the cyclopropane intermediate 366a which was further converted into pyridinophane $\mathbf{3 6 7}$ by a ring expansion (Scheme 66).

Claisen rearrangement: To develop new strategies to diverse cyclophanes, Kotha and Waghule [211] have reported the synthesis of cyclophane $\mathbf{3 7 3}$ by using the double Claisen rearrangement and an RCM as key steps. Bisphenol 368 was converted to $o$-allyl derivative $\mathbf{3 6 9}$, which on a Claisen rearrangement followed by protection of the phenolic hydroxy groups gave 371. An RCM of $\mathbf{3 7 1}$ followed by the hydrogenation of the RCM product 372 gave cyclophane 373 (Scheme 67). By using a similar approach various cyclophanes were synthesized starting with resorcinol as well as hydroquinone and attaching an ethyleneoxy chain of different length (Scheme 67) [212].

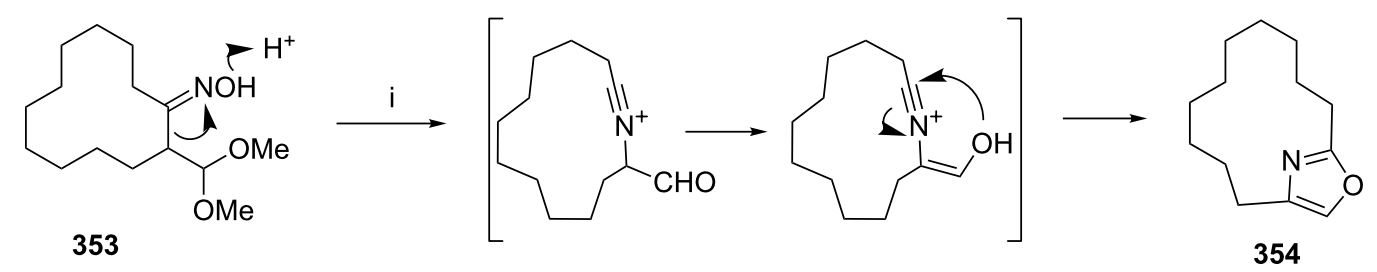

Scheme 63: Synthesis of oxazole-containing cyclophane 354 via Beckmann rearrangement. Reagents and conditions: (i) polyphosphoric acid, toluene, reflux, overnight, $46 \%$. 

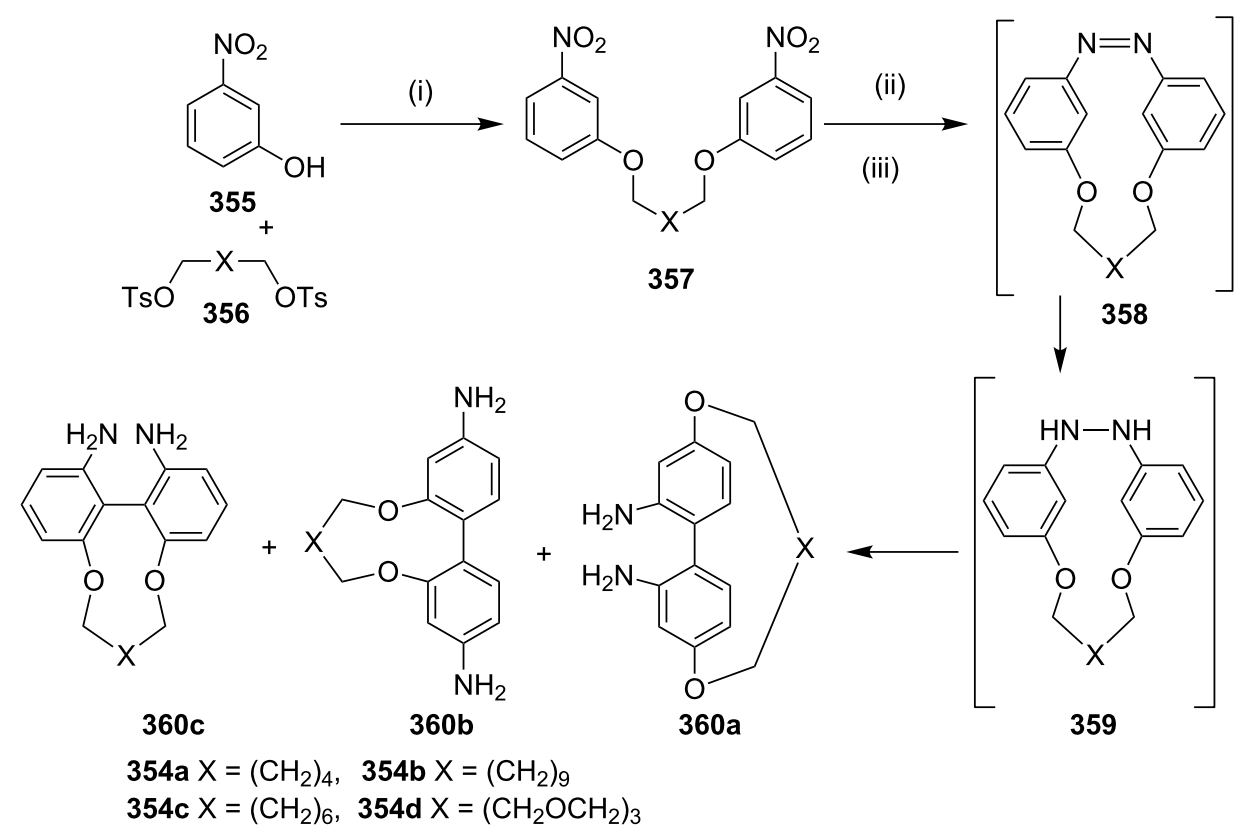

Scheme 64: Synthesis of cyclophanes $360 a-c$ via benzidine rearrangement. Reagents and conditions: (i) $356 a-d, \mathrm{~K}_{2} \mathrm{CO}_{3}, \mathrm{DMF}$; (ii) $\mathrm{Zn}, \mathrm{NaOH}$; (iii) $\mathrm{HCl}$.

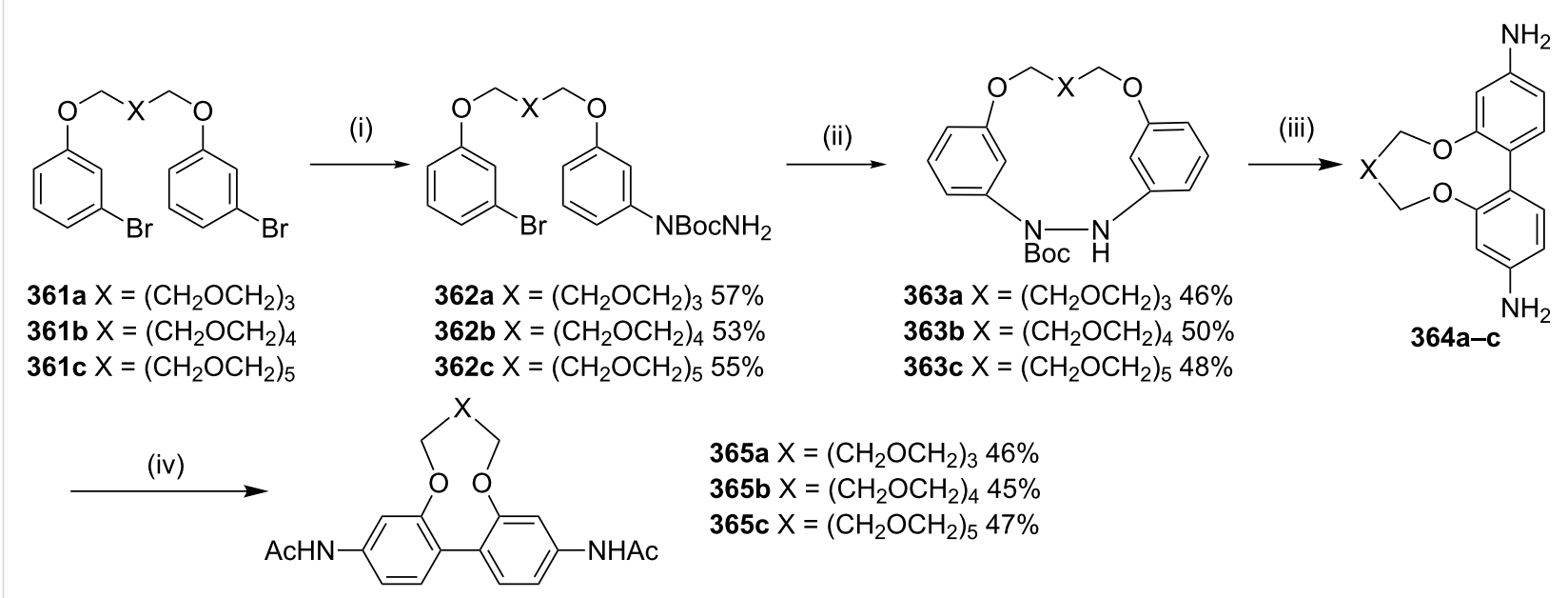

Scheme 65: Synthesis of cyclophanes 365a-c via benzidine rearrangement. Reagents and conditions: (i) $\mathrm{BocNHNH}_{2}, \mathrm{Cul} \mathrm{Cs}_{2} \mathrm{CO}_{3}, 1,10-\mathrm{phen}_{\text {, }}$ $\mathrm{DMF}, 80^{\circ} \mathrm{C}, 24 \mathrm{~h}$; (ii) $\mathrm{Pd}(\mathrm{OAc})_{2}, \mathrm{P}(\mathrm{t}-\mathrm{Bu})_{3}, \mathrm{PhMe}, 110^{\circ} \mathrm{C}, 12 \mathrm{~h}$; (iii) aq $\mathrm{HCl}, \mathrm{EtOH}, 80^{\circ} \mathrm{C}$, reflux, $2 \mathrm{~h}$; (iv) $\mathrm{AcCl}, \mathrm{NaOAc}, \mathrm{MeCN}, \mathrm{rt}, 12 \mathrm{~h}$.

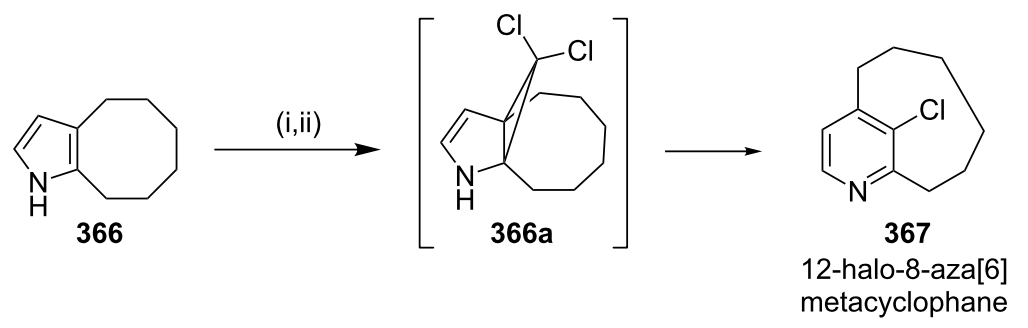

Scheme 66: Synthesis of metacyclophane 367 via Ciamician-Dennstedt rearrangement. Reagents and conditions: (i) $\mathrm{Cl}_{3} \mathrm{CCO}_{2} \mathrm{Na}_{(5}$ equiv), $1,2-$ dimethoxyethane, reflux, $4 \mathrm{~h}$; (ii) $\mathrm{Hg}(\mathrm{Ph})\left(\mathrm{CBr}_{3}\right)$ (2 equiv), benzene, reflux, $24 \mathrm{~h}$. 
<smiles>Oc1ccccc1OCCOCCOc1ccccc1O</smiles>

368<smiles>COc1cccc(CCCCOc2cccc(CCOCCO)c2OC)c1OC</smiles>

373<smiles>C=CCOc1ccccc1OCCOCCOc1ccccc1OCC=C</smiles>

369

(v)<smiles>COc1ccccc1C/C=C\Cc1cccc(OCCOCCOc2ccccc2OC)c1OC</smiles>

(iv) (ii)<smiles>C=CCc1cccc(OCCOCCOc2cccc(CC=C)c2O)c1O</smiles>

370<smiles>C=CCc1cccc(OCCOCCOc2cccc(CC=C)c2OC)c1OC</smiles>

371

Scheme 67: Synthesis of cyclophane by tandem Claisen rearrangement and RCM as key steps. Reagents and conditions: (i) allyl bromide, acetone, reflux, $12 \mathrm{~h}, 92 \%$; (ii) dichlorobenzene, reflux, $24 \mathrm{~h}, 64 \%$; (iii) Mel, $\mathrm{K}_{2} \mathrm{CO}_{3}$, acetone, reflux, $6 \mathrm{~h}, 88 \%$; (iv) $\mathrm{G}-\mathrm{I}$ (12), $\mathrm{PhMe}$, reflux, $12 \mathrm{~h}, 56 \%$; (v) $\mathrm{H}_{2}$, $\mathrm{Pd} / \mathrm{C}, \mathrm{EtOAc}, 12 \mathrm{~h}, \mathrm{rt}, 98 \%$.

Kotha and Shirbhate [213] have synthesized the cyclophane derivative 380. Commercially available 4-bromophenol (374) and allyl bromide were reacted in the presence of a mild base such as $\mathrm{K}_{2} \mathrm{CO}_{3}$ to generate $O$-allyl derivative 375 (98\%). Later, commercially available 2,6-pyridinedicarbonitrile (254) was reacted with the Grignard reagent prepared from $O$-allylbromophenol (375), activated magnesium turnings, and iodine (for activation) in THF. The desired bis- $O$-allyl derivative 377 was then directly subjected to a Claisen rearrangement at $180^{\circ} \mathrm{C}$ in $o$-dichlorobenzene $(o$-DCB) for $8 \mathrm{~h}$ (Scheme 68$)$. The diallylated compound $\mathbf{3 7 8}$ was subjected to RCM by using G-II (13) as a catalyst to generate the desired cyclophane $379(62 \%)$ as a
1:1 mixture of cis and trans-isomers. However, the trans-isomer of RCM product 379 was crystallized in methanol and acetonitrile (1:1) after several attempts (Scheme 68).

Cope rearrangement: In 1986, Vögtle and Eisen [214] have succeeded in assembling a tetraarylbiallyl skeleton by doubly bridged metacyclophane derivatives, which underwent a spontaneous Cope rearrangement under mild reaction conditions. Tetraaryl dialdehyde $\mathbf{3 8 1}$ was prepared in several steps and further reduction of the aldehyde functionality with $\mathrm{NaBH}_{4}$ in methanol gave the diol. Bromination of the diol with $\mathrm{PBr}_{3}$ gave the dibromotetraaryl derivative 382 (75\%). Subsequently,

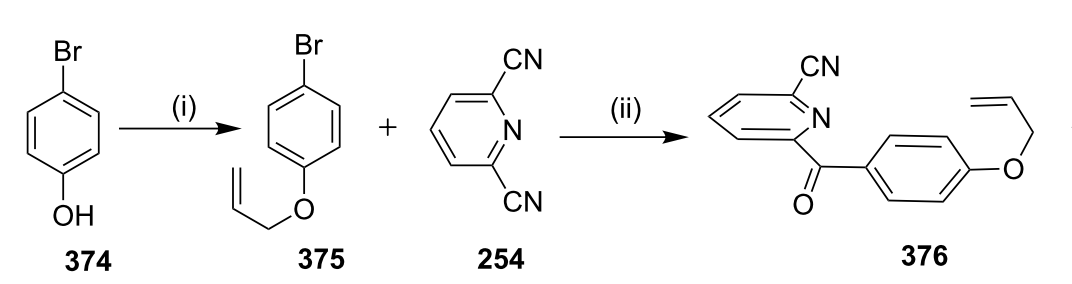

374

375

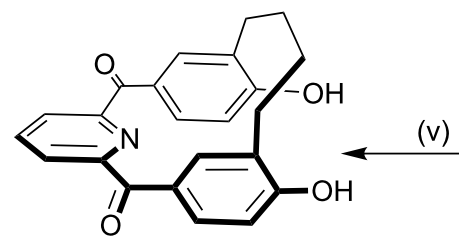

380 (v)

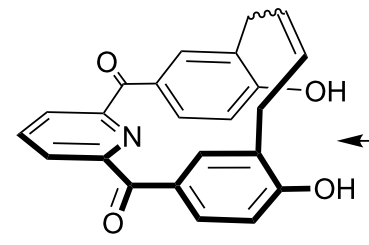

379<smiles>C=CCOc1ccc(C(=O)c2cccc(C(=O)c3cccc(OCC=C)c3)n2)cc1</smiles>

377

(iii) (iv)

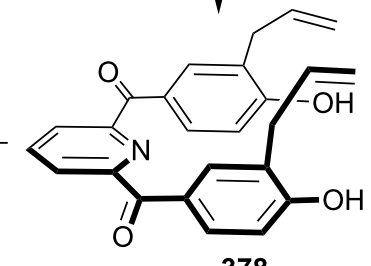

378 
cyclization of the bisbromide $\mathbf{3 8 2}$ gave the product $\mathbf{3 8 4}$ through a [3,3]-sigmatropic rearrangement (51\%, Scheme 69).

Favorskii rearrangement: In 2005, Gleiter and co-workers [215] have synthesized sterically stabilized cyclopropanophanes, containing non-benzenoid three-membered aromatic rings. Diketone $\mathbf{3 8 5}$ was subjected to bromination in the presence of bromine which afforded tetrabromide 386 with antiorientation to the keto group with four equatorial bromine atoms (46\%). Subsequently, tetrabromo derivative $\mathbf{3 8 6}$ was converted to cyclopropanophane $\mathbf{3 8 7}$ (27\%) by Favorskii rearrangement and thus generated the three-membered ring systems (Scheme 70).

Photo-Fries rearrangement: It was shown that Diazonamide has potent in vitro activity against HCT-116 human colon carcinoma and B-16 murine melanoma cancer cells and several attempts have been reported to synthesize this alkaloid. Magnus and Lescop have reported [216] the synthesis of the diazon- amide core $\mathbf{3 8 8}$ by using a photo-Fries rearrangement with the substrate 389 (Scheme 71).

Schmidt rearrangement: The first approach described here involves the Stobbe condensation of cyclododecanone (390) with ethyl succinate to deliver carboxylic acid 391, which on cyclization with zinc chloride in polyphosphoric acid gave cyclopentanone derivative 392. Acidic hydrolysis of ester 392 and simultaneous decarboxylation gave the unsaturated ketone 393. Wolff-Kishner reduction of the cyclopentenone derivative 393 gave the two isomeric olefins 394 and 395. An application of the Schmidt reaction with a mixture of compounds 394 and 395 followed by dehydrogenation with $\mathrm{Pd} / \mathrm{C}$ afforded [10](2,6)pyridinophane 223 and its 2,3-isomer 397 (Scheme 72) [217].

Tandem Claisen rearrangement: In 2008, Hiratani and co-workers [218] have reported the synthesis of the sulfurcontaining crownophane $\mathbf{4 0 1}$ by using the tandem Claisen<smiles>CC(C)(C)c1ccccc1/C=C/C(/C=C/c1ccccc1)c1cccc(C=O)c1</smiles>

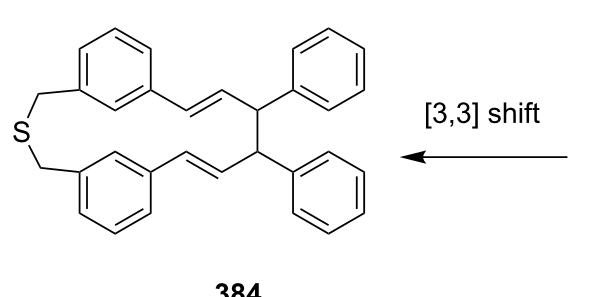<smiles>C[13C](=O)c1ccccc1/C=C/c1ccccc1/C=C/c1cccc(CBr)c1</smiles>

(iii)<smiles>CC(C)/C=C/c1cccc(C(/C=C/c2ccccc2)c2cccc(CSCc3ccccc3)c2)c1</smiles>

383

Scheme 69: Synthesis of metacyclophane via Cope rearrangement. Reagents and conditions: (i) $\mathrm{MeOH}, \mathrm{NaBH}_{4}, \mathrm{rt}, 1 \mathrm{~h}, 95 \%$; (ii) $\mathrm{PBr}_{3}, \mathrm{C}_{6} \mathrm{H}_{5} \mathrm{CH}_{3}$, $\mathrm{Et}_{2} \mathrm{O}, 12 \mathrm{~h}, 60^{\circ} \mathrm{C}, 96 \%$; (iii) $\mathrm{Na}_{2} \mathrm{~S}, \mathrm{C}_{6} \mathrm{H}_{6}, \mathrm{EtOH}, \mathrm{Cs}_{2} \mathrm{CO}_{3}, 8 \mathrm{~h}, 80^{\circ} \mathrm{C}, 51 \%$.

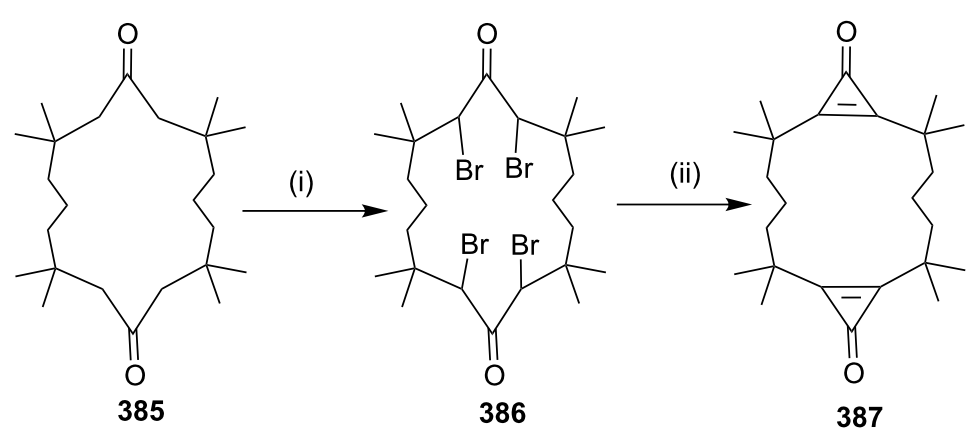

Scheme 70: Synthesis of cyclopropanophane via Favorskii rearrangement. Reagents and conditions: (i) $\mathrm{Br}_{2}, \mathrm{CH}_{2} \mathrm{Cl}_{2}, 5 \mathrm{~h}, \mathrm{rt}, 46 \%$; (ii) $\mathrm{KO}$ - $\mathrm{Bu}$, THF, $-40{ }^{\circ} \mathrm{C}, 30 \mathrm{~min}, 27 \%$. 


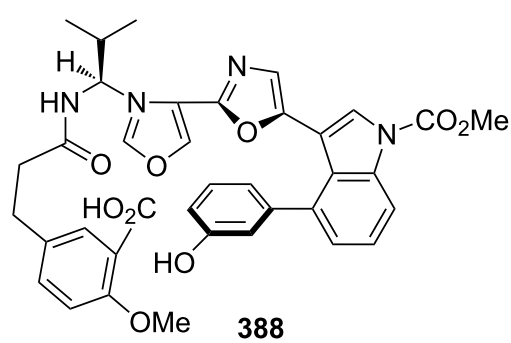

(i,ii)

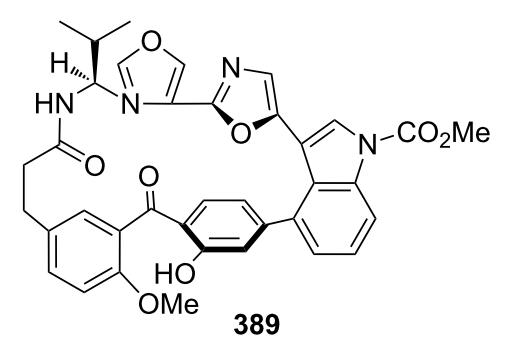

Scheme 71: Cyclophane 389 synthesis via photo-Fries rearrangement. Reagents and conditions: (i) DMAP, $\mathrm{EDCl} / \mathrm{CHCl}_{3},(0.004 \mathrm{M}), 66 \%$; (ii) $h \mathrm{v}$, benzene $(0.001 \mathrm{M}), 23{ }^{\circ} \mathrm{C}, 76 \%$

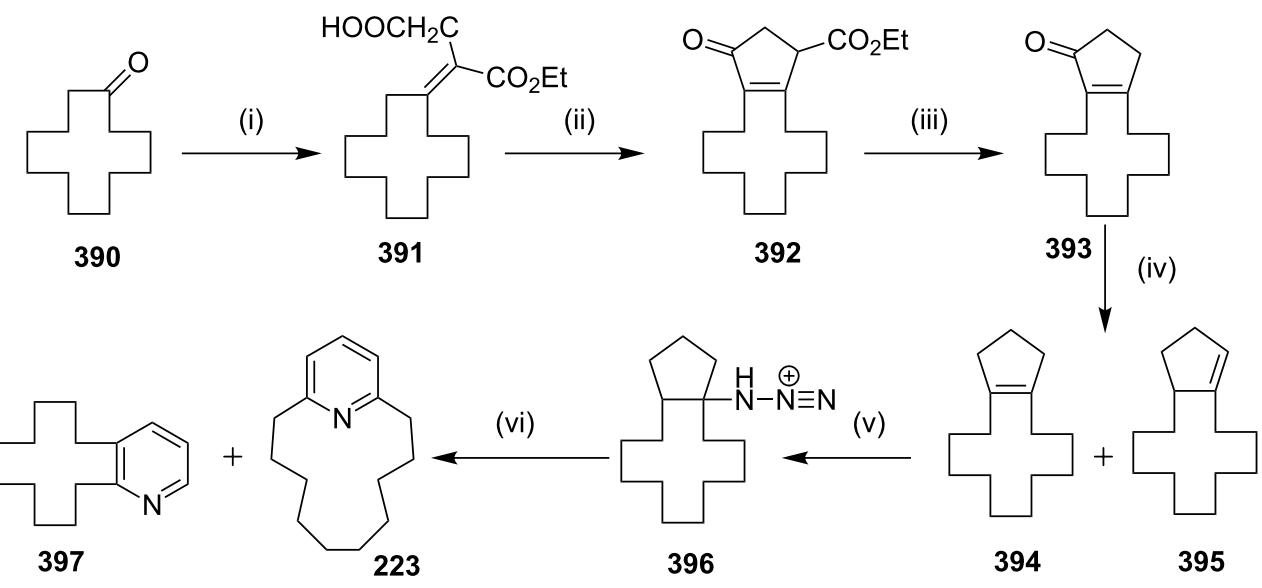

Scheme 72: Synthesis of normuscopyridine (223) via Schmidt rearrangement. Reagents and conditions: (i) ethyl succinate, $\mathrm{KO} t-\mathrm{Bu}, t-\mathrm{BuOH}$, reflux, $22 \mathrm{~h}, 84 \%$; (ii) $\mathrm{ZnCl}_{2}, \mathrm{PPA}, 95^{\circ} \mathrm{C}, 45 \mathrm{~h}$; (iii) $\mathrm{HCl}, \mathrm{AcOH}$, reflux, $19 \mathrm{~h}$, (2 steps 47\%); (iv) $\mathrm{Na}$, ethylene glycol, $\mathrm{N}_{2} \mathrm{H}_{4}, \mathrm{reflux} 3 \mathrm{~h}, 55 \%$; (v) $\mathrm{CHCl} 3$, EtOH, $\mathrm{HN}_{3}, 30 \mathrm{~min}, 50{ }^{\circ} \mathrm{C}$; (vi) 1-methylnaphthalene, $10 \% \mathrm{Pd} / \mathrm{C}$, reflux, $3.5 \mathrm{~h}(\mathbf{2 2 3}, 17 \%$ in 2 steps; $397,16 \%$ in 2 steps $)$.

rearrangement as a key step. Diacetyl chloride 398 was coupled with various sulfur-containing diamines followed by tandem Claisen rearrangement of the resulting exemplar amide derivative 399 in $N$-methyl-2-pyrrolidone (NMP) which yielded the desired sulfur-containing crownophane 400. Later, the reaction of this crownophane $\mathbf{4 0 0}$ with $\mathrm{Hg}(\mathrm{OAc})_{2}$ gave the organomercurated dihydrobenzofuran containing macrocycle $\mathbf{4 0 1}$ (Scheme 73).

Kotha and co-workwers [212] have also attempted the synthesis of cyclophane derivatives involving the tandem Claisen rearrangement and an RCM as key steps. To this end, $p$-cresol (402) was reacted with allyl bromide to give allyl ether $\mathbf{4 0 3}$, which undergoes a Claisen rearrangement to deliver $O$-allylphenol derivative 404. Phenol derivative 404 was reacted with 3-chloro-2-(chloromethyl)-1-propene (405) to generate the key precursor 406. Tandem Claisen rearrangement of 406 in the presence of $\mathrm{BCl}_{3}$ yielded the rearranged product 407 (27\%). Various attempts to generate the RCM product $\mathbf{4 0 8}$ from $\mathbf{4 0 7}$ or its derivatives were not successful (Scheme 74).

\section{Alkylation}

Bates and Ogle [219] have reported the synthesis of the normuscopyridine and its analogues by reacting the dipotassium salt of lutidine with dibromoalkanes. To this end, 2,6-dimethylpyridine (409) was treated with $n$ - $\mathrm{BuLi}$ and $\mathrm{KO} t$ - $\mathrm{Bu}$ to generate dianion 410, which on reaction with dibromoalkanes gave the symmetrical pyridinophanes $\mathbf{4 1 1}$ in $5-10 \%$ overall yield (Scheme 75).

\section{Friedel-Crafts alkylation}

In 1954, Schubert and co-workers [220] have synthesized dimeric and trimeric benzocyclanone via Friedel-Crafts reaction as a key step. In this regard, compound 7-phenylheptanoyl chloride (412), was subjected to cyclization under high-dilution conditions to deliver dimer $413(5 \%)$ and trimer 414 (0.4\%, Scheme 76).

\section{Friedel-Craft acylation}

Georgi and Retey [221] have synthesized the isomer of muscopyridine 418 involving the pyrylium salt 417 . The 
<smiles>C=C(COc1cc2ccccc2cc1C(=O)Cl)COc1cc2ccccc2cc1C(=O)Cl</smiles>

398

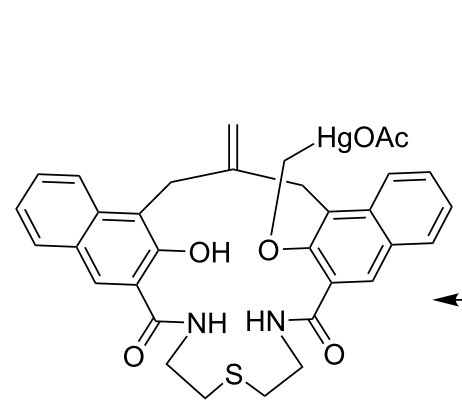

401<smiles>C#CCNC(=O)c1cc2ccccc2cc1C(=O)NCCSCCNC(=O)c1cc2ccccc2cc1OCC(=C)COc1cc2ccccc2cc1C</smiles>

399 (iii)<smiles></smiles>

400

Scheme 73: Synthesis of crownophanes by tandem Claisen rearrangement. Reagents and conditions: (i) diamine, Et ${ }_{3} \mathrm{~N}, \mathrm{THF}$; (ii) NMP, reflux; (ii) $\mathrm{Hg}(\mathrm{OAc})_{2}$, DMF/ether.

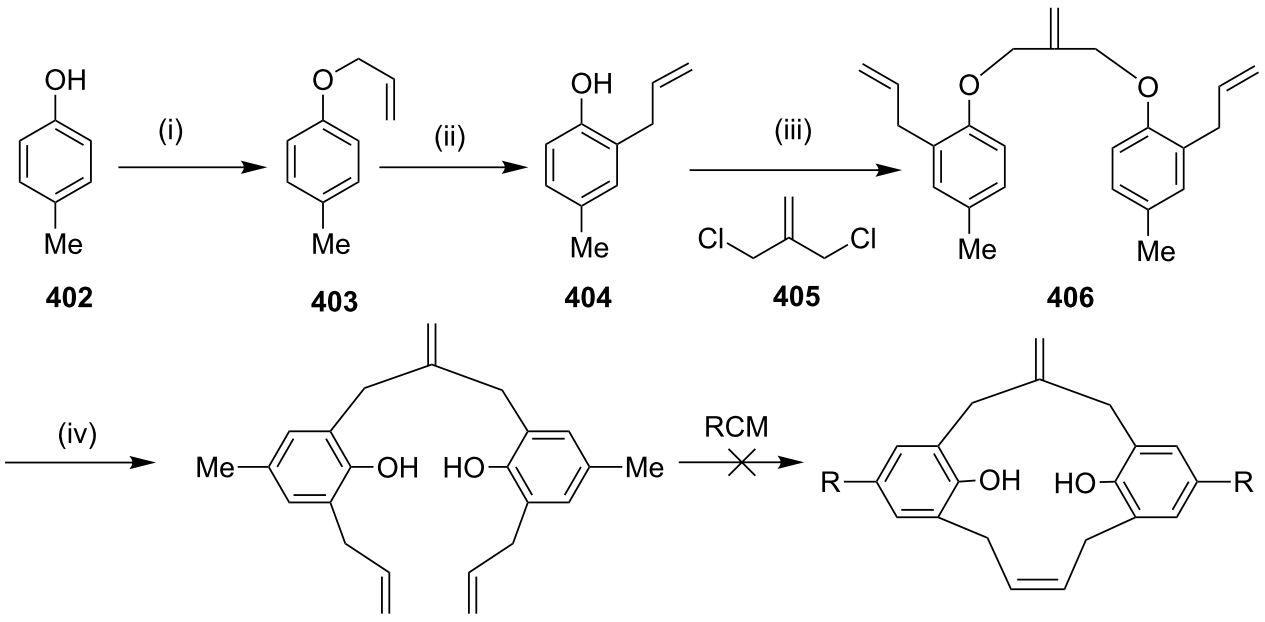

407

408

Scheme 74: Attempted synthesis of cyclophanes via tandem Claisen rearrangement and $\mathrm{RCM}$. Reagents and conditions: (i) allyl bromide, $\mathrm{K}_{2} \mathrm{CO}_{3}$, acetone, reflux, $16 \mathrm{~h}, 92 \%$; (ii) $160-180{ }^{\circ} \mathrm{C}, 6 \mathrm{~h}, 77 \%$; (iii) $405, \mathrm{~K}_{2} \mathrm{CO}_{3}$, acetone, reflux, $6 \mathrm{~h}, 84 \%$; (iv) $\mathrm{BCl}_{3}, \mathrm{CH}_{2} \mathrm{Cl}_{2},-60{ }^{\circ} \mathrm{C}$ to rt, $3 \mathrm{~h}, 27 \%$.

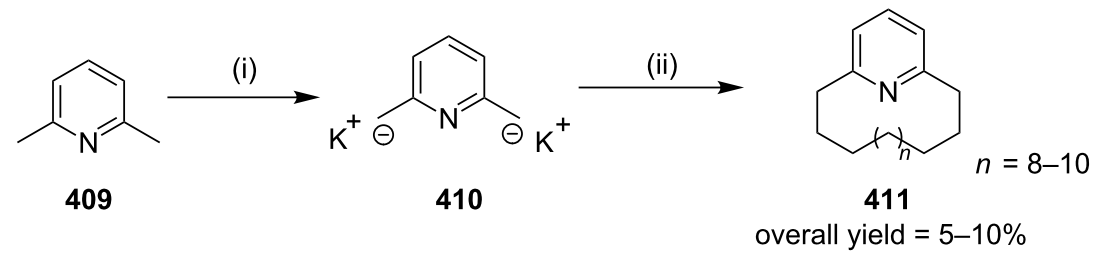

Scheme 75: Synthesis of muscopyridine via alkylation with 2,6-dimethylpyridine anion. Reagents and conditions: (i) $\mathrm{Kt} t-\mathrm{OBu}, n$-BuLi, $\mathrm{C}_{6} \mathrm{H}_{12}$, reflux, $1 \mathrm{~h}, 100 \%$; (ii) dibromoalkanes, THF, $-78^{\circ} \mathrm{C}$ to rt. 


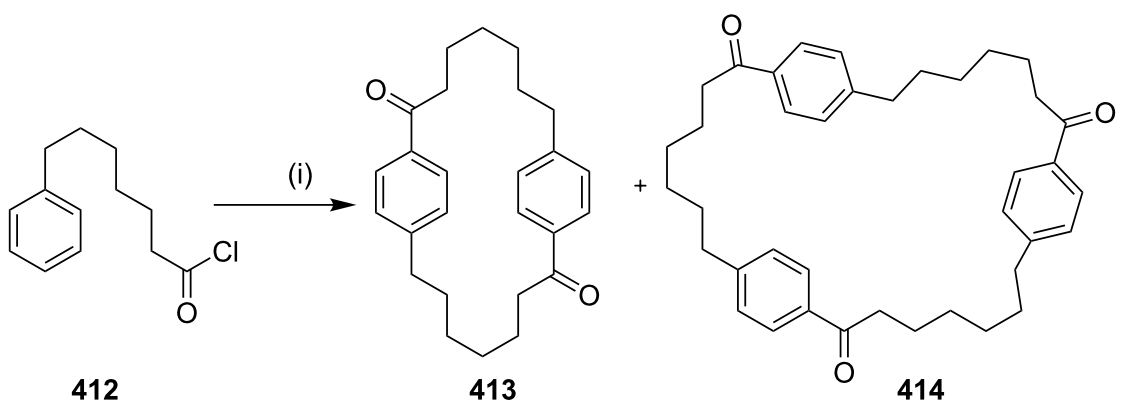

Scheme 76: Synthesis of cyclophane via Friedel-Craft acylation. Reagents and conditions: (i) $\mathrm{CS}_{2}, \mathrm{AlCl}_{3}, 7 \mathrm{~d}, \mathrm{rt},(\mathbf{4 1 3}, 5 \%, \mathbf{4 1 4}, 0.4 \%)$.

overall yield of the reaction was low. Diacylation of isobutylene (416) with dichloride 415 in the presence of aluminum chloride gave pyrylium salt $\mathbf{4 1 7}$ which on further treatment with ammonia gave pyridinophane $\mathbf{4 1 8}$ in low yield (Scheme 77).

\section{Kotha-Schölkopf reagent [222]}

Kotha and co-workers [223] have reported the first and unexpected synthesis of macrocyclic cyclophane containing the unusual amino acid derivative $\mathbf{4 2 3}$ by using phosphazene as a base without high-dilution conditions (Scheme 78). Coupling of

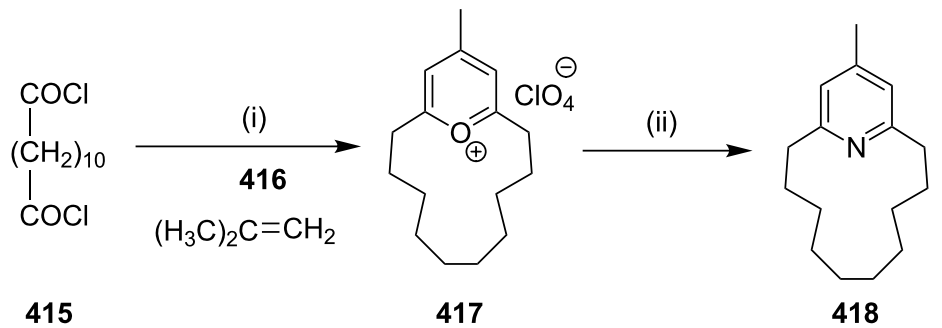

Scheme 77: Pyridinophane 418 synthesis via Friedel-Craft acylation. Reagents and conditions: (i) $416, \mathrm{AlCl}_{3}, \mathrm{CH}_{3} \mathrm{NO}_{2}, 50{ }^{\circ} \mathrm{C}, 8 \mathrm{~h}, 2 \%$; (ii) liquid $\mathrm{NH}_{3} / t-\mathrm{BuOH}, 1 \%$.<smiles>Cc1ccc(-c2ccccc2-c2ccc(C)cc2)cc1</smiles>

419<smiles>NC(Cc1ccccc1)(Cc1ccc(-c2ccccc2-c2ccc(CC(N)(Cc3ccc(-c4ccccc4-c4ccccc4)cc3)C(=O)O)cc2)cc1)C(=O)O</smiles>

423

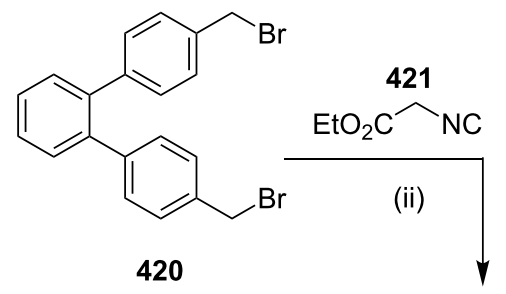

(iii)<smiles>CCOC(=O)C([NH3+])(Cc1ccc(-c2ccccc2)cc1)Cc1ccc(-c2ccccc2-c2ccc(CC(Cc3ccc(-c4ccccc4-c4ccccc4)cc3)(OCC)C(=O)OC)cc2)cc1</smiles>

422

Scheme 78: Cyclophane synthesis involving the Kotha-Schölkopf reagent 421. Reagents and conditions: (i) $\mathrm{NBS}, \mathrm{AIBN}^{\mathrm{C}} \mathrm{CCl}{ }_{4}$; (ii) $\mathrm{BEMP} \mathrm{CH}_{3} \mathrm{CN}$, $0^{\circ} \mathrm{C}$; (iii) $\mathrm{HCl}$. 
the two bromo-substituted rings was carried out with ethyl isocyanoacetate (Kotha-Schölkopf reagent).

They also reported the synthesis of macrocyclic cyclophanebased unusual $\alpha$-amino acid (AAA) derivatives $\mathbf{4 2 6}$ involving ethyl isocyanoacetate (421) and 1,2-bis(4-(bromomethyl)phenyl)ethane under phase-transfer catalysis (PTC) conditions using a phosphazene base (BEMP). Out of two isomers formed, transisomer 426a was crystallized from petroleum ether (Scheme 79) $[224,225]$.

\section{(p-Tolylsulfonyl)methyl isocyanide (TosMIC)}

Shinmyozu and co-workers [226] have reported the synthesis of [34](1,2,4,5)cyclophane $\mathbf{4 3 0}$ by using the TosMIC reagent. This reagent is useful to prepare barrelenophane which can be further converted into semibullvalenophane (Scheme 80).

\section{Synthesis of azacyclophane via nitrobenzenesul- fonyl (Ns)-amide method}

In 2008, Okamoto and co-workers [227] have synthesized diaza $\left[3_{2}\right]$ cyclophanes and triaza $\left[3_{3}\right]$ cyclophanes. To this end,
bis-Ns-amide 431 was prepared by several steps and it was further treated with $\mathrm{NaH}$ in DMF to generate the bis-amidate anion, which was coupled under high-dilution conditions with 1,4-bis(chloromethyl)benzene $(\mathbf{4 3 2})$ at $70{ }^{\circ} \mathrm{C}$ to give the dimer 433 as well as the trimer 434 . Subsequently, deprotection of cyclophanes 433 and 434 was carried out with sodium ethanethiolate at $50{ }^{\circ} \mathrm{C}$ and the amino derivatives were acetylated with trifluroacetic anhydride to generate cyclophanes 435 (26\%) and $436(5 \%)$, respectively (Scheme 81).

\section{Acyloin condensation}

Rubin and coworkers [228] have synthesized cyclophane 439 by acyloin condensation. Furthermore, studies were carried out to find out the behavior of intramolecular energy transfer reaction (Scheme 82).

\section{Aldol condensation}

Shinmyozu and co-workers [229] have reported the synthesis of multibridged $\left[3_{n}\right]$ cyclophanes $\mathbf{4 4 2}$ by aldol condensation. Due to an enhanced transannular $\pi-\pi$ interaction between two benzene rings and the hyperconjugation of the benzyl hydro-

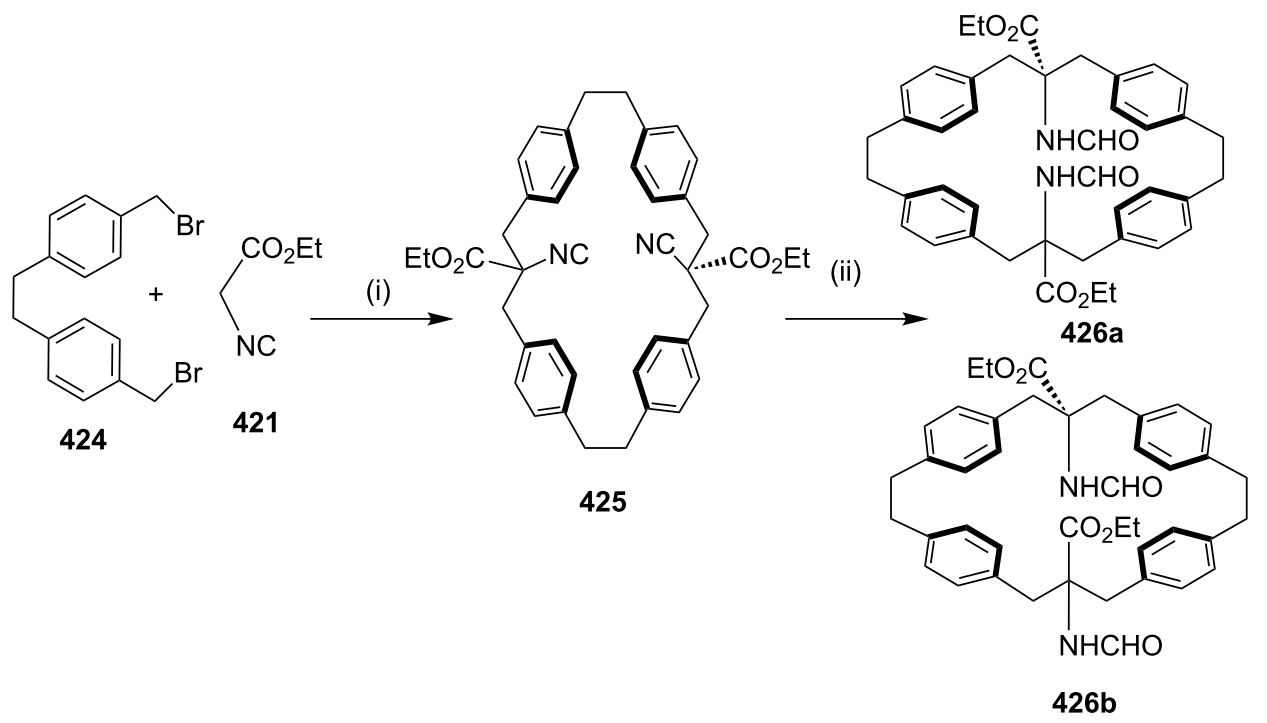

Scheme 79: Cyclophane synthesis involving the Kotha-Schölkopf reagent 421. Reagents and conditions: (i) $\mathrm{BEMP}, \mathrm{CH}_{3} \mathrm{CN}, 0^{\circ} \mathrm{C}$; (ii) $\mathrm{HCl}$.

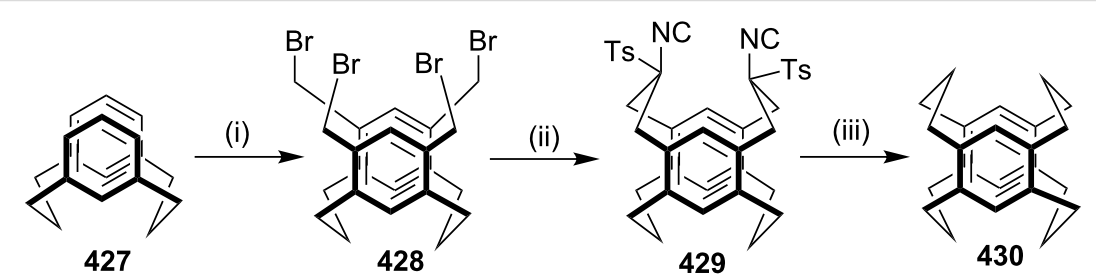

Scheme 80: Cyclophane synthesis by coupling with TosMIC. Reagents and conditions: (i) (a) $\mathrm{ClCH}_{2} \mathrm{OCH}_{3}, \mathrm{TiCl}_{4}, \mathrm{CS}_{2}$; (b) $\mathrm{NaBr}, \mathrm{EtBr}, \mathrm{DMF}$; (ii) $\mathrm{NaH}$, TosMIC, DMF, rt.; (iii) Li, liquid $\mathrm{NH}_{3}$, EtOH. 


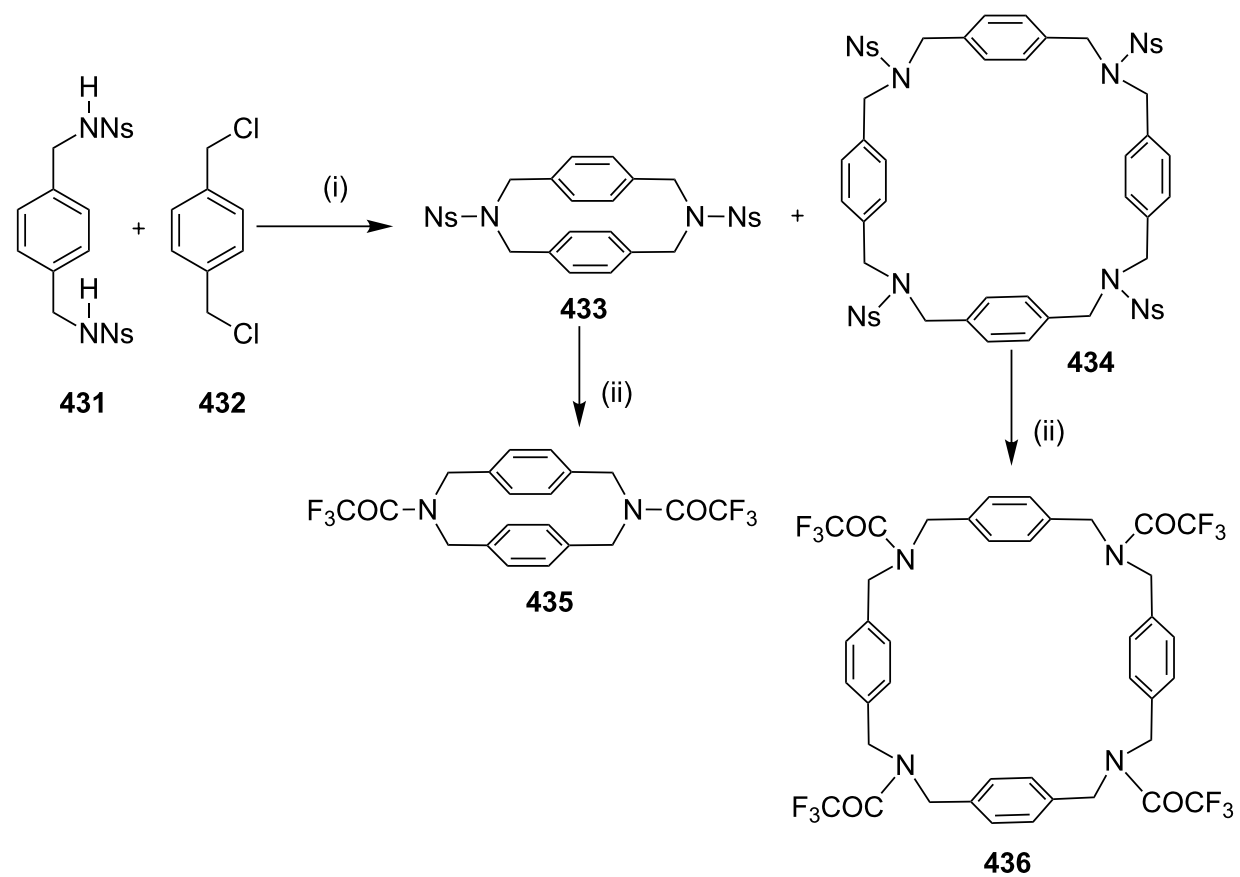

Scheme 81: Synthesis of diaza[3 $\left.3_{2}\right]$ cyclophanes and triaza[3 3 ]cyclophanes. Reagents and conditions: (i) DMF, NaH, $6 \mathrm{~h}, 70{ }^{\circ} \mathrm{C}, 26 \%$; (ii) $\mathrm{EtSNa}$, DMSO, $50{ }^{\circ} \mathrm{C}$, TFAA, $\mathrm{Et}_{3} \mathrm{~N}$, dioxane, rt, $435,26 \%, 436,5 \%$.

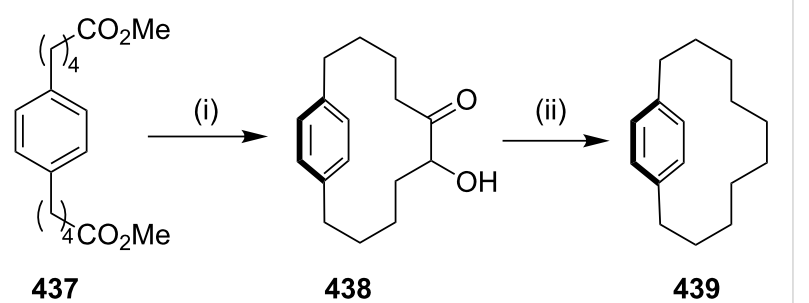

Scheme 82: Synthesis of cyclophane $\mathbf{4 3 9}$ via acyloin condensation. Reagents and conditions: (i) $\mathrm{Na}$, xylene, $75 \%$; (ii) $\mathrm{Zn}, \mathrm{HCl} / \mathrm{AcOH}, 36 \%$.

gens with the benzene rings multibridged cyclophane $\mathbf{4 4 2}$ shows a high $\pi$-donating ability. Aldol condensation of ketoaldehyde 440 gave keto derivative 441 which was further extended to multibridged cyclophane $\mathbf{4 4 2}$ (Scheme 83).

\section{Intramolecular esterification reaction}

In 2014, Preobrazhenskaya and co-workers [230] have synthesized [15]-, [16]-, and [17]-membered lactones containing bis3,4(indol-1-yl)maleimide framework via an intramolecular esterification reaction as a key step. 2,3-Dibromomaleimide (443) was coupled with various (2,3-dihydroindol-3-yl)alkanols $(444 \mathrm{a}-\mathrm{c})$ in the presence of $\mathrm{Et}_{3} \mathrm{~N}$ to give the corresponding $\omega$-hydroxyalkyl derivatives $445 a-c$. Next, the protection of the hydroxy groups with TBDMSCl led to the protected derivatives 446 (72-80\%). The bromo derivatives 446 were subjected to dehydrogenation by 2,3-dichloro-5,6-dicyano-1,4benzoquinone (DDQ) to obtain 3-bromo-4-[3-( $\omega$-hydroxyalkyl)indol-1-yl])maleimides 447 (72-75\%), which were further coupled with various (3,4-dihydroindol-3-yl)alkanoic acids 448 to deliver the bisindole derivatives 449. The bisindoles 449 were then treated with a catalytic amount of $p$-toluenesulfonic

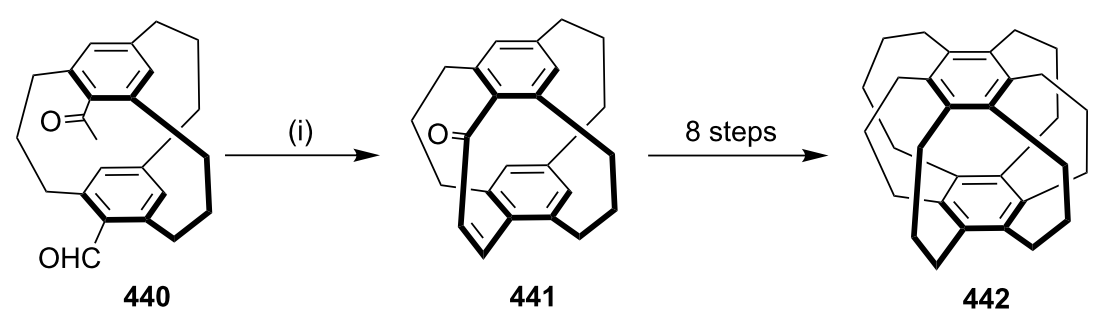

Scheme 83: Synthesis of multibridged binuclear cyclophane $\mathbf{4 4 2}$ by aldol condensation. Reagents and conditions: (i) aq $\mathrm{NaOH}, \mathrm{THF}, \mathrm{MeOH}$. 
acid in benzene and heated under reflux to afford the macrolactones 450. Dehydrogenation by using DDQ oxidation gave various macrolactones 451 (68-75\%, Scheme 84).

\section{Yamaguchi esterification}

Rohanna and Rainier [231] have reported the synthesis of muscopyridine (73) by using an olefin lactone cyclization strategy. The Yamaguchi esterification of acid derivative $\mathbf{4 5 2}$ gave lactone 454. Cyclization of lactone 454 yielded macrocyclic dihydropyran $\mathbf{4 5 5}$. Silica gel mediated hydrolysis of the enol ether gave hydroxy ketone $\mathbf{4 5 6}$, which served as a useful precursor to both muscone (458) and muscopyridine (73). Muscopyridine (73) has been generated via oxidation of the secondary alcohol 456, followed by treatment of the 1,5diketone with $\mathrm{NH}_{4} \mathrm{OH}$. Alternatively, $(R)-(-)$-muscone (458) has been obtained from hydroxy ketone 456 by using the Barton-McCombie deoxygenation conditions (Scheme 85).

\section{Elimination reactions}

Double elimination reaction: In 2001, Bickelhaupt and co-workers [232] have synthesized a [5]metacyclophane derivative with an $\mathrm{sp}^{2}$-center embedded at the central position of the bridge. Ditosylate 459 was converted to dibromide 460 by treatment with $\mathrm{LiBr}$ followed by the addition of dichlorocarbene to give the cyclopropane derivative $\mathbf{4 6 1}$ according to the Skattebøl method [233]. Next, it was rearranged to cyclopentane derivative $\mathbf{4 6 2}$ by using flash vacuum pyrolysis (FVP) [234]. The addition of dichlorocarbene to compound $\mathbf{4 6 2}$ by the method of Makosza [235] gave compound $\mathbf{4 6 3}$ which was cyclized with TosMIC [236,237] to generate propellane derivative 464 . Finally, the cyclophane 465 was obtained (70\%) from 464 by a double elimination reaction by using $\mathrm{AgClO}_{4}$ and lutidine in THF (Scheme 86).

Hofmann elimination reaction: The Hofmann elimination [238-241] is also named the Hofmann degradation. This reaction involves the elimination of alkyltrimethylamines and the product formation proceeds with an anti-stereochemistry. This reaction is generally suitable for assembling alkenes with one or two substituents. A general procedure involves the conversion of an amine into a tertiary amine followed by the treatment with an excess amount of methyl iodide. Further treatment with silver oxide, water and heating finally generates the alkene. The least substituted alkene is formed as a major product which is also known as the Hofmann rule [242,243]. The Hofmann elimination reaction is a classical and useful method to generate cyclophanes by cyclization of the obtained alkene compounds. Using this method a variety of cyclophanes have been prepared, including 1,6(2,5)-difuranacyclodecaphane (466) [244], paracyclo[2](2,5)-furanophane (467) [244], and quadrapole-layered<smiles>CC(C)(C)OC(=O)C1CN(C2=C(Br)C(=O)NC2=O)c2ccccc21</smiles>

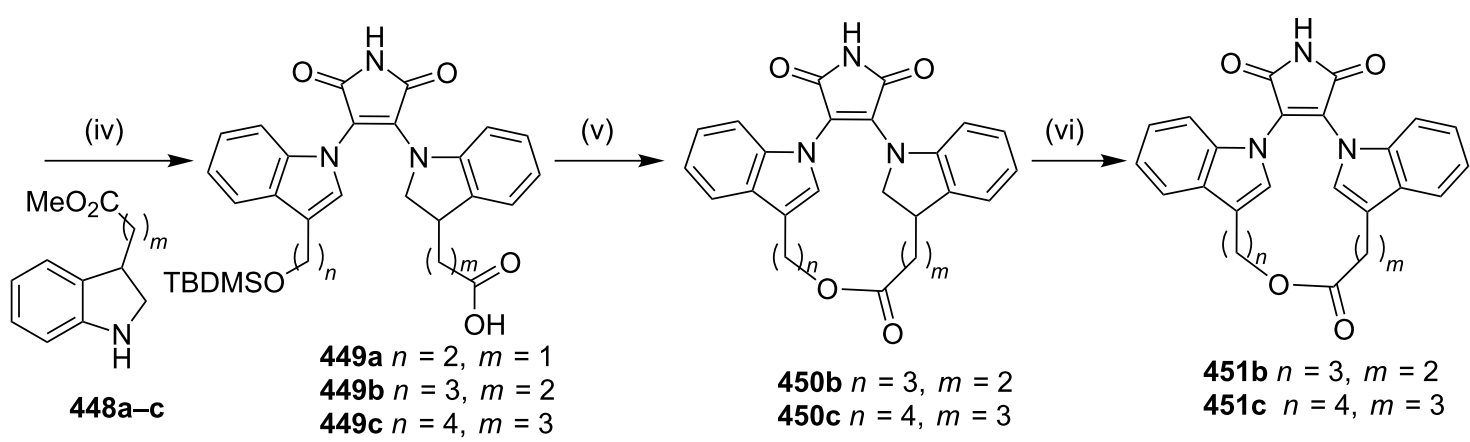

Scheme 84: Synthesis of various macrolactones. Reagents and conditions: (i) $\operatorname{Pr}_{2} \mathrm{EtN}, \mathrm{DMF}, 77-83 \%$; (ii) TBDMSCl, imidazole, DMF, $12 \mathrm{~h}, \mathrm{rt}, 10 \mathrm{~h}$, 72-80\%; (iii) DDQ, PhMe, 6 h, reflux, 72-75\%; (iv) $\mathrm{PPr}_{2} \mathrm{EtN}, \mathrm{DMF}, 12 \mathrm{~h}$, rt, 51-63\%; (v) $p \mathrm{TSA}, \mathrm{C}_{6} \mathrm{H}_{6}$, reflux, 30 min, 15\%; (vi) DDQ, PhMe, reflux, $3 \mathrm{~h}$, $71-75 \%$. 
<smiles>C=CCCC(C)(O)CC(C)CC(=O)O</smiles>

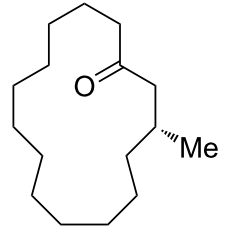

muscone (458)<smiles>O=C(Cl)c1c(Cl)cc(Cl)cc1Cl</smiles><smiles>C=CCCC(CCCCCCCC(C)C)OC(=O)CC</smiles>

454 (ii)<smiles>CCCCCCCCCC1CCC=C(C)O1</smiles>

$45569 \%$

453

(iv)

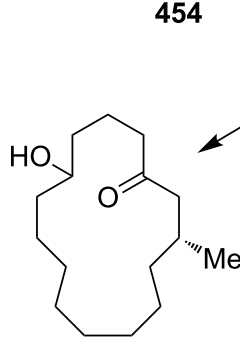

456 (iii)
$98 \%$

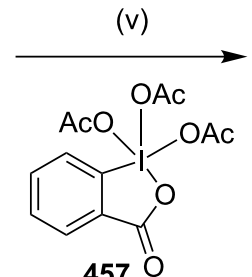

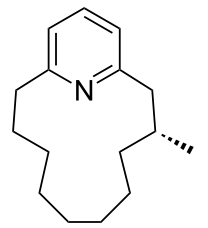

(+)-muscopyridine (73)

Scheme 85: Synthesis of muscone and muscopyridine via Yamaguchi esterification. Reagents and conditions: (i) 453, THF, PhMe, NEt 3 , DMAP, $45^{\circ} \mathrm{C}, 6 \mathrm{~h}, 90 \%$; (ii) $\mathrm{TiCl}_{4}, \mathrm{Zn}, \mathrm{TMEDA}, \mathrm{PbCl}_{2}, \mathrm{CH}_{3} \mathrm{CHBr}_{2}$, THF, $0{ }^{\circ} \mathrm{C}$ to rt, $2 \mathrm{~h}, 69 \%$; (iii) $\mathrm{SiO}_{2}, \mathrm{CH}_{2} \mathrm{Cl}_{2}, 48{ }^{\circ} \mathrm{C}, 2 \mathrm{~h}, 98 \%$; (iv) (a) PhOC(S) Cl, DMAP, pyridine, $\mathrm{CH}_{2} \mathrm{Cl}_{2}, 0{ }^{\circ} \mathrm{C}$ to rt, $10 \mathrm{~h}, 49 \%$; (b) $\mathrm{Bu}_{3} \mathrm{SnH}$, AIBN, $\mathrm{PhH}$, reflux, $4 \mathrm{~h}, 97 \%$; (v) $454, \mathrm{NH}_{4} \mathrm{OH}, \mathrm{EtOH}, 160{ }^{\circ} \mathrm{C}, 18.5 \mathrm{~h}, 54 \%$.

Scheme 86: Synthesis of [5]metacyclophane via a double elimination reaction. Reagents and conditions: (i) LiBr, acetone, $12 \mathrm{~h}$, reflux, $81 \%$; (ii) $\mathrm{CHCl}_{3}, t$-BuOK, $\mathrm{C}_{6} \mathrm{H}_{6}, \mathrm{rt}, 80 \%$; (ii) $\mathrm{FVP}, 480{ }^{\circ} \mathrm{C}, 5 \times 10^{-5} \mathrm{mbar}, 90 \%$; (iv) $\mathrm{CHCl}_{3}, \mathrm{PTC}, \mathrm{NaOH}\left(50 \%\right.$ ), $83 \%$; (v) $\mathrm{NaH}, \mathrm{TosMIC}^{\mathrm{DMSO}} \mathrm{Et}{ }_{2} \mathrm{O}, 15 \%$; (vi) $\mathrm{AgClO}_{4}$ /lutidine, $\mathrm{THF}, 90 \%$.

paracyclophane 468 having charge-transfer properties [245]. Other examples of cyclophanes such as octamethyl[2.2]paracyclophane (469) [246,247], $(2 E, 6 E, 9 E, 13 E)$-1,8(1,4)-dibenzenacyclotetradecaphane-2,6,9,13-tetraene (470) [248], difluoro[2,2]paracylophane (471) [249], and 2,6-azulylene (472) [250] are shown in Figure 12.

\section{Baylis-Hillman reaction}

In 1994, Foucaud and co-workers [251] have synthesized a macrocyclic cryptophane based on the Baylis-Hillman reaction. Dialdehyde 473 was reacted with methyl acrylate in the presence of diazabicyclooctane (DABCO) for 14 days at room temperature which resulted in the formation of diol 474. Diol 474 was then subjected to an acetylation in the presence of
AcOH to obtain allylic acetate 475 (97\%). Finally, diacetate 475 was subjected to a nucleophilic substitution reaction by using ammonia in methanol to generate cryptophane 476 (28\%, Scheme 87).

\section{Double Chichibabin reaction}

The Chichibabin reaction is one of the most elegant reactions to synthesize 2-substituted aminopyridines. Caulton and co-workers [252] have reported the synthesis of [2.n.1] $(2,6)$ pyridinophane $\mathbf{4 7 9}$ by double Chichibabin reaction starting with 477 (Scheme 88). Also, using ab initio and DFT calculations, they reported new macrocyclic ligands to achieve an "intermediate" degree of stability and reactivity of d6 metal alkyl hydrido complexes. 


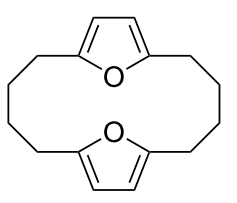

466

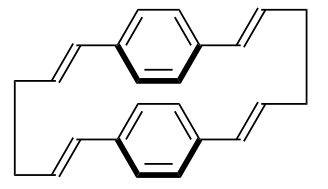

470

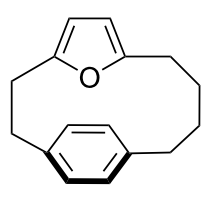

467

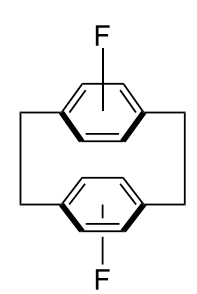

471

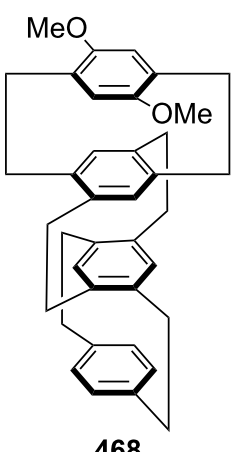

468

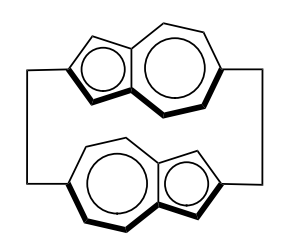

472

Figure 12: Cyclophanes 466-472 synthesized via Hofmann elimination.<smiles>C=C(C)C(O)c1ccc(C(O)C(=C)C(C)=O)cc1</smiles>

473

474<smiles>C=C(C(C)=O)C(C(C)=O)c1ccc(C(OC(C)=O)C(C)=O)cc1</smiles>

475

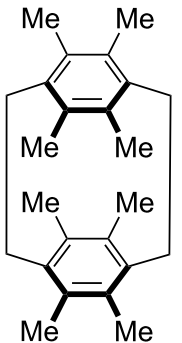

469

Scheme 87: Synthesis of cryptophane via Baylis-Hillman reaction. Reagents and conditions: (i) methyl acrylate, $\mathrm{DABCO}, \mathrm{CH}_{3} \mathrm{CN}$, for $1-14$ days, $\mathrm{rt}$; (ii) $\mathrm{CH}_{3} \mathrm{COCl}, \mathrm{Et}_{3} \mathrm{~N}$, THF, 5 h, rt, $97 \%$; (iii) $8 \mathrm{M}, \mathrm{NH}_{3}, \mathrm{MeOH}, 40 \mathrm{~min}, 28 \%$.<smiles>c1ccc(CCc2ccccn2)nc1</smiles>

477<smiles>CC(C)(C)c1cc(CCl)nc(CCl)c1</smiles>

478

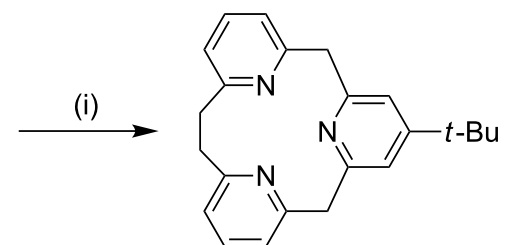

479

Scheme 88: Synthesis of cyclophane 479 via double Chichibabin reaction. Reagents and conditions: (i) excess $478, \mathrm{MeOH} / \mathrm{H}_{2} \mathrm{O}, 170{ }^{\circ} \mathrm{C}, 24 \mathrm{~h}, 60 \%$.

Zabel and co-workers [253] have reported the synthesis of 3,3biindolizine-based cyclophane $\mathbf{4 8 3}$ via Chichibabin reaction as a key step. Compound $\mathbf{4 8 0}$ was reacted with $\omega$-bromoacetophenone (481) by adopting standard Chichibabin reaction conditions to deliver the crown ether derivative 482 (28\%). Subsequently, compound $\mathbf{4 8 2}$ was treated with potassium hexacyano- ferrate to get the desired cyclophane $\mathbf{4 8 3}$ via an intramolecular oxidative coupling (Scheme 89).

\section{Intramolecular $\mathrm{S}_{\mathrm{N}} \mathrm{Ar}$ reaction}

In 2002, Zhu and co-workers [254] have synthesized cyclopeptide alkaloids containing paracyclophane with a peptidic tether 


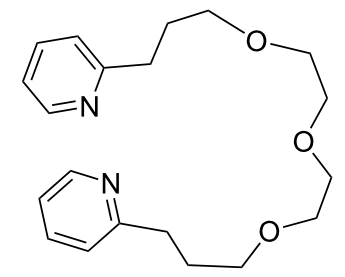

480

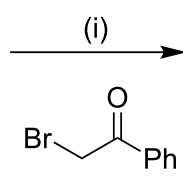

481<smiles>c1ccc(-c2cn3ccccc3c2CCOCCOCCOCCc2c(-c3ccccc3)cn3ccccc23)cc1</smiles>

482

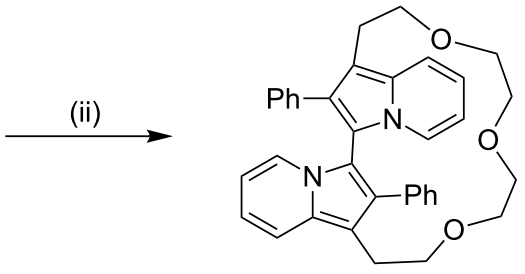

483

Scheme 89: Synthesis of cyclophane 483 via double Chichibabin reaction. Reagents and conditions: (i) $481, \mathrm{OH}^{-}$; (ii) $\mathrm{K}_{3}\left[\mathrm{Fe}\left(\mathrm{CN}_{6}\right]\right.$.

via an intramolecular $\mathrm{S}_{\mathrm{N}} \mathrm{Ar}$ reaction. Compound $\mathbf{4 8 4}$ was subjected to a ring closure in THF with TBAF as a base to give a mixture of two isomers 485 and 486 (65\%). Subsequent acetylation gave cyclophane derivatives $\mathbf{4 8 7}$ and $\mathbf{4 8 8}$ (Scheme 90).

\section{Muscopyridine via C-zip ring enlargement}

Hadjabo and Hesse [255] have synthesized muscopyridine (73) via the C-zip ring enlargement reaction as a key step (Scheme 91). Aldehyde 489 was protected with ethylene glycol to generate the mono-acetal 490 . Then, enone 491 was afforded with lithium diisopropylamide (LDA) and $\mathrm{PhSeBr} / \mathrm{H}_{2} \mathrm{O}_{2}$. The intramolecular conjugated addition of the enone system 491 in the presence of $\mathrm{Me}_{2} \mathrm{CuLi}$ gave a mixture of two diastereomers 492. The deprotection of the ketal with $\mathrm{TsOH}$ furnished aldehyde 493. A ring expansion involving an enamine reaction gave compound 494 (Figure 13), which was then hydrolyzed in 10\% $\mathrm{HCl}$ to deliver 495 . Nitroderivative 495 was subjected to a modified Nef reaction with $\mathrm{TiCl}_{3}$ to deliver diketone 496. Finally, diketone 496 was converted to a pyridine derivative with hydroxylamine hydrochloride to generate muscopyridine (73, Scheme 91).

\section{Nicholas reaction}

Green and co-workers [256] have reported the synthesis of an indolophanetetrayne-cobalt complex by using the Nicholas reaction as a key step (Scheme 92). Sonogashira coupling of $\mathrm{N}$-propargylindoles $497 \mathbf{a}-\mathbf{c}$ with iodoarylpropargyl acetate 498 gave $\mathrm{N}$-functionalized indole precursors 499a-c [257,258]. Both alkyne units of diynes $499 \mathbf{a}-\mathbf{c}$ can be converted to the corresponding cobalt complexes $\mathbf{5 0 0 a}-\mathbf{c}$ in the presence of an excess amount of $\mathrm{Co}_{2}(\mathrm{CO})_{8}$. The protected complex 500a was

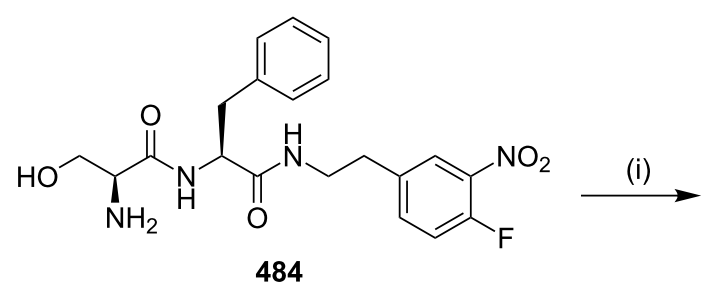<smiles>O=C(CO)NC(CO)C(=O)Nc1ccc(CCNC(=O)Nc2ccccc2)cc1</smiles>

486 (ii)<smiles>CC(=O)OCC(Nc1ccc(CCCNC(=O)[C@H](Cc2ccccc2)NC(=O)[O-])cc1[N+](=O)[O-])C(=O)O</smiles>

487<smiles>CC(=O)OCC(=O)NC(Cc1ccccc1)C(=O)Nc1cc2ccc1NC(COC(C)=O)C(=O)NCCC2</smiles>

488 


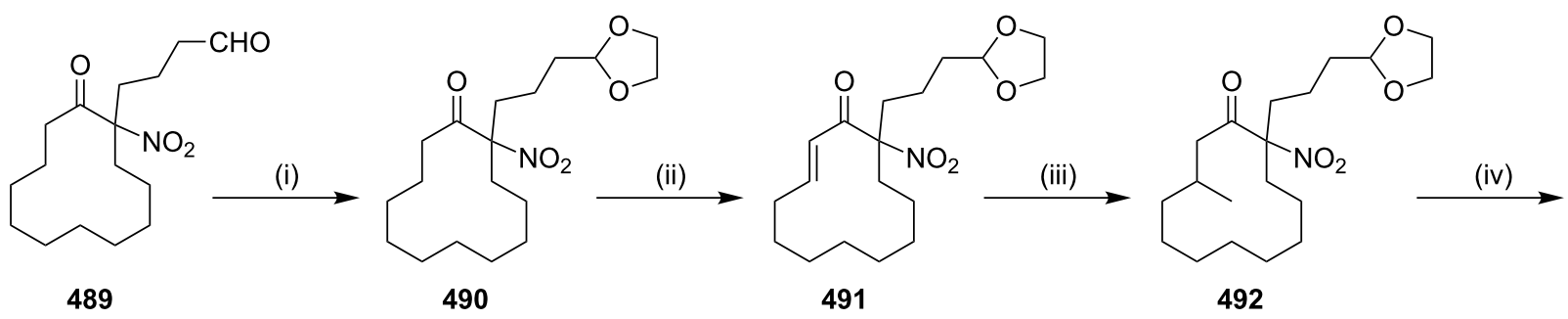

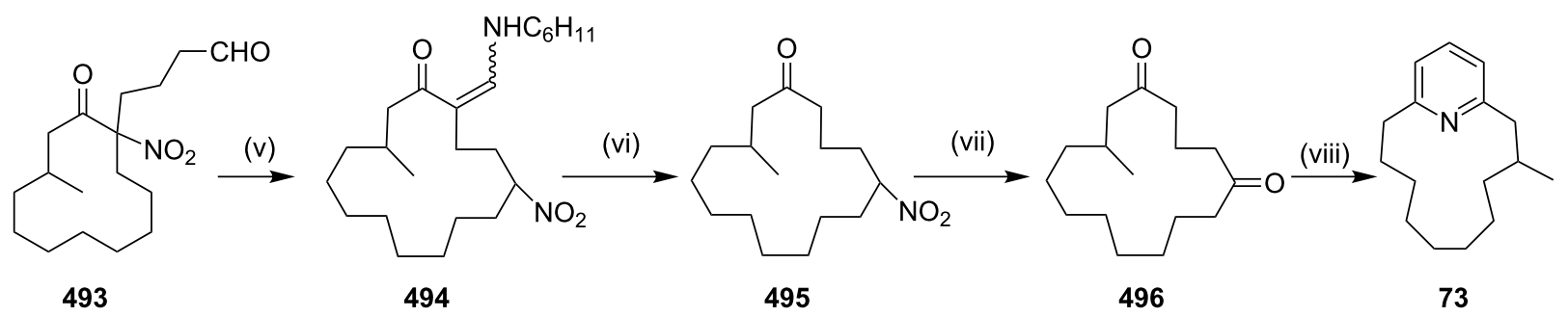

Scheme 91: Synthesis of muscopyridine (73) via C-zip ring enlargement reaction. Reagents and conditions: (i) $\mathrm{HO}\left(\mathrm{CH}_{2}\right)_{2} \mathrm{OH}, \mathrm{TsOH}$, benzene, $\Delta$; (ii) (a) LDA, PhSeBr, THF, $-78{ }^{\circ} \mathrm{C}$; (b) $\mathrm{H}_{2} \mathrm{O}_{2}, \mathrm{AcOH}$; (iii) $\mathrm{Me}_{2} \mathrm{CuLi}, \mathrm{PhMe},-50{ }^{\circ} \mathrm{C}$; (iv) $\mathrm{TsOH}$, acetone, $\mathrm{H}_{2} \mathrm{O}$; (v) $\mathrm{C}_{5} \mathrm{H}_{11} \mathrm{NH}_{2}, \mathrm{EtOH}, 23{ }^{\circ} \mathrm{C}$; (vi) $10 \% \mathrm{HCl}$, $\mathrm{EtOH}$; (vii) (a) $\mathrm{MeOH}, \mathrm{MeONa}, \mathrm{TiCl}_{3}, \mathrm{NaOAc}$, (b) $\mathrm{HCl}, \mathrm{H}_{2} \mathrm{O}$; (viii) $\mathrm{NH}_{2} \mathrm{OH} \cdot \mathrm{HCl}, \mathrm{EtOH}, 165^{\circ} \mathrm{C}, 64 \%$.
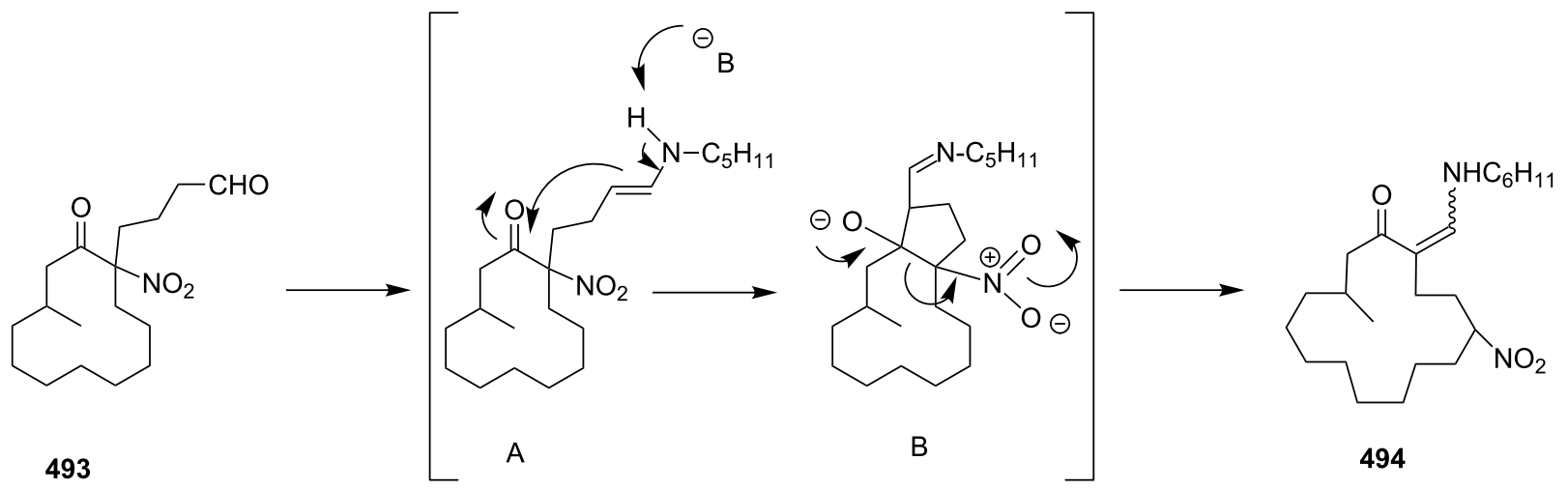

Figure 13: Mechanism of the formation of compound 494.

subjected to a cyclization reaction using $\mathrm{BF}_{3} \cdot \mathrm{OEt}_{2}$ at room temperature to generate $\mathrm{C}$-2-linked indolophanetetrayne 501a (55\%, Scheme 92).

\section{Radical cyclization}

In 1990, Turro and co-workers [259] have demonstrated a new methodology involving the photolysis of large $\alpha$-phenylcycloalkanes by an intramolecular para coupling of the acylbenzyl biradical intermediate. Cyclododecanone $\mathbf{5 0 2}$ was subjected to photolysis to generate both $\alpha$-cleavage and $\gamma$-hydrogen abstraction reaction to give compound 503. The photochemical irradiation of the large-ring containing 2-phenylalkenones $\mathbf{5 0 4}$ produce cyclophane $\mathbf{5 0 5}$ as the major product (Scheme 93).

\section{Ramberg-Bäcklund olefination reaction}

In 2010 Nicolaou and co-workers [260] have reported the asymmetric synthesis of (-)-cylindrocyclophanes A and F $(\mathbf{1 5 6}, \mathbf{1 5 5})$ by employing the head-to-tail dimerization approach to this class of compounds, based on the Ramberg-Bäcklund olefination reaction. The monomeric bifunctional precursor 506 was dimerized to [7.7]paracyclophane by using $\mathrm{NaOMe}$ in $\mathrm{MeOH}$ at ambient temperature to generate macrocyclic bis(thioether). Macrocyclic bis(sulfone) 507 (51\%) has been obtained by oxidation of bis(thioether) with $\mathrm{H}_{2} \mathrm{O}_{2}$ in the presence of $\left.\left(\mathrm{NH}_{4}\right)_{6} \mathrm{Mo}_{7} \mathrm{O}_{24} \cdot 4 \mathrm{H}_{2} \mathrm{O}\right)$. Then, sulfone 507 on treatment with alumina-impregnated $\mathrm{KOH}\left(\mathrm{KOH} / \mathrm{Al}_{2} \mathrm{O}_{3}\right)$ in the presence of $\mathrm{CF}_{2} \mathrm{Br}_{2}$ in $\mathrm{CH}_{2} \mathrm{Cl}_{2} / t$ - $\mathrm{BuOH} \mathrm{1:1}$ gave the bis(olefin) 508 (70\%). The dihydroxylation of compound $\mathbf{5 0 8}$ with AD-mix- $\beta$ 


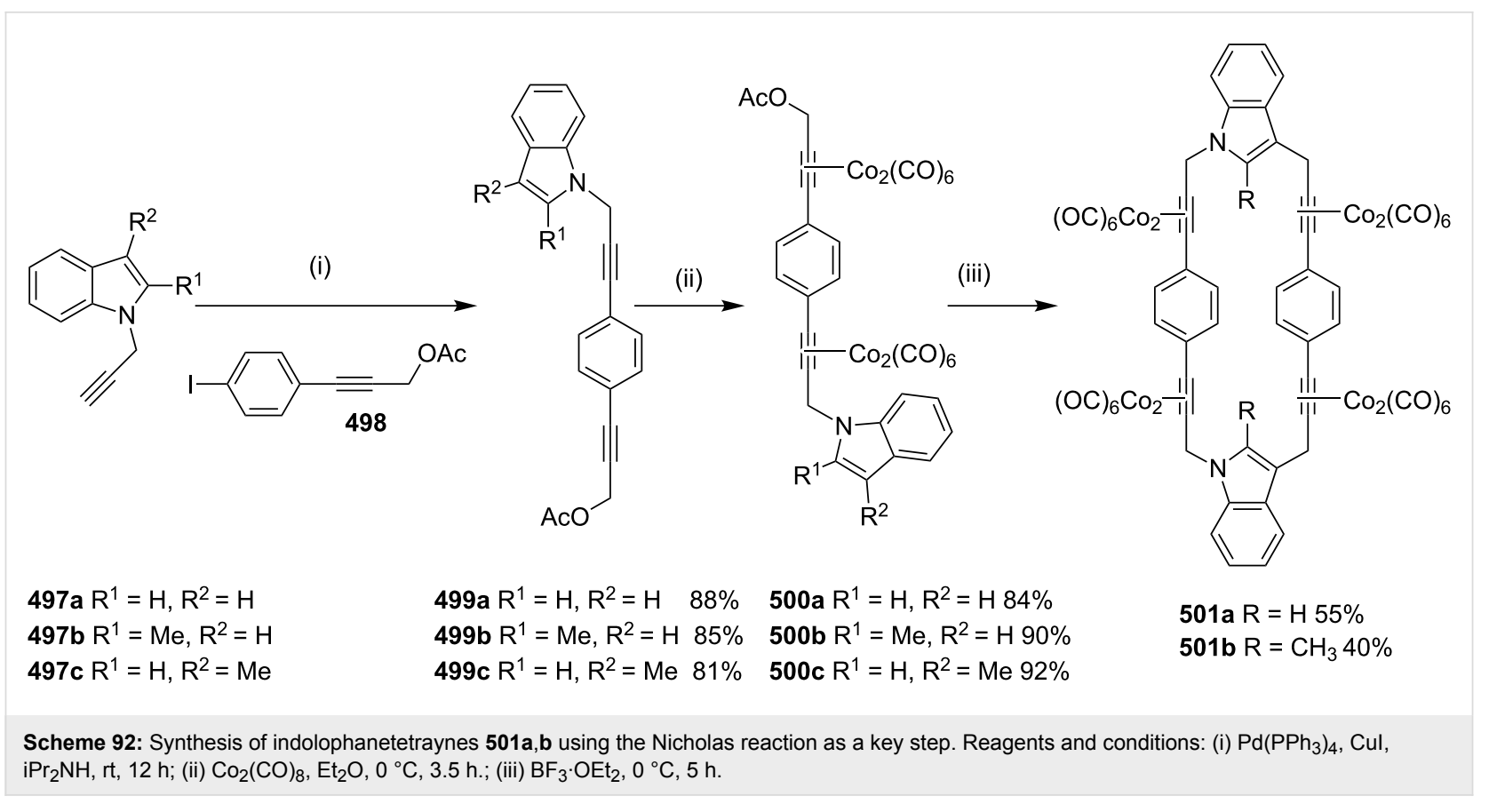<smiles>O=C1CCCCC1c1ccccc1</smiles>

502

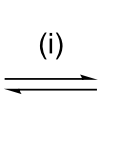<smiles>O=CCCCCc1ccccc1</smiles>

503
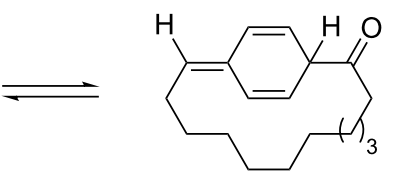

504 (ii)

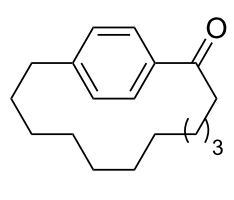

505

Scheme 93: Synthesis of cyclophane via radical cyclization. Reagents and conditions: (i) cyclododecanone, phenyllithium $2 \mathrm{M}, \mathrm{THF},-78^{\circ} \mathrm{C}, h \mathrm{v}, 2 \mathrm{~h}$, $78 \%$; (ii) $450 \mathrm{~W}$ mercury lamp, $\mathrm{K}_{2} \mathrm{CrO}_{3}, 20-40 \mathrm{~min}$.

$\left(\mathrm{MeSO}_{2} \mathrm{NH}_{2}, t-\mathrm{BuOH} / \mathrm{H}_{2} \mathrm{O} 2: 1\right.$ at ambient temperature) generated the tetrol which was selectively deoxygenated under Barton's conditions to deliver diol 510. The installation of the methyl group in $\mathbf{5 1 0}$ followed by a subsequent demethylation generated cylindrocyclophane F (155, 71\%). Also, compound 510 was oxidized followed by enol triflate formation and Kumada-type coupling with $\mathrm{MeMgBr}$ to give bis(olefin) 511 (74\%) which was further converted into cylindrocyclophane A (156) by using Hoye's protocol [261] (Scheme 94).

\section{Wittig reaction}

$\pi$-Conjugated molecules are topologically interesting entities due to their structural and electronic properties. Various $\pi$-conjugated cyclophanes involving arylene-ethynylene or -ethenylene moieties have been reported in the literature. Otera and co-workers [262] have reported the synthesis of the magazine rack molecule 514 by using a Wittig reaction as a key step. In addition, these molecules were found to be quite fluxional even at low temperatures (Scheme 95).
Over 40 different alkaloids were isolated from the Lythraceae family ranging from type A-E. Type C-E were reported previously, but Fujita and co-workers [263] reported the synthesis of type A alkaloid lythranidine for the first time. The key intermediate 515 was synthesized by using the McMurry reaction as a key step. For decades, caged compounds have been found to be useful targets to accommodate different ions. By a simple modification and the utilization of the flexibility of the crown ethers they can be used for the trapping of a variety of metal ions. Wennerström and co-workers [264] reported the synthesis of bicyclophane $\mathbf{5 1 6}$ by using a six-fold Wittig reaction. The use of conjugated polymers in chemical and biological sensors is well-known. However, water solubility poses limitations on the extensive use of these molecules. Bazan and co-workers [265] have reported the synthesis of the water-soluble oligomer dimers 517 based on paracyclophane with two chromophores in close proximity which results in a strong interchromophore delocalization and a decreased tendency toward aggregation as shown by light-scattering experiments (Figure 14). 
<smiles>CCCC[C@H](CCCCCOC)c1c(OC)cc(CS(C)(C)C)cc1OC</smiles>

506

507

508<smiles>S=C(n1cccc1)n1cccc1</smiles><smiles>CCCCCC(CCCC)c1c(OC)cc(/C=C(/C)CCCCCCCCC#N)cc1OC</smiles>

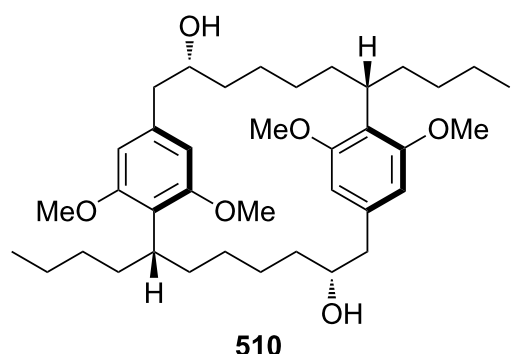

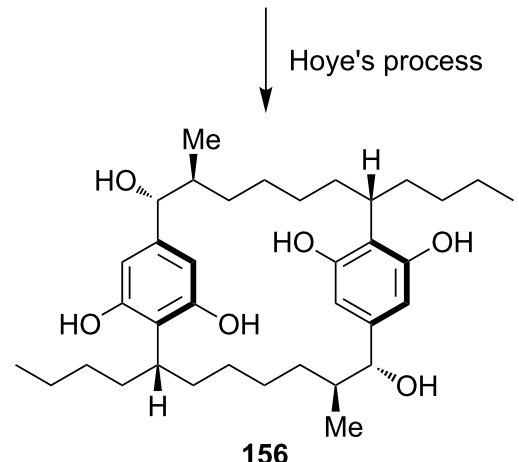

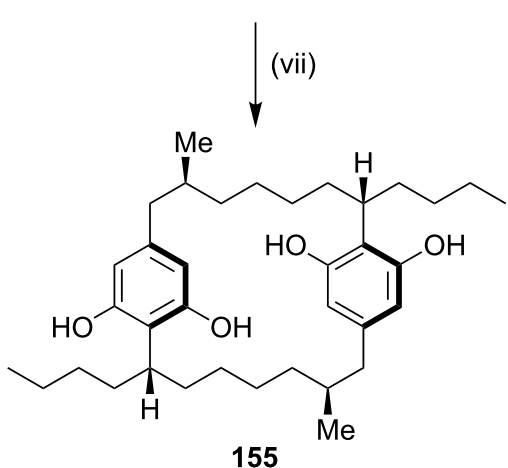

Scheme 94: Synthesis of (-)-cylindrocyclophanes $\mathrm{A}(156)$ and (-)-cylindrocyclophanes $\mathrm{F}$ (155). Reagents and conditions: (i) $\mathrm{NaOMe}, \mathrm{MeOH}, 23^{\circ} \mathrm{C}$, $36 \mathrm{~h}$; (ii) $\left(\mathrm{NH}_{4}\right)_{6} \mathrm{Mo}_{7} \mathrm{O}_{24} \cdot 4 \mathrm{H}_{2} \mathrm{O}, \mathrm{H}_{2} \mathrm{O}_{2}, \mathrm{EtOH}, 23^{\circ} \mathrm{C}, 12 \mathrm{~h}, 51 \%$ over two steps; (iii) $\mathrm{CF}_{2} \mathrm{Br}_{2}, \mathrm{KOH} / \mathrm{Al}_{2} \mathrm{O}_{3}, \mathrm{CH}_{2} \mathrm{Cl}_{2} / \mathrm{t}-\mathrm{BuOH} 1: 1,0-23{ }^{\circ} \mathrm{C}, 2 \mathrm{~h}$; then $\left[\mathrm{Pd}\left(\mathrm{CH}_{3} \mathrm{CN}\right)_{2} \mathrm{Cl}_{2}\right.$ ], $40{ }^{\circ} \mathrm{C}, 4 \mathrm{~h}, 70 \%$; (iv) $\mathrm{AD}-\mathrm{mix}-\beta, \mathrm{MeSO}_{2} \mathrm{NH}_{2}, t-\mathrm{BuOH} / \mathrm{H}_{2} \mathrm{O}$ 2:1, $23^{\circ} \mathrm{C}, 12 \mathrm{~h}$; (v) 509, PhMe, $125^{\circ} \mathrm{C}, 5 \mathrm{~h}$; (vi) AlBN, $n$-Bu $\mathrm{SnH}, \mathrm{PhMe}$, $10{ }^{\circ} \mathrm{C}, 1.5 \mathrm{~h}, 50 \%$ over three steps; (vii) $\mathrm{MsCl}, \mathrm{Et}_{3} \mathrm{~N}, \mathrm{CH}_{2} \mathrm{Cl}_{2}, 0{ }^{\circ} \mathrm{C}, 0.5 \mathrm{~h}$; then $\mathrm{AlMe}_{3}, 0{ }^{\circ} \mathrm{C}, 10 \mathrm{~min}$; then $\mathrm{BBr}_{3}, 23^{\circ} \mathrm{C}, 5 \mathrm{~h}, 71 \%$ one pot; (viii) DMP, $\mathrm{NaHCO}_{3}, \mathrm{CH}_{2} \mathrm{Cl}_{2}, 2{ }^{\circ} \mathrm{C}, 1 \mathrm{~h}$; (ix) KHMDS, Comins reagent, THF, $-78^{\circ} \mathrm{C}, 1 \mathrm{~h}$; (x) Fe(acac) $)_{3}, \mathrm{MeMgBr}$, THF/NMP 20:1, $0{ }^{\circ} \mathrm{C}, 1 \mathrm{~h}, 74 \%$ over three steps.

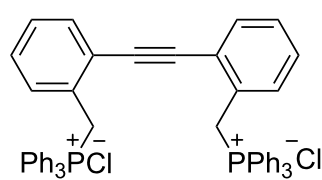

512 (i,ii)

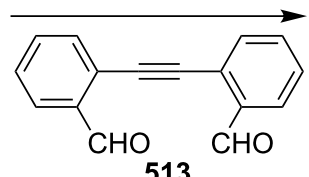

513

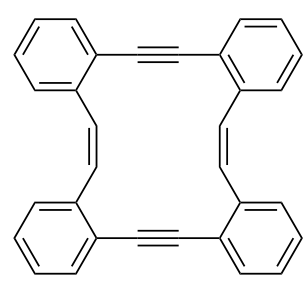

514

Scheme 95: Cyclophane synthesis via Wittig reaction. Reagents and conditions: (i) LiOEt (2.1 equiv), THF, $-78^{\circ} \mathrm{C}$ to $0{ }^{\circ} \mathrm{C}, 0.5 \mathrm{~h}$; (ii) 513 (1.1 equiv), THF, $-78^{\circ} \mathrm{C}$ to $0{ }^{\circ} \mathrm{C}, \mathrm{rt}, 4 \mathrm{~h}$. 


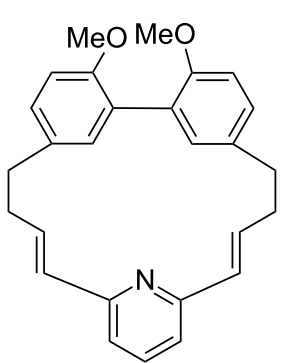

515

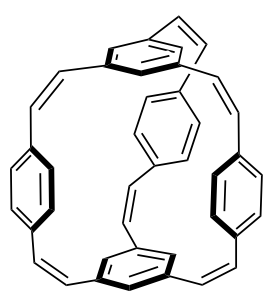

516

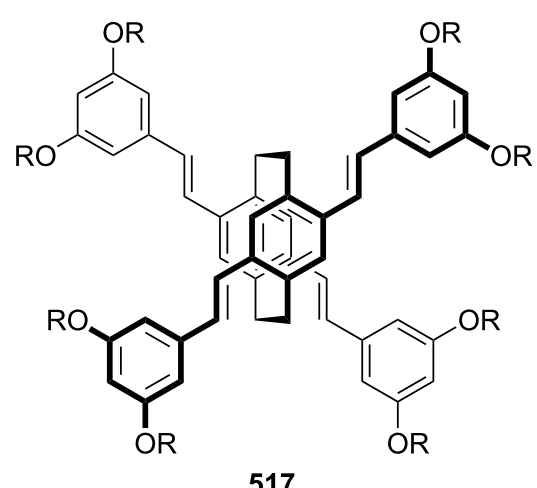

517

$$
\begin{aligned}
& \mathrm{R}=\left[\left(\mathrm{CH}_{2}\right)_{4} \mathrm{SO}_{3}\right]\left[\mathrm{NBu}_{4}\right] \\
& \mathrm{R}=\mathrm{TBDMS}
\end{aligned}
$$

Figure 14: Representative examples of cyclophanes synthesized via Wittig reaction.

\section{Thermal isomerization of Dewar benzene}

In 1987, Tobe and co-workers [266] have explored different routes to assemble the [6]paracyclophane structure by utilizing thermal valence isomerization of Dewar benzene. The photocycloaddition of bicyclic enone $\mathbf{5 1 8}$ with methyl acrylate gave the head-to-tail endo product 519 (49\%), which was subjected to ring contraction via (i) $\alpha$-formylation (ii) diazo-transfer and (iii) Wolff photo rearrangement to generate propellane derivative $\mathbf{5 2 0}(35 \%)$. Phenylselenylation of $\mathbf{5 2 0}$ with an excess amount of LDA and diphenyl diselenide gave bis-selenide 521 (32\%). Oxidation of $\mathbf{5 2 1}$ with hydrogen peroxide generated the Dewar benzene derivative $\mathbf{5 2 2}$ (73\%). Finally, valence isomerization of propellane derivative $\mathbf{5 2 2}$ afforded [6]paracyclophane $\mathbf{5 2 3}$ (90\%, Scheme 96).

\section{Conclusion}

We have summarized the utility of various popular reactions related to cyclophane synthesis. In some instances, cyclophanes are formed in low yield and also with side products. We feel that this compilation will be beneficial to design better routes and to improve the existing routes to cyclophanes. We have included popular reactions which in our view have potential for further expansion. We have also included structures of interesting cyclophane derivatives without going into detailed schemes to keep the volume of information at a manageable level.

\section{Acknowledgements}

The authors thank the Council of Scientific and Industrial Research (CSIR), New Delhi and the Department of Science

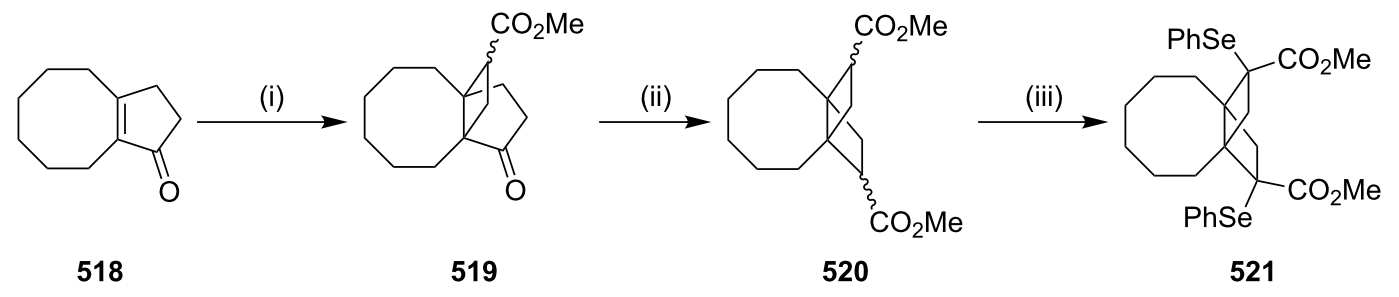<smiles>COCC12CCCCCC13CCCCCC32C(=O)OC</smiles>

522

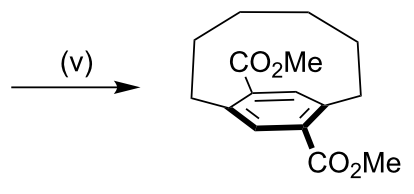

523

Scheme 96: Synthesis of the [6]paracyclophane via isomerization of Dewar benzene. Reagents and conditions: (i) methyl acrylate, ether, $500 \mathrm{~W}$, 3-5 h, 49\%; (ii) $\mathrm{HCO}_{2} \mathrm{Me}, \mathrm{MeONa}, \mathrm{TsN}_{3}, h v, \mathrm{MeOH}, 2 \mathrm{~h}, 35 \%$; (iii) LDA, THF, $-78^{\circ} \mathrm{C}, \mathrm{Ph}_{2} \mathrm{Se}_{2}, \mathrm{HMPA}, 1 \mathrm{~h}, 32 \%$; (iv) pyridine, $\mathrm{CH}_{2} \mathrm{Cl}_{2}, \mathrm{H}_{2} \mathrm{O}_{2}, 1.5 \mathrm{~h}$, $40{ }^{\circ} \mathrm{C}, 73 \%$; (v) $\mathrm{C}_{6} \mathrm{H}_{6}, 50{ }^{\circ} \mathrm{C}, 95 \mathrm{~h}, 90 \%$. 
and Technology (DST), New Delhi for the financial support. M. E. S. and G. T. W. are grateful to the IRCC for research fellowships. S. K thanks DST for the award of a J. C. Bose fellowship. The authors thank Prof. S. Sankaraman, Prof. G. J. Bodwell and Prof. J. Thomas for their valuable suggestions.

\section{References}

1. Faust, R. Angew. Chem., Int. Ed. Engl. 1995, 34, 1429-1432. doi:10.1002/anie.199514291

2. Li, C. Chem. Commun. 2014, 50, 12420-12433. doi:10.1039/C4CC03170A

3. Kim, J. N.; Lee, K. Y. Curr. Org. Chem. 2002, 6, 627-645. doi:10.2174/1385272023374094

4. Śliwa, W.; Zujewska, T. Heterocycles 2005, 65, 1713-1739. doi:10.3987/REV-05-596

5. Bodwell, G. J.; Nandaluru, P. R. Isr. J. Chem. 2012, 52, 105-138. doi:10.1002/ijch.201200003

6. Okada, Y.; Nishimura, J. J. Inclusion Phenom. Mol. Recognit. Chem. 1994, 19, 41-53. doi:10.1007/BF00708973

7. Schwartz, M. H. J. Inclusion Phenom. Mol. Recognit. Chem. 1990, 9, 1-35. doi:10.1007/BF01133501

8. Ángeles Herranz, M.; Rivera, J. A.; Alvarado, R. J.; Martn, N.; Thilgen, C.; Diederich, F.; Echegoyen, L. J. Supramol. Chem. 2001, 1, 299-303. doi:10.1016/S1472-7862(02)00075-8

9. Gulder, T.; Baran, P. S. Nat. Prod. Rep. 2012, 29, 899-934. doi:10.1039/c2np20034a

10. McGlinchey, M. J.; Milosevic, S. Isr. J. Chem. 2012, 52, 30-40. doi:10.1002/ijch.201100080

11. Ramaiah, D.; Neelakandan, P. P.; Nair, A. K.; Avirah, R. R. Chem. Soc. Rev. 2010, 39, 4158-4168. doi:10.1039/b920032k

12. Gaich, T.; Baran, P. S. J. Org. Chem. 2010, 75, 4657-4673. doi:10.1021/jo1006812

13. Tang, R.-Y.; Li, G.; Yu, J.-Q. Nature 2014, 507, 215-220. doi:10.1038/Nature12963

14. Naini, S. R.; Ranganathan, S.; Yadav, J. S.; Ramakrishna, K. V. S.; Gayatri, G.; Sastry, G. N.; Roy, K. B.; Shamala, N. RSC Adv. 2014, 4, 5322-5328. doi:10.1039/C3ra44327b

15. Juriček, M.; Strutt, N. L.; Barnes, J. C.; Butterfield, A. M.; Dale, E. J.; Baldridge, K. K.; Stoddart, F.; Siegel, J. S. Nat. Chem. 2014, 6, 222-228. doi:10.1038/Nchem.1842

16. Gago, S.; González, J.; Blasco, S.; Parola, A. J.; Albelda, M. T.; Garcia-España, E.; Pina, F. Dalton Trans. 2014, 43, 2437-2447. doi:10.1039/C3dt52061g

17. Wang, M. Chin. Sci. Bull. 2013, 58, 2898-2902. doi:10.1007/s11434-013-5703-8

18. Rajakumar, P.; Padmanabhan, R.; Rajesh, N. Bioorg. Med. Chem. Lett. 2012, 22, 3770-3775. doi:10.1016/j.bmcl.2012.04.010

19. Kanda, K.; Hamanaka, R.; Endo, K.; Shibata, T. Tetrahedron 2012, 68, 1407-1416. doi:10.1016/j.tet.2011.12.031

20. Hayashida, O.; Ichimura, K. Chem. Lett. 2012, 41, 1650-1651. doi:10.1246/cl.2012.1650

21. Vermeij, R. J.; Miller, D. O.; Dawe, L. N.; Aprahamian, I.; Sheradsky, T.; Rabinovitz, M.; Bodwell, G. J. Aust. J. Chem. 2010, 63, 1703-1716. doi:10.1071/Ch10356

22. Bodwell, G. J.; Frim, R.; Hopf, H.; Rabinovitz, M. Chem. Ber. 1993, 126, 167-175. doi:10.1002/cber.19931260125
23. D'yakonov, V. A.; Trapeznikova, O. A.; de Meijere, A.; Dzhemilev, U. M. Chem. Rev. 2014, 114, 5775-5814. doi:10.1021/Cr400291c

24. Sankararaman, S.; Srinivasan, M.; Narayanan, V.; Varghese, B. Indian J. Chem., Sect. B: Org. Chem. Incl. Med. Chem. 2004, 43, 1499-1503.

25. Yang, Y.; Mannion, M. R.; Dawe, L. N.; Kraml, C. M.; Pascal, R. A., Jr.; Bodwell, G. J. J. Org. Chem. 2012, 77, 57-67. doi:10.1021/Jo201013q

26. Bodwell, G. J.; Miller, D. O.; Vermeij, R. J. Org. Lett. 2001, 3, 2093-2096. doi:10.1021/OI016053i

27. Bodwell, G. J.; Houghton, T. J.; Miller, D. Tetrahedron Lett. 1997, 38, 1469-1472. doi:10.1016/S0040-4039(97)00132-9

28. Boyle, G. A.; Govender, T.; Kruger, H. G.; Maguire, G. E. M. Tetrahedron: Asymmetry 2004, 15, 3775-3781. doi:10.1016/j.tetasy.2004.10.015

29. Ashton, P. R.; Balzani, V.; Credi, A.; Kocian, O.; Pasini, D.; Prodi, L.; Spencer, N.; Stoddart, J. F.; Tolley, M. S.; Venturi, M.; White, A. J. P.; Williams, D. J. Chem. - Eur. J. 1998, 4, 590-607. doi:10.1002/(Sici)1521-3765(19980416)4:4<590::Aid-Chem590>3.0.C o;2-C

30. Bremner, J. B.; Keller, P. A.; Pyne, S. G.; Robertson, A. D.; Skelton, B. W.; White, A. H.; Witchard, H. M. Aust. J. Chem. 2000, 53, 535-540. doi:10.1071/Ch00029

31. Baker, M. V.; Brown, D. H.; Haque, R. A.; Skelton, B. W.; White, A. H. Dalton Trans. 2010, 39, 70-72. doi:10.1039/B916498g

32. Davy, J. R.; Reiss, J. A. Aust. J. Chem. 1976, 29, 163-171. doi:10.1071/CH9760163

33. Davies, C.; Ren, L.; Gustafson, R.; Buthelezi, T.; Bartsch, R. A.; Surowiec, M. J. Inclusion Phenom. Macrocyclic Chem. 2008, 61, 347-352. doi:10.1007/s10847-008-9428-2

34. Bartsch, R. A.; Kus, P.; Dalley, N. K.; Kou, X. Tetrahedron Lett. 2002, 43, 5017-5019. doi:10.1016/S0040-4039(02)01033-X

35. Swann, R. T.; Boekelheide, V. J. Organomet. Chem. 1982, 231, 143-149. doi:10.1016/S0022-328X(00)81953-1

36. Gerson, F.; Lopez, J.; Boekelheide, V. J. Chem. Soc., Perkin Trans. 2 1981, 1298-1303. doi:10.1039/P29810001298

37. Morisaki, Y.; Hifumi, R.; Lin, L.; Inoshita, K.; Chujo, Y. Chem. Lett. 2012, 41, 990-992. doi:10.1246/Cl.2012.990

38. Morisaki, Y.; Chujo, Y. Chem. Lett. 2002, 31, 194-195. doi:10.1246/Cl.2002.194

39. Takemura, H.; Nakata, S.; Inoue, A.; Mishima, A. J. Inclusion Phenom. Macrocyclic Chem. 2013, 77, 483-487. doi:10.1007/s10847-013-0321-2

40. Barnes, J. C.; Juriček, M.; Strutt, N. L.; Frasconi, M.; Sampath, S.; Giesener, M. A.; McGrier, P. L.; Bruns, C. J.; Stern, C. L.; Sarjeant, A. A.; Stoddart, J. F. J. Am. Chem. Soc. 2013, 135, 183-192. doi:10.1021/Ja307360n

41. Wald, P.; Schneider, H.-J. Eur. J. Org. Chem. 2009, 3450-3453. doi:10.1002/ejoc.200900384

42. Takemura, H. Curr. Org. Chem. 2009, 13, 1633-1653.

43. Masci, B.; Pasquale, S.; Thuéry, P. Org. Lett. 2008, 10, 4835-4838. doi:10.1021/OI801919q

44. Schmitt, A.; Perraud, O.; Payet, E.; Chatelet, B.; Bousquet, B.; Valls, M.; Padula, D.; Di Bari, L.; Dutasta, J.-P.; Martinez, A. Org. Biomol. Chem. 2014, 12, 4211-4217. doi:10.1039/C4ob00156g

45. Abe, H.; Ohtani, K.; Suzuki, D.; Chida, Y.; Shimada, Y.; Matsumoto, S.; Inouye, M. Org. Lett. 2014, 16, 828-831. doi:10.1021/OI403579e 
46. Juriček, M.; Barnes, J. C.; Dale, E. J.; Liu, W.-G.; Strutt, N. L.; Bruns, C. J.; Vermeulen, N. A.; Ghooray, K. C.; Sarjeant, A. A.; Stern, C. L.; Botros, Y. Y.; Goddard, W. A., III; Stoddart, J. F. J. Am. Chem. Soc. 2013, 135, 12736-12746. doi:10.1021/Ja4052763

47. Elacqua, E.; Friščić, T.; MacGillivray, L. R. Isr. J. Chem. 2012, 52, 53-59. doi:10.1002/ijch.201100089

48. Hu, P.; Yang, S.; Feng, G. Org. Biomol. Chem. 2014, 12, 3701-3706. doi:10.1039/C4ob00184b

49. Bruns, C. J.; Frasconi, M.; lehl, J.; Hartlieb, K. J.; Schneebeli, S. T.; Cheng, C.; Stupp, S. I.; Stoddart, J. F. J. Am. Chem. Soc. 2014, 136, 4714-4723. doi:10.1021/Ja500675y

50. Takase, M.; Inabe, A.; Sugawara, Y.; Fujita, W.; Nishinaga, T.; Nomura, K. Org. Lett. 2013, 15, 3202-3205. doi:10.1021/OI400882q

51. Marullo, S.; D'Anna, F.; Cascino, M.; Noto, R. J. Org. Chem. 2013, 78, 10203-10208. doi:10.1021/Jo401594r

52. Zhu, Z.; Fahrenbach, A. C.; Li, H.; Barnes, J. C.; Liu, Z.; Dyar, S. M.; Zhang, H.; Lei, J.; Carmieli, R.; Sarjeant, A. A.; Stern, C. L.; Wasielewski, M. R.; Stoddart, J. F. J. Am. Chem. Soc. 2012, 134, 11709-11720. doi:10.1021/ja3037355

53. Chan, T.-L.; Hung, C.-W.; Man, T.-O.; Leung, M.-K. J. Chem. Soc., Chem. Commun. 1994, 1971-1972. doi:10.1039/C39940001971

54. Marcus, L.; Klingebiel, U.; Lameyer, L.; Stalke, D. Z. Anorg. Allg. Chem. 1998, 624, 1041-1045. doi:10.1002/(Sici)1521-3749(199806)624:6<1041::Aid-Zaac1041>3.0. Co;2-G

55. Marcus, L.; Klingebiel, U.; Noltemeyer, M. Z. Naturforsch., B 1995, 50, 687-690.

56. Schulz, J.; Bartram, S.; Nieger, M.; Vögtle, F. Chem. Ber. 1992, 125, 2553-2569. doi:10.1002/cber.19921251130

57. Alcalde, E.; Gisbert, M.; Pérez-Garcia, L. Chem. Lett. 1995, 24, 865-866. doi:10.1246/Cl.1995.865

58. Alcalde, E.; Mesquida, N.; Pérez-García, L.; Ramos, S.; Alemany, M.; Rodríguez, M. L. Chem. - Eur. J. 2002, 8, 474-484. doi:10.1002/1521-3765(20020118)8:2<474::AID-CHEM474>3.0.CO;29

59. Chande, M. S.; Athalye, S. S.; Godbole, A. A. Indian J. Chem., Sect. B: Org. Chem. Incl. Med. Chem. 2004, 43, 670-673.

60. Takeshita, M.; Koike, M.; Tsuzuki, H.; Tashiro, M. J. Org. Chem. 1992, 57, 4654-4658. doi:10.1021/Jo00043a023

61. Hayashida, O.; Takaoka, Y.; Hamachi, I. Tetrahedron Lett. 2005, 46, 6589-6592. doi:10.1016/j.tetlet.2005.07.010

62. Schmidtchen, F. P. J. Inclusion Phenom. 1987, 5, 161-164. doi:10.1007/Bf00655641

63. Weber, E.; Skobridis, K.; Ouchi, M.; Hakushi, T.; Inoue, Y. Bull. Chem. Soc. Jpn. 1990, 63, 3670-3677. doi:10.1246/Bcsj.63.3670

64. Graupner, P. R.; Carr, A.; Clancy, E.; Gilbert, J.; Bailey, K. L.; Derby, J.-A.; Gerwick, B. C. J. Nat. Prod. 2003, 66, 1558-1561. doi:10.1021/Np030193e

65. Ploutno, A.; Carmeli, S. J. Nat. Prod. 2000, 63, 1524-1526. doi:10.1021/np0002334

66. Ridley, D. D.; Ritchie, E.; Taylor, W. C. Aust. J. Chem. 1970, 23, 147-183. doi:10.1071/CH9700147

67. Newman, D. J.; Cragg, G. M.; Snader, K. M. Nat. Prod. Rep. 2000, 17, 215-234. doi:10.1039/A902202C

68. Driggers, E. M.; Hale, S. P.; Lee, J.; Terrett, N. K Nat. Rev. Drug Discovery 2008, 7, 608-624. doi:10.1038/Nrd2590
69. Jimenez, L.; Diederich, F. Tetrahedron Lett. 1989, 30, 2759-2762. doi:10.1016/S0040-4039(00)99118-4

70. Diederich, F.; Lutter, H. D. J. Am. Chem. Soc. 1989, 111, 8438-8446. doi:10.1021/Ja00204a017

71. Seel, C.; Vögtle, F. Angew. Chem., Int. Ed. 1992, 31, 528-549. doi:10.1002/anie.199205281

72. Fürstner, A.; Stelzer, F.; Rumbo, A.; Krause, H. Chem. - Eur. J. 2002, 8, 1856-1871.

doi:10.1002/1521-3765(20020415)8:8<1856::AID-CHEM1856>3.0.CO ;2-R

73. Kotha, S.; Dipak, M. K. Tetrahedron 2012, 68, 397-421. doi:10.1016/j.tet.2011.10.018

74. Kotha, S.; Seema, V. Synlett 2011, 2329-2334. doi:10.1055/s-0030-1260315

75. Kotha, S.; Mandal, K. Chem. - Asian J. 2009, 4, 354-362. doi:10.1002/asia.200800244

76. Kotha, S.; Manivannan, E. ARKIVOC 2003, No. iii, 67-76. doi:10.3998/ark.5550190.0004.308

77. Kotha, S.; Chinnam, A. K.; Tiwari, A. Beilstein J. Org. Chem. 2013, 9 , 2709-2714. doi:10.3762/Bjoc.9.307

78. Kotha, S.; Deb, A. C.; Kumar, R. V. Bioorg. Med. Chem. Lett. 2005, 15, 1039-1043. doi:10.1016/j.bmcl.2004.12.034

79. Kotha, S.; Dipak, M. K. Chem. - Eur. J. 2006, 12, 4446-4450. doi:10.1002/chem.200501366

80. Kotha, S.; Goyal, D.; Thota, N.; Srinivas, V. Eur. J. Org. Chem. 2012, 1843-1850. doi:10.1002/ejoc.201101744

81. Kotha, S.; Shah, V. R. Eur. J. Org. Chem. 2008, 1054-1064. doi:10.1002/ejoc.200700921

82. Kotha, S.; Singh, K. Eur. J. Org. Chem. 2007, 5909-5916. doi:10.1002/ejoc.200700744

83. Schinz, H.; Ruzicka, L.; Geyer, U.; Prelog, V. Helv. Chim. Acta 1946, 29, 1524-1528.

84. Liptau, P.; Knüppel, S.; Kehr, G.; Kataeva, O.; Fröhlich, R.; Erker, G. J. Organomet. Chem. 2001, 637-639, 621-630. doi:10.1016/S0022-328X(01)01139-1

85. Ullmann, A.; Gruner, M.; Reißig, H.-U. Chem. - Eur. J. 1999, 5, 187-197. doi:10.1002/(SICI)1521-3765(19990104)5:1<187::AID-CHEM187>3.0 CO;2-D

86. Kondo, H.; Miyake, A. Japanese Patent JP 49110837, Oct 22, 1974

87. Kinder, J. D.; Tessier, C. A.; Youngs, W. J. Synlett 1993, 149-150. doi:10.1055/s-1993-22384

88. Cloninger, M. J.; Whitlock, H. W. J. Org. Chem. 1998, 63, 6153-6159. doi:10.1021/Jo980193x

89. Bukownik, R. R.; Wilcox, C. S. J. Org. Chem. 1988, 53, 463-471. doi:10.1021/jo00238a001

90. Haley, M. M.; Langsdorf, B. L. Chem. Commun. 1997, 1121-1122. doi:10.1039/a701712j

91. Eglinton, G.; Galbraith, A. R. J. Chem. Soc. 1959, 889-896. doi:10.1039/JR9590000889

92. Kotha, S.; Waghule, G. T. Heterocycles 2015, 90, 1289-1298. doi:10.3987/COM-14-S(K)37

93. Rajakumar, P.; Visalakshi, K. ARKIVOC 2011, No. x, 213-220. doi:10.3998/ark.5550190.0012.a17

94. Whitlock, B. J.; Jarvi, E. T.; Whitlock, H. W. J. Org. Chem. 1981, 46, 1832-1835. doi:10.1021/jo00322a018

95. Morisaki, Y.; Gon, M.; Sasamori, T.; Tokitoh, N.; Chujo, Y. J. Am. Chem. Soc. 2014, 136, 3350-3353. doi:10.1021/Ja412197j

96. Bolduc, P.; Jacques, A.; Collins, S. K. J. Am. Chem. Soc. 2010, 132, 12790-12791. doi:10.1021/ja106053x 
97. Kalinin, A. V.; Chauder, B. A.; Rakhit, S.; Snieckus, V. Org. Lett. 2003, 5, 3519-3521. doi:10.1021/OI035398t

98. Weber, H.; Pant, J.; Wunderlich, H. Chem. Ber. 1985, 118, 4259-4270. doi:10.1002/cber.19851181032

99. Kuroda, S.; Obata, Y.; Thanh, N. C.; Miyatake, R.; Horino, Y.; Oda, M. Tetrahedron Lett. 2008, 49, 552-556. doi:10.1016/j.tetlet.2007.11.067

100.Richards, I. C. Encyclopedia of Reagents for Organic Synthesis; John Wiley \& Sons, Ltd., 2001.

101.McMurry, J. E.; Fleming, M. P. J. Am. Chem. Soc. 1974, 96, 4708-4709. doi:10.1021/ja00821a076

102. Rajakumar, P.; Sekar, K.; Venkatesan, N. Synlett 2012, 23, 2504-2510. doi:10.1055/s-0032-1317324

103.Rajakumar, P.; Swaroop, M. G.; Jayavelu, S.; Murugesan, K. Tetrahedron 2006, 62, 12041-12050. doi:10.1016/j.tet.2006.09.078

104. Yamato, T.; Fujita, K.; Tsuzuki, H. J. Chem. Soc., Perkin Trans. 1 2001, 2089-2097. doi:10.1039/b010075g

105. Yamato, T.; Fujita, K.; Abe, T.; Tsuzuki, H. New J. Chem. 2001, 25, 728-736. doi:10.1039/b010205i

106. Yamato, T.; Fujita, K.; Okuyama, K.-i.; Tsuzuki, H. New J. Chem. 2000, 24, 221-228. doi:10.1039/b001145m

107.Tsuge, A.; Nishimoto, T.; Uchida, T.; Yasutake, M.; Moriguchi, T.; Sakata, K. J. Org. Chem. 1999, 64, 7246-7248. doi:10.1021/jo990488q

108. Rajakumar, P.; Selvam, S. Tetrahedron 2007, 63, 8891-8901. doi:10.1016/j.tet.2007.06.015

109. Rajakumar, P.; Swaroop, M. G. Tetrahedron Lett. 2004, 45, 6165-6167. doi:10.1016/j.tetlet.2004.06.020

110.Rajakumar, P.; Murali, V. Tetrahedron 2004, 60, 2351-2360. doi:10.1016/j.tet.2004.01.008

111.Memminger, K.; Oeser, T.; Müller, T. J. J. Org. Lett. 2008, 10, 2797-2800. doi:10.1021/ol800920d

112.Lee, W. Y.; Park, C. H. J. Org. Chem. 1993, 58, 7149-7157. doi:10.1021/jo00077a044

113.Lee, W. Y.; Park, C. H.; Kim, Y. D. J. Org. Chem. 1992, 57, 4074-4079. doi:10.1021/jo00041a007

114. Kurata, H.; Haruki, K.; Nakaminami, H.; Kawase, T.; Oda, M. Chem. Lett. 2003, 32, 422-423. doi:10.1246/cl.2003.422

115. Kostiuk, S. L.; Woodcock, T.; Dudin, L. F.; Howes, P. D.; Harrowven, D. C. Chem. - Eur. J. 2011, 17, 10906-10915. doi:10.1002/chem.201101550

116. Kawase, T.; Daifuku, Y.; Hirao, Y.; Matsumoto, K.; Kurata, H.; Kubo, T. C. R. Chim. 2009, 12, 403-411. doi:10.1016/j.crci.2008.09.016

117. Kasahara, A.; Izumi, T.; Shimizu, I. Chem. Lett. 1979, 8, 1119-1122. doi:10.1246/Cl.1979.1119

118. Kawase, T.; Ueda, N.; Tanaka, K.; Seirai, Y.; Oda, M. Tetrahedron Lett. 2001, 42, 5509-5511. doi:10.1016/S0040-4039(01)00862-0

119.Darabi, H. R.; Jadidi, K.; Mohebbi, A. R.; Faraji, L.; Aghapoor, K.; Shahbazian, S.; Azimzadeh, M.; Nasseri, S. M. Supramol. Chem. 2008, 20, 327-333. doi:10.1080/10610270701258642

120.Chen, H.-B.; Yin, J.; Wang, Y.; Pei, J. Org. Lett. 2008, 10, 3113-3116. doi:10.1021/ol801163v

121.Kawase, T.; Nakamura, T.; Utsumi, K.; Matsumoto, K.; Kurata, H.; Oda, M. Chem. - Asian J. 2008, 3, 573-577. doi:10.1002/asia.200700274

122.Saito, S.; Tsuboya, N.; Yamamoto, Y. J. Org. Chem. 1997, 62, 5042-5047. doi:10.1021/Jo970727e

123. Ueda, T.; Kanomata, N.; Machida, H. Org. Lett. 2005, 7, 2365-2368. doi:10.1021/ol0506258
124. Fittig, R. Justus Liebigs Ann. Chem. 1859, 110, 17-23. doi:10.1002/jlac. 18591100103

125. Tran-Van, A.-F.; Huxol, E.; Basler, J. M.; Neuburger, M.; Adjizian, J.-J.; Ewels, C. P.; Wegner, H. A. Org. Lett. 2014, 16, 1594-1597. doi:10.1021/ol500194s

126. Sonogashira, K. J. Organomet. Chem. 2002, 653, 46-49. doi:10.1016/S0022-328X(02)01158-0

127.Bodwell, G. J.; Li, J. Org. Lett. 2002, 4, 127-130. doi:10.1021/ol017014+

128. Miyaura, N.; Suzuki, A. Chem. Rev. 1995, 95, 2457-2483. doi:10.1021/cr00039a007

129.Suzuki, A. Pure Appl. Chem. 1991, 63, 419-422. doi:10.1351/pac199163030419

130. Miyaura, N.; Suzuki, A. J. Chem. Soc., Chem. Commun. 1979, 866-867. doi:10.1039/C39790000866

131. Miyaura, N.; Yamada, K.; Suzuki, A. Tetrahedron Lett. 1979, 20 , 3437-3440. doi:10.1016/S0040-4039(01)95429-2

132. Kotha, S.; Lahiri, K.; Kashinath, D. Tetrahedron 2002, 58, 9633-9695. doi:10.1016/S0040-4020(02)01188-2

133. Kotha, S.; Behera, M.; Shah, V. R. Synlett 2005, 1877-1880. doi:10.1055/s-2005-871569

134. Kotha, S.; Mandal, K.; Arora, K. K.; Pedireddi, R. Adv. Synth. Catal. 2005, 347, 1215-1218. doi:10.1002/adsc.200404373

135. Kotha, S.; Mandal, K. Eur. J. Org. Chem. 2006, 5387-5393. doi:10.1002/ejoc.200600549

136. Cochrane, J. R.; White, J. M.; Wille, U.; Hutton, C. A. Org. Lett. 2012, 14, 2402-2405. doi:10.1021/OI300831t

137. Kotha, S.; Lahiri, K. Eur. J. Org. Chem. 2007, 1221-1236. doi:10.1002/ejoc.200600519

138. Baker, W.; McOmie, J. F. W.; Warburton, W. K. J. Chem. Soc. 1952, 2991-2993. doi:10.1039/JR9520002991

139. Jarikote, D. V.; Murphy, P. V. Eur. J. Org. Chem. 2010, 4959-4970. doi:10.1002/ejoc.201000491

140.Zhang, C.; Long, H.; Zhang, W. Chem. Commun. 2012, 48, 6172-6174. doi:10.1039/c2cc32571c

141.Beer, S.; Brandhorst, K.; Grunenberg, J.; Hrib, C. G.; Jones, P. G.; Tamm, M. Org. Lett. 2008, 10, 981-984. doi:10.1021/ol800154y

142. Kotha, S.; Waghule, G. T. J. Org. Chem. 2012, 77, 6314-6318. doi:10.1021/Jo300766f

143.Moore, B. S.; Chen, J.-L.; Patterson, G. M. L.; Moore, R. E. Tetrahedron 1992, 48, 3001-3006. doi:10.1016/S0040-4020(01)92244-6

144.Smith, A. B., III; Adams, C. M.; Kozmin, S. A.; Paone, D. V. J. Am. Chem. Soc. 2001, 123, 5925-5937. doi:10.1021/ja0106164

145. Kotha, S.; Chavan, A. S.; Shaikh, M. J. Org. Chem. 2012, 77, 482-489. doi:10.1021/Jo2020714

146. Adachi, K.; Hirao, Y.; Matsumoto, K.; Kubo, T.; Kurata, H. Org. Lett. 2014, 16, 5870-5873. doi:10.1021/ol5027816

147. Fürstner, A.; Szillat, H.; Gabor, B.; Mynott, R. J. Am. Chem. Soc. 1998, 120, 8305-8314. doi:10.1021/Ja981183g

148. Wasserman, H. H.; Keith, D. D.; Nadelson, J. J. Am. Chem. Soc. 1969, 91, 1264-1265. doi:10.1021/Ja01033a066

149.Wasserman, H. H.; Rodgers, G. C.; Keith, D. D. J. Am. Chem. Soc. 1969, 91, 1263-1264. doi:10.1021/Ja01033a065

150.Wasserman, H. H.; Gosselink, E.; Keith, D. D.; Nadelson, J.; Sykes, R. J. Tetrahedron 1976, 32, 1863-1866. doi:10.1016/0040-4020(76)85187-3

151.Tsushima, S.; Yamada, Y.; Onami, T.; Oshima, K.; Chaney, M. O.; Jones, N. D.; Swartzendruber, J. K. Bull. Chem. Soc. Jpn. 1989, 62, 1167-1178. doi:10.1246/Bcsj.62.1167 
152.Tae, J.; Yang, Y.-K. Org. Lett. 2003, 5, 741-744. doi:10.1021/ol027557z

153.Alcaide, B.; Almendros, P.; Quirós, M. T.; Lázaro, C.; Torres, M. R. J. Org. Chem. 2014, 79, 6244-6255. doi:10.1021/Jo500993x

154.Camacho, D. H.; Salo, E. V.; Guan, Z. Org. Lett. 2004, 6, 865-868. doi:10.1021/ol036173I

155. Watson, M. D.; Jäckel, F.; Severin, N.; Rabe, J. P.; Müllen, K. J. Am. Chem. Soc. 2004, 126, 1402-1407. doi:10.1021/ja037520p

156. Vonlanthen, D.; Rudnev, A.; Mishchenko, A.; Käslin, A.; Rotzler, J.; Neuburger, M.; Wandlowski, T.; Mayor, M. Chem. - Eur. J. 2011, 17, 7236-7250. doi:10.1002/chem.201003763

157. Winkelmann, O.; Linder, D.; Lacour, J.; Näther, C.; Lüning, U. Eur. J. Org. Chem. 2007, 3687-3697. doi:10.1002/ejoc.200700206

158.Simpkins, S. M. E.; Kariuki, B. M.; Cox, L. R. J. Organomet. Chem. 2006, 691, 5517-5523. doi:10.1016/j.jorganchem.2006.07.021

159.Mori, K.; Ohmori, K.; Suzuki, K. Angew. Chem., Int. Ed. 2009, 48, 5638-5641. doi:10.1002/anie.200901974

160.Locke, A. J.; Jones, C.; Richards, C. J. J. Organomet. Chem. 2001, 637-639, 669-676. doi:10.1016/S0022-328X(01)00980-9

161. Martinez, V.; Blais, J.-C.; Bravic, G.; Astruc, D. Organometallics 2004, 23, 861-874. doi:10.1021/om030623w

162. Martinez, V.; Blais, J.-C.; Astruc, D. Angew. Chem., Int. Ed. 2003, 42, 4366-4369. doi:10.1002/anie.200351795

163.Majchrzak, M.; Marciniec, B.; Kubicki, M.; Pawełczyk, A. Organometallics 2005, 24, 3731-3736. doi:10.1021/om050194x

164.Lund, C. L.; Schachner, J. A.; Burgess, I. J.; Quail, J. W.; Schatte, G.; Müller, J. Inorg. Chem. 2008, 47, 5992-6000. doi:10.1021/ic800336f

165.Li, S.; Liu, M.; Zheng, B.; Zhu, K.; Wang, F.; Li, N.; Zhao, X.-L.; Huang, F. Org. Lett. 2009, 11, 3350-3353. doi:10.1021/ol9012052

166. Huang, M.; Song, L.; Liu, B. Org. Lett. 2010, 12, 2504-2507. doi:10.1021/ol100692x

167.Branowska, D.; Buczek, I.; Kalińska, K.; Nowaczyk, J.; Rykowski, A. Tetrahedron Lett. 2005, 46, 8539-8541. doi:10.1016/j.tetlet.2005.10.003

168.Zakarian, J. E.; El-Azizi, Y.; Collins, S. K. Org. Lett. 2008, 10, 2927-2930. doi:10.1021/ol800821f

169. Kotha, S.; Shirbhate, M. E. Synlett 2012, 23, 2183-2188. doi:10.1055/s-0032-1317020

170.Nicolaou, K. C.; Xu, H. Chem. Commun. 2006, 600-602. doi:10.1039/B517385J

171. Fürstner, A.; Leitner, A. Angew. Chem., Int. Ed. 2003, 42, 308-311. doi:10.1002/anie.200390103

172.Donohoe, T. J.; Basutto, J. A.; Bower, J. F.; Rathi, A. Org. Lett. 2011, 13, 1036-1039. doi:10.1021/Ol103088r

173. Hagiwara, H.; Katsumi, T.; Kamat, V. P.; Hoshi, T.; Suzuki, T.; Ando, M. J. Org. Chem. 2000, 65, 7231-7234. doi:10.1021/Jo000785r

174.Kotha, S.; Waghule, G. T.; Shirbhate, M. E. Eur. J. Org. Chem. 2014, 984-992. doi:10.1002/ejoc.201301493

175. Roemer, M.; Lentz, D. Chem. Commun. 2011, 47, 7239-7241. doi:10.1039/c1cc11812a

176. Tanaka, K.; Shirasaka, K. Org. Lett. 2003, 5, 4697-4699. doi:10.1021/OI035963s

177.Tanaka, K.; Sagae, H.; Toyoda, K.; Noguchi, K. Eur. J. Org. Chem. 2006, 3575-3581. doi:10.1002/ejoc.200600232

178.Araki, T.; Hojo, D.; Noguchi, K.; Tanaka, K. Synlett 2011, 539-542. doi:10.1055/s-0030-1259539

179.Araki, T.; Noguchi, K.; Tanaka, K. Angew. Chem., Int. Ed. 2013, 52, 5617-5621. doi:10.1002/anie.201300696

180.Shibata, T.; Uchiyama, T.; Endo, K. Org. Lett. 2009, 11, 3906-3908. doi:10.1021/ol9014893
181.Chouraqui, G.; Petit, M.; Phansavath, P.; Aubert, C.; Malacria, M. Eur. J. Org. Chem. 2006, 1413-1421. doi:10.1002/ejoc.200500762 182. Kinoshita, H.; Shinokubo, H.; Ohsima, K. J. Am. Chem. Soc. 2003, 125, 7784-7785. doi:10.1021/Ja035438o

183.Zhang, H.-C.; Boñaga, L. V. R.; Ye, H.; Derian, C. K.; Damiano, B. P.; Maryanoff, B. E. Bioorg. Med. Chem. Lett. 2007, 17, 2863-2868. doi:10.1016/j.bmcl.2007.02.059

184.Boñaga, L. V. R.; Zhang, H.-C.; Moretto, A. F.; Ye, H.; Gauthier, D. A.; Li, J.; Leo, G. C.; Maryanoff, B. E. J. Am. Chem. Soc. 2005, 127, 3473-3485. doi:10.1021/ja045001w

185. Rajesh, R.; Periyasami, G.; Raghunathan, R. Tetrahedron Lett. 2010, 51, 1896-1898. doi:10.1016/j.tetlet.2010.02.020

186. Leyden, R.; Murphy, P. V. Synlett 2009, 1949-1950. doi:10.1055/s-0029-1217534

187.Hou, J.-T.; Zhang, Q.-F.; Xu, B.-Y.; Lu, Q.-S.; Liu, Q.; Zhang, J.; Yu, X.-Q. Tetrahedron Lett. 2011, 52, 4927-4930. doi:10.1016/j.tetlet.2011.07.050

188. Yu, Y.; Li, Y.; Chen, S.; Liu, T.; Qin, Z.; Liu, H.; Li, Y. Eur. J. Org. Chem. 2012, 4287-4292. doi:10.1002/ejoc.201200169

189.Wang, H.; Huang, J.; Wulff, W. D.; Rheingold, A. L. J. Am. Chem. Soc. 2003, 125, 8980-8981. doi:10.1021/ja035428n

190.Wang, H.; Wulff, W. D. J. Am. Chem. Soc. 1998, 120, 10573-10574. doi:10.1021/ja9826183

191.Dötz, K. H.; Gerhardt, A. J. Organomet. Chem. 1999, 578, 223-228. doi:10.1016/S0022-328X(98)01125-5

192.Suwa, K.; Morie, Y.; Suzuki, Y.; Ikeda, K.; Sato, M. Tetrahedron Lett. 2008, 49, 1510-1513. doi:10.1016/j.tetlet.2007.12.112

193. Tochtermann, W.; Kuckling, D.; Meints, C.; Kraus, J.; Bringmann, G Tetrahedron 2003, 59, 7791-7801. doi:10.1016/j.tet.2003.07.009

194.Gassman, P. G.; Bailey, T. F.; Hoye, R. C. J. Org. Chem. 1980, 45, 2923-2924. doi:10.1021/Jo01302a039

195. Fu, X.; Ferreira, M. L. G.; Schmitz, F. J. J. Nat. Prod. 1999, 62, 1306-1310. doi:10.1021/np9900977

196. Layton, M. E.; Morales, C. A.; Shair, M. D. J. Am. Chem. Soc. 2002, 124, 773-775. doi:10.1021/ja016585u

197.Fu, X.; Hossain, M. B.; van der Helm, D.; Schmitz, F. J. J. Am. Chem. Soc. 1994, 116, 12125-12126. doi:10.1021/ja00105a092

198. Nicolaou, K. C.; Wang, J.; Tang, Y.; Botta, L. J. Am. Chem. Soc. 2010, 132, 11350-11363. doi:10.1021/Ja1048994

199.Zhao, P.; Beaudry, C. M. Angew. Chem., Int. Ed. 2014, 53, 10500-10503. doi:10.1002/anie.201406621

200.Ichino, T.; Arimoto, H.; Uemura, D. Chem. Commun. 2006, 1742-1744. doi:10.1039/B517149k

201.Benniston, A. C.; Clegg, W.; Harriman, A.; Harrington, R. W.; Li, P.; Sams, C. Tetrahedron Lett. 2003, 44, 2665-2667. doi:10.1016/S0040-4039(03)00343-5

202.Schwarz, W. M.; Shain, I. J. Phys. Chem. 1965, 69, 30-40. doi:10.1021/J100885a008

203. Shine, H. J.; Stanley, J. P. Chem. Commun. 1965, 294-295. doi:10.1039/C19650000294

204.Shine, H. J.; Chamness, J. T. J. Org. Chem. 1967, 32, 901-905. doi:10.1021/Jo01279a010

205. Kenner, J. Nature 1968, 219, 153. doi:10.1038/219153a0

206. Banthorpe, D. Tetrahedron Lett. 1972, 13, 2707-2710. doi:10.1016/S0040-4039(01)84912-1

207.Lupes, M. E. Rev. Roum. Chim. 1972, 17, 1253-1260.

208. Vögtle, F.; Böckmann, K. Chem. Ber. 1979, 112, 1400-1409. doi:10.1002/cber.19791120434 
209.Kim, H.-Y.; Lee, W.-J.; Kang, H.-M.; Cho, C.-G. Org. Lett. 2007, 9, 3185-3186. doi:10.1021/ol071320r

210.Dhanak, D.; Reese, C. B. J. Chem. Soc., Perkin Trans. 1 1987, 2829-2832. doi:10.1039/P19870002829

211.Kotha, S.; Waghule, G. T. Tetrahedron Lett. 2014, 55, 4264-4268. doi:10.1016/j.tetlet.2014.05.129

212. Kotha, S.; Chavan, A. S.; Waghule, G. T. J. Indian Chem. Soc. 2015, in press.

213. Kotha, S.; Shirbhate, M. E. Tetrahedron Lett. 2014, 55, 6972-6975. doi:10.1016/j.tetlet.2014.10.092

214. Eisen, N.; Vögtle, F. Angew. Chem. 1986, 98, 1029-1030. doi:10.1002/ange.19860981130

215.Werz, D. B.; Schuster, A.; Gleiter, R.; Rominger, F. Org. Lett. 2005, 7, 917-920. doi:10.1021/ol047317e

216.Magnus, P.; Lescop, C. Tetrahedron Lett. 2001, 42, 7193-7196. doi:10.1016/S0040-4039(01)01515-5

217.Biemann, K.; Büchi, G.; Walker, B. H. J. Am. Chem. Soc. 1957, 79, 5558-5564. doi:10.1021/ja01577a061

218.Seo, J.; Lee, S. S.; Gong, W.-T.; Hiratani, K. Tetrahedron Lett. 2008, 49, 3770-3774. doi:10.1016/j.tetlet.2008.04.013

219.Bates, R. B.; Ogle, C. A. J. Org. Chem. 1982, 47, 3949-3952. doi:10.1021/jo00141a027

220.Schubert, W. M.; Sweeney, W. A.; Latourette, H. K. J. Am. Chem. Soc. 1954, 76, 5462-5466. doi:10.1021/ja01650a060

221.Georgi, U. K.; Rétey, J. J. Chem. Soc. D 1971, 32-33. doi:10.1039/C29710000032

222. Namboothiri, I. N. N.; Hassner, A. Organic Syntheses Based on Name Reactions, 3rd ed.; Elsevier: Oxford, 2012; pp 269-270.

223. Kotha, S.; Halder, S.; Damodharan, L.; Pattabhi, V. Bioorg. Med. Chem. Lett. 2002, 12, 1113-1115. doi:10.1016/S0960-894x(02)00068-9

224. Kotha, S.; Halder, S. ARKIVOC 2005, No. iii, 56-66. doi:10.3998/ark.5550190.0006.308

225.Damodharan, L.; Syed Ibrahim, B.; Pattabhi, V.; Halder, S.; Kotha, S. Acta Crystallogr., Sect. E 2002, 58, o1038-01039. doi:10.1107/S1600536802015313

226.Sentou, W.; Satou, T.; Yasutake, M.; Lim, C.; Sakamoto, Y.; Itoh, T.; Shinmyozu, T. Eur. J. Org. Chem. 1999, 1223-1231. doi:10.1002/(SICI)1099-0690(199905)1999:5<1223::AID-EJOC1223> 3.0.CO;2-S

227. Okamoto, H.; Takemura, H.; Satake, K. Synthesis 2008, 39-44. doi:10.1055/s-2007-1000825

228. Rubin, M. B.; Migdal, S.; Speiser, S.; Kaftory, M. Isr. J. Chem. 1985, 25, 66-73. doi:10.1002/ijch.198500012

229.Sakamoto, Y.; Miyoshi, N.; Hirakida, M.; Kusumoto, S.; Kawase, H.; Rudzinski, J. M.; Shinmyozu, T. J. Am. Chem. Soc. 1996, 118, 12267-12275. doi:10.1021/ja961944k

230.Simonov, A. Y.; Bykov, E. E.; Lakatosh, S. A.; Luzikov, Y. N.; Korolev, A. M.; Reznikova, M. I.; Preobrazhenskaya, M. N. Tetrahedron 2014, 70, 625-630. doi:10.1016/j.tet.2013.12.004

231.Rohanna, J. C.; Rainier, J. D. Org. Lett. 2009, 11, 493-495. doi:10.1021/OI802737h

232.van Es, D. S.; Gret, N.; de Rijke, M.; van Eis, M. J.; de Kanter, F. J. J.; de Wolf, W. H.; Bickelhaupt, F.; Menzer, S.; Spek, A. L. Tetrahedron 2001, 57, 3557-3565. doi:10.1016/S0040-4020(01)00239-3

233.Skattebøl, L. J. Org. Chem. 1964, 29, 2951-2956. doi:10.1021/jo01033a035

234.Brown, R. F. C. Pyrolytic Methods in Organic Chemistry. Application of Flow and Flash Vacuum Pyrolytic Techniques; Academic Press: New York, 1980. doi:10.1002/ange.19810930646
235. Makosza, M.; Fedorynski, M. Rocz. Chem. 1976, 50, 2223-2225.

236. Possel, O.; van Leusen, A. M. Tetrahedron Lett. 1977, 18, 4229-4231. doi:10.1016/S0040-4039(01)83472-9

237.van Leusen, D.; van Leusen, A. M. Synthesis 1980, 325-326. doi:10.1055/s-1980-29013

238. Yao, Z. Y.; Zhang, H.; Sheng, H. M.; Wu, X. M.; Bin Sun, H. Chin. Chem. Lett. 2010, 21, 1334-1337. doi:10.1016/j.cclet.2010.06.022

239. Ramos, D. R.; Castillo, R.; Canle, M.; Garcia, M. V.; Andrés, J.; Santaballa, J. A. Chem. Phys. Lett. 2006, 429, 425-429. doi:10.1016/j.cplett.2006.08.055

240.Xie, W.; Gao, Z.; Pan, W.-P.; Hunter, D.; Singh, A.; Vaia, R. Chem. Mater. 2001, 13, 2979-2990. doi:10.1021/Cm010305s

241. Sakai, S. J. Phys. Chem. 1995, 99, 5883-5888. doi:10.1021/J100016a023

242.Xu, X.; Yao, Z.; Ye, X.; Tang, Y.; Fu, H.; Qian, M. Acta Phys.-Chim. Sin. 1989, 5, 398-402. doi:10.3866/Pku.Whxb19890405

243. Freedman, L. D. J. Chem. Educ. 1966, 43, 662. doi:10.1021/ed043p662

244. Küsefoglu, S. H.; Longone, D. T. Tetrahedron Lett. 1978, 19 , 2391-2394. doi:10.1016/S0040-4039(01)94782-3

245. Machida, H.; Tatemitsu, H.; Otsubo, T.; Sakata, Y.; Misumi, S. Bull. Chem. Soc. Jpn. 1980, 53, 2943-2952. doi:10.1246/bcsj.53.2943

246. Eltamany, S. H.; Hopf, H. Tetrahedron Lett. 1980, 21, 4901-4904. doi:10.1016/S0040-4039(00)71150-6

247.Nagel, M.; Allmann, R.; Eltamany, S. H.; Hopf, H. Chem. Ber. 1982, 115, 3203-3207. doi:10.1002/cber.19821150923

248. Glatzhofer, D. T.; Longone, D. T. Tetrahedron Lett. 1986, 27 , 5923-5926. doi:10.1016/S0040-4039(00)85363-0

249. Huang, X.; Qu, F.; Li, Z. J. Fluorine Chem. 1988, 40, 33-39. doi:10.1016/S0022-1139(00)81059-3

250.Koenig, T.; Rudolf, K.; Chadwick, R.; Geiselmann, H.; Patapoff, T.; Klopfenstein, C. E. J. Am. Chem. Soc. 1986, 108, 5024-5025. doi:10.1021/ja00276a063

251.Bauchat, P.; Le Bras, N.; Rigal, L.; Foucaud, A. Tetrahedron 1994, 50, 7815-7826. doi:10.1016/S0040-4020(01)85265-0

252. Vedernikov, A. N.; Pink, M.; Caulton, K. G. J. Org. Chem. 2003, 68, 4806-4814. doi:10.1021/jo034268v

253.Sonnenschein, H.; Kreher, T.; Gründemann, E.; Krüger, R.-P.; Kunath, A.; Zabel, V. J. Org. Chem. 1996, 61, 710-714. doi:10.1021/Jo951419o

254.Temal-Laïb, T.; Chastanet, J.; Zhu, J. J. Am. Chem. Soc. 2002, 124, 583-590. doi:10.1021/Ja0170807

255. Hadj-Abo, F.; Hesse, M. Helv. Chim. Acta 1992, 75, 1834-1839. doi:10.1002/hlca.19920750609

256. Gibe, R.; Green, J. R.; Davidson, G. Org. Lett. 2003, 5, 1003-1005. doi:10.1021/ol027564n

257.Nicholas, K. M.; Pettit, R. J. Organomet. Chem. 1972, 44, C21-C24. doi:10.1016/0022-328X(72)80037-8

258. Lockwood, R. F.; Nicholas, K. M. Tetrahedron Lett. 1977, 18, 4163-4165. doi:10.1016/S0040-4039(01)83455-9

259. Han, N.; Lei, X.; Turro, N. J. J. Org. Chem. 1991, 56, 2927-2930. doi:10.1021/Jo00008a065

260. Nicolaou, K. C.; Sun, Y.-P.; Korman, H.; Sarlah, D. Angew. Chem., Int. Ed. 2010, 49, 5875-5878. doi:10.1002/anie.201003500

261. Hoye, T. R.; Humpal, P. E.; Moon, B. J. Am. Chem. Soc. 2000, 122, 4982-4983. doi:10.1021/ja000429q 
262.Orita, A.; Jiang, L.; Tsuruta, M.; Otera, J. Chem. Lett. 2002, 31, 136-137. doi:10.1246/cl.2002.136

263. Fuji, K.; Ichikawa, K.; Fujita, E. Tetrahedron Lett. 1979, 20, 361-364. doi:10.1016/S0040-4039(01)85971-2

264.Högberg, H.-E.; Thulin, B.; Wennerström, O. Tetrahedron Lett. 1977, 18, 931-934. doi:10.1016/S0040-4039(01)92795-9

265.Hong, J. W.; Gaylord, B. S.; Bazan, G. C. J. Am. Chem. Soc. 2002, 124, 11868-11869. doi:10.1021/ja027170r

266. Tobe, Y.; Nakayama, A.; Kakiuchi, K.; Odaira, Y.; Kai, Y.; Kasai, N. J. Org. Chem. 1987, 52, 2639-2644. doi:10.1021/Jo00389a002

\section{License and Terms}

This is an Open Access article under the terms of the Creative Commons Attribution License

(http://creativecommons.org/licenses/by/2.0), which permits unrestricted use, distribution, and reproduction in any medium, provided the original work is properly cited.

The license is subject to the Beilstein Journal of Organic Chemistry terms and conditions:

(http://www.beilstein-journals.org/bjoc)

The definitive version of this article is the electronic one which can be found at: doi:10.3762/bjoc. 11.142 